\title{
Horisfieldones A and B, Two Aromatic Ring-contracted Dimeric Diarylpropanes with Human DOPA Decarboxylase Inhibitory Activity from Horsfieldia kingii
}

Rui Zhan, ${ }^{\dagger, \#}$ You-Tian Hu, ${ }^{\ddagger}, \#$ Li-Dong Shao, ${ }^{\S, \# ~ X u-J i e ~ Q i n, ~}{ }^{\circledR}$ Fang Kuang, ${ }^{\dagger}$ Shou-Zhen Du, ${ }^{\dagger}$ Fang Wu, *,* Ye-Gao, Chen ${ }^{*}{ }^{\dagger}$

${ }^{\dagger}$ School of Chemistry and Chemical Engineering, Yunnan Normal University, Kunming 650500, China

${ }^{*}$ Key Laboratory of Systems Biomedicine (Ministry of Education), Shanghai Center for Systems Biomedicine, Shanghai Jiao Tong University, Shanghai 200240, China

${ }^{\S}$ Department of Traditional Chinese Medicine, Yunnan University of Chinese Medicine, Kunming 650500, China

" State Key Laboratory of Phytochemistry and Plant Resources in West China, Kunming Institute of Botany, Chinese Academy of Sciences, Kunming 650201, China

Table of Contents

\begin{tabular}{|c|c|c|}
\hline & Supplementary Material Content & Page \\
\hline 1 & Detailed experimental procedures (contained Figure S1-S2) & S2-S6 \\
\hline 2 & Figure S3-S5. ${ }^{1} \mathrm{H}$ NMR spectra of compound 1 & S7-S9 \\
\hline 3 & Figure S6-S8. ${ }^{13} \mathrm{C}$ NMR spectra of compound 1 & $\mathrm{~S} 10-\mathrm{S} 12$ \\
\hline 4 & Figure S9-S10. ${ }^{1} \mathrm{H}-{ }^{1} \mathrm{H}$ COSY spectra of compound 1 & S13-S14 \\
\hline 5 & Figure S11-S14. HSQC spectra of compound 1 & S15-S18 \\
\hline 6 & Figure S15-S24. HMBC spectra of compound 1 & S19-S28 \\
\hline & Figure S25. HR-ESIMS spectrum of compound 1 & S29 \\
\hline 8 & Figure S26. UV spectrum of compound 1 & S30 \\
\hline & Figure S27. ORD spectrum of compound $(+)-\mathbf{1}$ & S31 \\
\hline & Figure S28. ORD spectrum of compound (-)-1 & S32 \\
\hline & Figure S29. CD spectrum of compound $(+)-1$ & S33 \\
\hline 12 & Figure S30. CD spectrum of compound (-)-1 & S34 \\
\hline 13 & Figure S31-33. ${ }^{1} \mathrm{H}$ NMR spectra of compound 2 & S35-S37 \\
\hline 14 & Figure S34-S36. ${ }^{13} \mathrm{C}$ NMR spectra of compound 2 & $\mathrm{~S} 38-\mathrm{S} 40$ \\
\hline 15 & Figure S37-38. ${ }^{1} \mathrm{H}-{ }^{1} \mathrm{H}$ COSY spectrum of compound 2 & S41-S42 \\
\hline 16 & Figure S39-S42. HSQC spectra of compound 2 & S43-S44 \\
\hline & Figure S43-S55. HMBC spectra of compound 2 & S45-S59 \\
\hline 18 & Figure S56. HRESI of compound 2 & S60 \\
\hline 19 & Figure S57. UV spectrum of compound 2 & S61 \\
\hline 20 & Figure S58. ORD spectrum of compound $(+)-2$ & S62 \\
\hline & Figure S59. ORD spectrum of compound (-)-2 & S63 \\
\hline & Figure S60. CD spectrum of compound $(+)-2$ & S64 \\
\hline & Figure S61. CD spectrum of compound (-)-2 & S65 \\
\hline & References & S66 \\
\hline
\end{tabular}




\section{Detailed experimental procedures}

General Experimental Procedures. Optical rotations were measured using a Jasco P-1020 polarimeter equipped with a $1 \mathrm{dm}$ pathlength cell. UV spectra were obtained using a Shimadzu UV-2401A spectrophotometer equipped with a DAD and a $1 \mathrm{~cm}$ pathlength cell. Samples in methanol solution were scanned from $190-400 \mathrm{~nm}$ in $1 \mathrm{~nm}$ steps. All ${ }^{1} \mathrm{H},{ }^{13} \mathrm{C}$, and $2 \mathrm{D}$ NMR (HSQC, ${ }^{1} \mathrm{H}-{ }^{1} \mathrm{H}$ COSY, HMBC, ROESY) spectra were collected with a Bruker AV III-800 spectrometer at $800 \mathrm{MHz}$ for ${ }^{1} \mathrm{H}$ and $200 \mathrm{MHz}$ for ${ }^{13} \mathrm{C}$ nuclei. Mass spectra were obtained on an Anilent 6540 Q-Tof instrument (ESI and HRESI mode). HRMS data were recorded via positive ion electrospray or electron impact mass spectrometry using a time of flight analyzer. Experimental ECD spectra were measured on a Chirascan instrument. Semi-preparative HPLC was performed on an Agilent 1260 HPLC with a Zorbax XDB-C ${ }_{18}(9.4 \mathrm{~mm} \times 25 \mathrm{~cm})$ column. Chiral semi-preparative HPLC was performed on an Agilent 1260 HPLC with the Ultimate Cellu-DR $(10 \mathrm{~mm} \times 25 \mathrm{~cm})$ column. Column chromatography (CC) was performed using silica gel (200-300 mesh, Qingdao Marine Chemical Co. Ltd., Qingdao, People's Republic of China), MCI gel (75-150 $\mu \mathrm{m}$; Mitsubishi Chemical Corporation, Japan), and Sephadex LH-20 (Amersham Biosciences AB, Uppsala, Sweden).

Plant Material. The twigs and leaves of Horsfieldia kingii was collected from Xishuangbanna, Yunnan Province, People's Republic of China, and was identified by Mr. Shishun Zhou, Xishuangbanna Tropical Botanical Garden, Chinese Academy of Sciences. A voucher specimen of this collection (No.140418) has been deposited at Herbarium of Yunnan Normal University, Kunming, China.

Extraction and Isolation. The twigs and leaves of Horsfieldia kingii $(10 \mathrm{~kg})$ were extracted with $70 \%$ aqueous acetone $(20 \mathrm{~L})$ four times (two days each time) at room temperature and filtered. The filtrate was evaporated in vacuo. Then the concentrate without acetone $(6 \mathrm{~L})$ was partitioned between EtOAc and $\mathrm{H}_{2} \mathrm{O}$. The EtOAc-soluble portion (376 g) was subjected to silica gel CC (2000 g, 100-200 mesh). Five fractions were produced from the silica gel column, eluting with $\mathrm{CHCl}_{3}-\mathrm{Me}_{2} \mathrm{CO}$ (1:0-0:1 gradient system), and were each decolorized on MCI gel, eluted with 90\% $\mathrm{MeOH}-\mathrm{H}_{2} \mathrm{O}$, to yield fractions A-F. 
Fraction B (28 g), a brown gum, was subjected to CC on Sephadex LH-20 and eluted with $\mathrm{CHCl}_{3}-\mathrm{MeOH}(3: 2)$, to provide four fractions, B1-B4. B2 (320 mg) was purification by repeated semi-preparative HPLC was performed on an Agilent $1260 \mathrm{HPLC}$ with a Zorbax XDB-C 18 (9.4 mm $\times 25 \mathrm{~cm})$ column $\left(\mathrm{MeOH}-\mathrm{H}_{2} \mathrm{O}\right.$ 48:52, v/v, $3 \mathrm{~mL} / \mathrm{min}$; Acetonitrile- $\left.\mathrm{H}_{2} \mathrm{O} 35: 65 \mathrm{v} / \mathrm{v}, 3 \mathrm{~mL} / \mathrm{min}\right)$ to afford horisfieldones A $(3.7 \mathrm{mg})$ and B $(3.3 \mathrm{mg})$. Horisfieldones A and B was then chiral separated on Agilent 1260 HPLC with Ultimate Cellu-DR $(10 \mathrm{~mm} \times 25 \mathrm{~cm})$ column $\left(\mathrm{MeOH}-\mathrm{H}_{2} \mathrm{O}\right.$ 95:5, v/v, 3 $\mathrm{mL} / \mathrm{min})$ respectively to provide (+)-horisfieldone $\mathrm{A}(1.3 \mathrm{mg}),(-)$-horisfieldone $\mathrm{A}(1.1 \mathrm{mg})$, (+)-horisfieldone B (1.2 mg), and (-)-horisfieldone B (1.0 mg).

Horisfieldone A (1): brown oil; UV (MeOH) $\lambda_{\max }(\log \varepsilon) 204$ (4.05), 226 (3.60), 288 (3.30) nm; ${ }^{1} \mathrm{H}$ and ${ }^{13} \mathrm{C}$ NMR data, see Tables 1 and 2; negative-ion HRESIMS m/z $571.1971[\mathrm{M}-\mathrm{H}]^{-}$(calcd for $\mathrm{C}_{33} \mathrm{H}_{32} \mathrm{O}_{9}$, 571.1974).

(+)-horisfieldone A: $[\alpha]_{\mathrm{D}}^{19.2}+138.6(c 0.06, \mathrm{MeOH}) ; \mathrm{CD}(\mathrm{MeOH}), \lambda_{\max }(\Delta \varepsilon) 330(1.61)$.

(-)-horisfieldone A: $[\alpha]_{\mathrm{D}}^{18.9}-87.3(c 0.12, \mathrm{MeOH}) ; \mathrm{CD}(\mathrm{MeOH}), \lambda_{\max }(\Delta \varepsilon) 333(-1.67)$.

Horisfieldone B (2): brown oil; UV (MeOH ) $\lambda_{\max }(\log \varepsilon) 204$ (3.78), 226 (3.33), 292 (3.05) nm; ${ }^{1} \mathrm{H}$ and ${ }^{13} \mathrm{C}$ NMR data, see Tables 1 and 2; negative-ion HRESIMS $m / z 601.2071[\mathrm{M}-\mathrm{H}]^{-}$(calcd for $\left.\mathrm{C}_{34} \mathrm{H}_{34} \mathrm{O}_{10}, 601.2079\right)$.

(+)-horisfieldone B: $[\alpha]_{\mathrm{D}}^{19.0}+86.4(c 0.17, \mathrm{MeOH}) ; \mathrm{CD}(\mathrm{MeOH}), \lambda_{\max }(\Delta \varepsilon) 335(1.55)$.

(-)-horisfieldone B: $[\alpha]_{\mathrm{D}}^{18.8}-124.0(c 0.12, \mathrm{MeOH}) ; \mathrm{CD}(\mathrm{MeOH}), \lambda_{\max }(\Delta \varepsilon) 334(-1.68)$.

\section{ECD Calculations of 1}

ECD Calculations were performed by a Gaussian 09 software. More specifically, the 3D structures were first established randomly or according to the ROESY spectra, which were then subjected to conformational analysis using CONFLEX software with MMFF94S force fields to afford six reliable conformations with relative energy of less than $1.00 \mathrm{kcal} / \mathrm{mol}$. The selected conformers were further optimized by using the Density Functional Theory (DFT) at the B3LYP/6-31+G(d) level in gas phase. The optimized geometries were subsequently checked by frequency calculation and resulted in no imaginary frequencies. The optimized conformations were subjected to ECD calculations using Time Dependent DFT (TDDFT) at the B3LYP/6-311++G(2d, p) level in CH3OH. The calculated ECD curves were generated by SpecDis version 1.63 software. (Reference: Frisch, M.J.; Trucks, G. W.; Schlegel, H. B.; et al. Gaussian 09, Revision E. 01. Gaussian, Inc: Wallingford, CT, 2013. Bruhn, T.; Schaumlöffel, A., Hemberger, Y., Bringmann, G. Chirality 2013, 25, 243-249.) 


\section{Molecular Modeling}

The ligand and receptor were prepared using DiscoveryStudio 4.0 software. Autodock Tools v1.56 ${ }^{1}$ was used to perform grid and docking. Docking parameters were set as the default values AutoGrid v4.01 and AutoDock v4.01. The Grid box contained the whole active cavity of human DDC (PDB: 3rbf) was chosen. ${ }^{2}$ Docking conformations were classified into different clusters by binding energy, and the cluster with the lowest binding energy was selected. In the selected cluster, conformations with the lowest binding energy and RMSD $(<2.0 \AA)$ were finally chosen to analyze the receptor-ligand interaction.

\section{The activity assay of human cystathionine $\chi$-lyase (hCSE).}

The inhibition of compounds on the activity of hCSE was determined using our previously reported method that is based on a 192-tandem-well plate. ${ }^{3}$ Briefly, $25 \mu 150 \mathrm{mM}$ HEPES buffer containing $500 \mathrm{nM}$ purified recombinant GST-tagged hCSE protein and $100 \mu \mathrm{M}$ PLP (final concentrations; $\mathrm{pH}$ 7.4) was first incubated with $1 \mu \mathrm{L}$ DMSO or compounds in the reaction well at a concentration of $100 \mu \mathrm{M}$ for $45 \mathrm{~min}$. Then, $50 \mu \mathrm{l}$ detection buffer $(300 \mu \mathrm{M}$ DTNB in $262 \mathrm{mM}$ Tris- $\mathrm{HCl}$ and $13 \mathrm{mM}$ EDTA, pH 8.9) was added into the interlinked detection well. Finally, $25 \mu 150$ mM HEPES buffer containing $5 \mathrm{mM}$ L-Cys (final concentrations) was added in the reaction well and the plate was immediately and tightly sealed with UltraClear film (Platemax PCR-TS from Axygen, Union City, CA). The assay plate was then incubated for additional $60 \mathrm{~min}$ at $37{ }^{\circ} \mathrm{C}$ before the absorbance was measured at $413 \mathrm{~nm}$ with a microplate reader (Cytation5 from BioTek, Winooski, VT).

\section{The activity assay of human DOPA decarboxylase (hDDC).}

The DDC assay was performed under standard assay conditions as previously described. ${ }^{2 b}$ Briefly, $1 \mu \mathrm{L}$ DMSO or compounds at a concentration of $100 \mu \mathrm{M}$ were mixed with $24.5 \mu \mathrm{L}$ of the enzyme mix [50 mM Tris-HCl, $50 \mathrm{mM} \mathrm{NaCl}, 0.015 \%$ (w/v) bovine serum albumin, $5 \mathrm{mM} \mathrm{MgCl}_{2}, 2 \mathrm{mM}$ $\beta$-mercaptoethanol, $760 \mu \mathrm{M}$ NADH, $330 \mathrm{nM}$ PEPC, $100 \mu \mathrm{M}$ PLP and $284 \mathrm{nM} 6 \times$ His-tagged hDDC, $\mathrm{pH}$ 8.05; final concentrations]. Then, the reaction was started by adding $24.5 \mu \mathrm{L}$ substrate mix [50 mM Tris- $\mathrm{HCl}$ containing $50 \mathrm{mM} \mathrm{NaCl}, 0.015 \%$ (w/v) bovine serum albumin, $5 \mathrm{mM} \mathrm{MgCl} 2$, $2 \mathrm{mM} \beta$-mercaptoethanol, $10 \mathrm{mM}$ phosphoenolpyruvic acid, $0.49 \mathrm{U}$ malate dehydrogenase and 1.5 $\mathrm{mM}$ 3,4-dihydroxy-L-phenylalanine, $\mathrm{pH}$ 8.05; final concentration]. The plates were then tightly sealed with UltraClear film and incubated for $30 \mathrm{~min}$ at $37{ }^{\circ} \mathrm{C}$ before the absorbance of $340 \mathrm{~nm}$ was measured in a microplate reader. The remaining activity of compound was expressed as percentage of control (DMSO) with the following equation: Remaining activity $(\%)=\left\{\left[\left(\mathrm{OD}_{0} \mathrm{~min}-\mathrm{OD}_{30} \mathrm{~min}\right)\right.\right.$ of compound $]-\left[\left(\mathrm{OD}_{0} \min -\mathrm{OD}_{30} \mathrm{~min}\right)\right.$ of blank $\left.]\right\} /\left\{\left[\left(\mathrm{OD}_{0 \mathrm{~min}}-\mathrm{OD}_{30 \mathrm{~min}}\right)\right.\right.$ of $\left.\mathrm{DMSO}\right]-\left[\left(\mathrm{OD}_{0} \min -\right.\right.$ $\left.\mathrm{OD}_{30 \mathrm{~min}}\right)$ of blank]\} $\times 100$. 


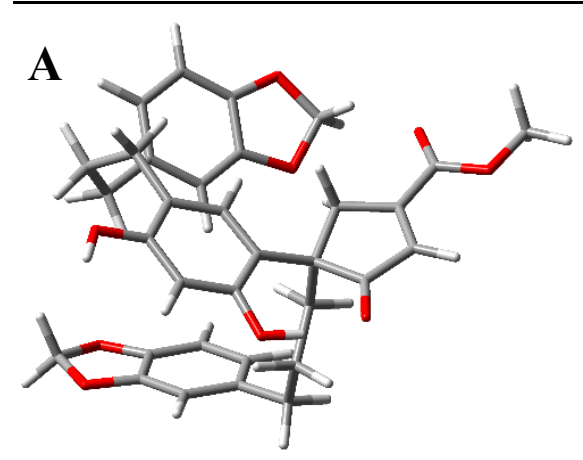

Conf. 1 (15.45 \%)

$\Delta \mathrm{E}=0.00 \mathrm{kcal} / \mathrm{mol}$

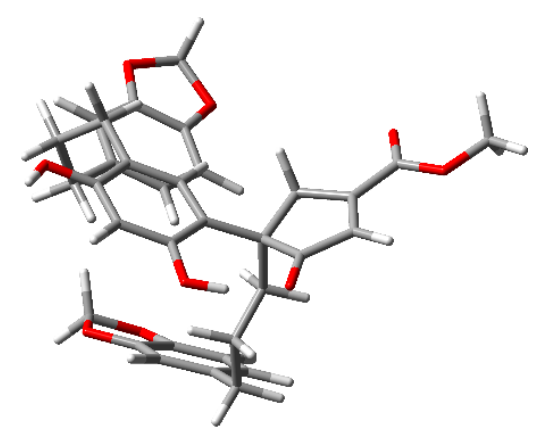

Conf. 4 (5.78\%)

$\Delta \mathrm{E}=0.59 \mathrm{kcal} / \mathrm{mol}$

B

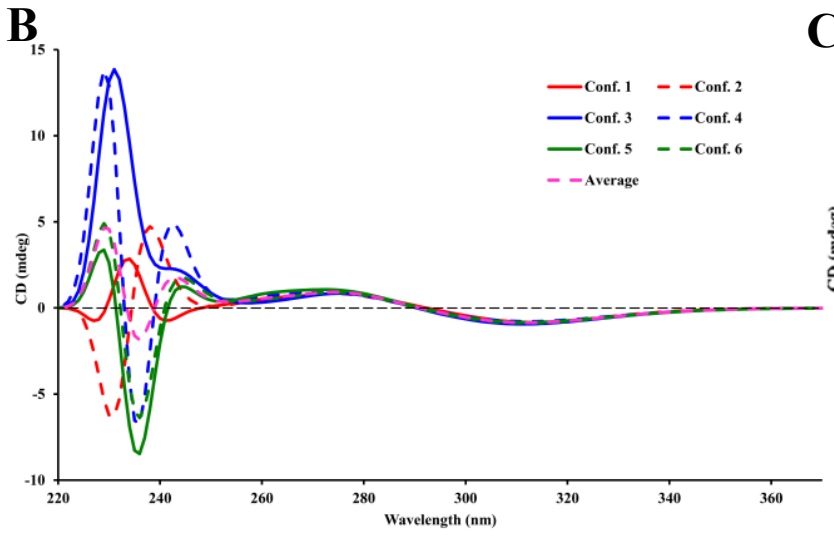

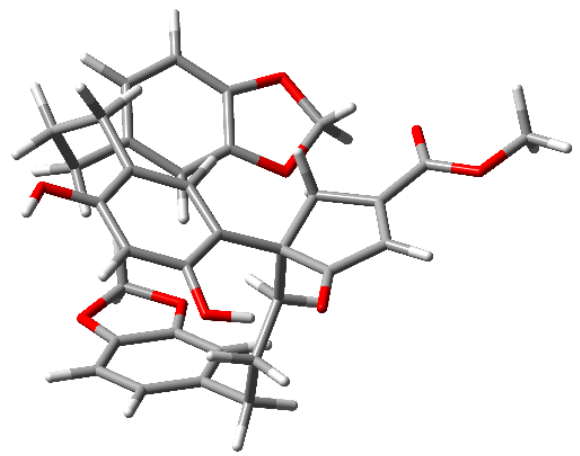

Conf. $2(15.22 \%)$

$\Delta \mathrm{E}=0.01 \mathrm{kcal} / \mathrm{mol}$

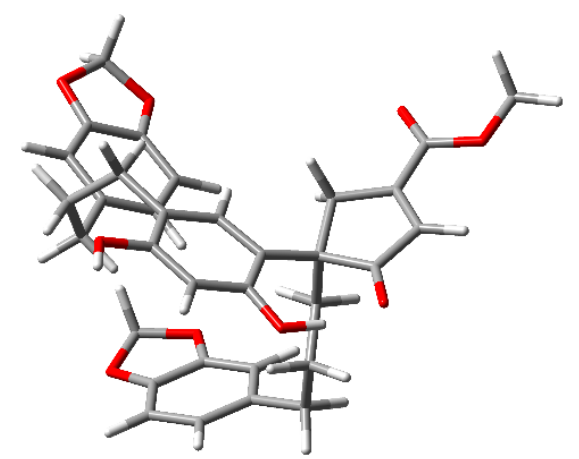

Conf. 5 (4.66\%)

$\Delta \mathrm{E}=0.71 \mathrm{kcal} / \mathrm{mol}$

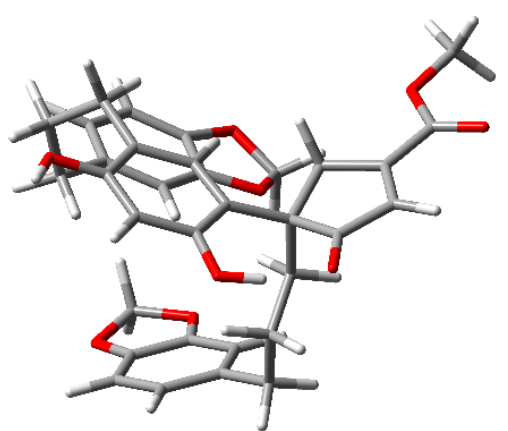

Conf. $3(9.38 \%)$

$\Delta \mathrm{E}=0.20 \mathrm{kcal} / \mathrm{mol}$

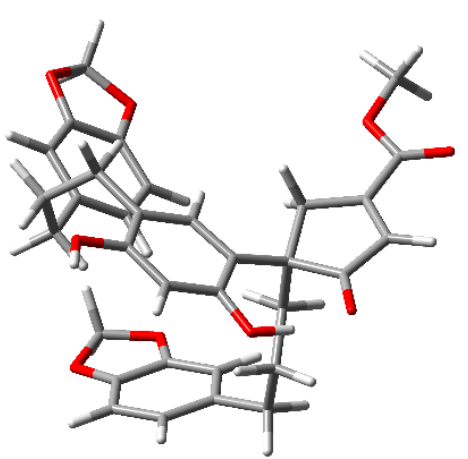

Conf. $6(3.22 \%)$

$\Delta \mathrm{E}=0.93 \mathrm{kcal} / \mathrm{mol}$

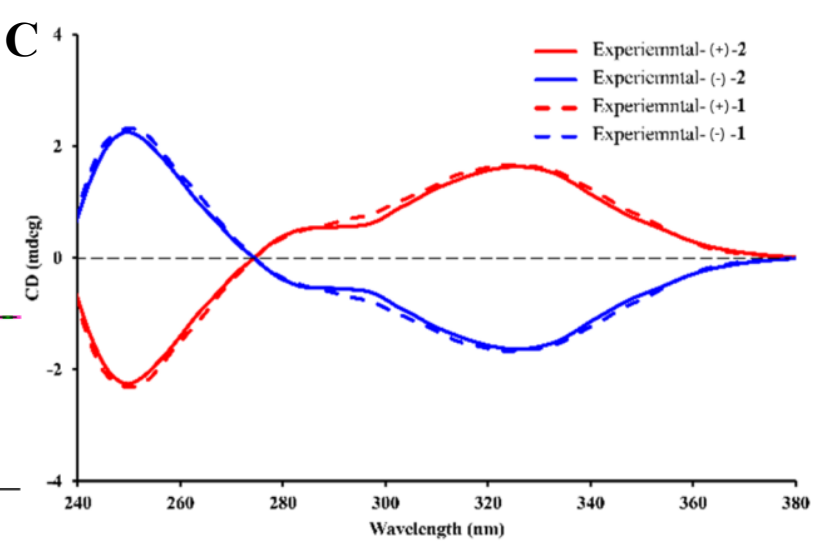

Figure S1. Computational data of 1. (A) Six receivable conformers with lower relative energy of 1. (B) Calculated ECD spectra for the low energy structures. (C) Experimental CD spectra of compounds $\mathbf{1}$ and $\mathbf{2}$. 

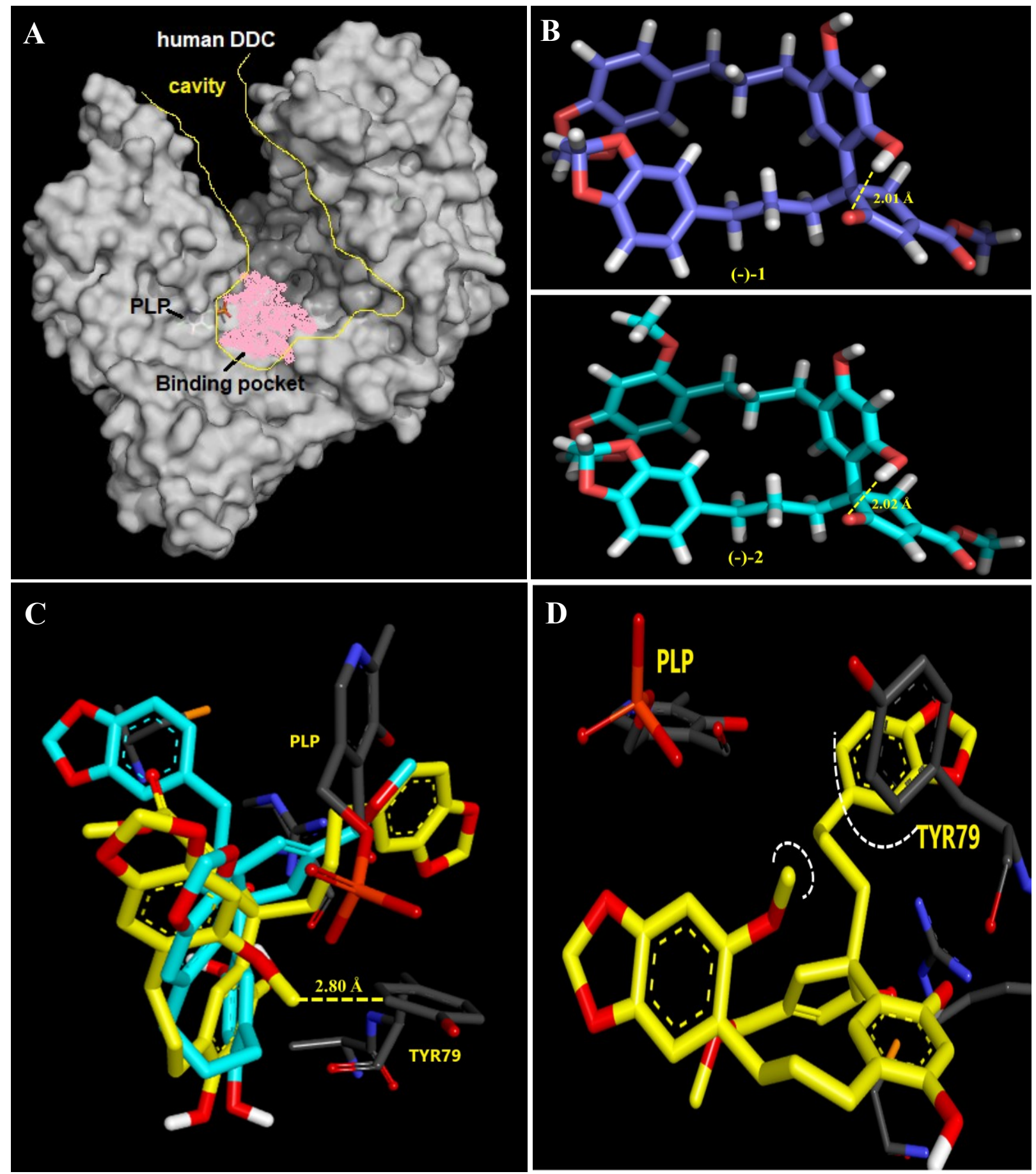

Figure S2. Molecular docking analysis of compounds (-)-1, (+)-1, (-)-2, and (+)-2 into human DOPA decarboxylase (hDDC) (pdb: 3rbf). (A) The active cavity of hDDC and the calculated binding pocket (shown in pink color, an approximate area overlapped the L-DOPA binding region [ref. 2a]) of compounds (-)-1, (+)-1, (-)-2, and $(+)$-2. The receptor was showed as solid surface in white with 20\% transparence. PLP was shown as sticks. Ligands were shown as spheres. (B) Minimized configurations of (-)-1 and (-)-2, yellow-dotted lines represented intramolecular hydrogen bonds with length of $2.01 \AA$ and $2.02 \AA$, respectively. (C) Superposition of (+)-1 and $(+)$-2 docking into the hDDC. Ligands were shown as sticks. Namely, $(+)-\mathbf{1}$ was shown in cyan color, and (+)-2 was shown in yellow color. The key residues were shown as sticks (C, pale; O, red; N, blue; $\mathrm{P}$, orange). (D) Zoomed docking pose of (+)-2. The white-dotted arcs represented the steric bump between the C6a"-OMe of (+)-2 with the aromatic ring of residue TYR79. 


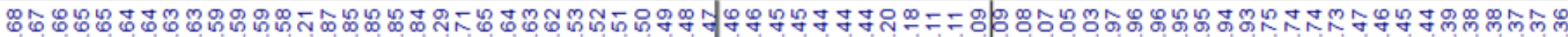
OQ

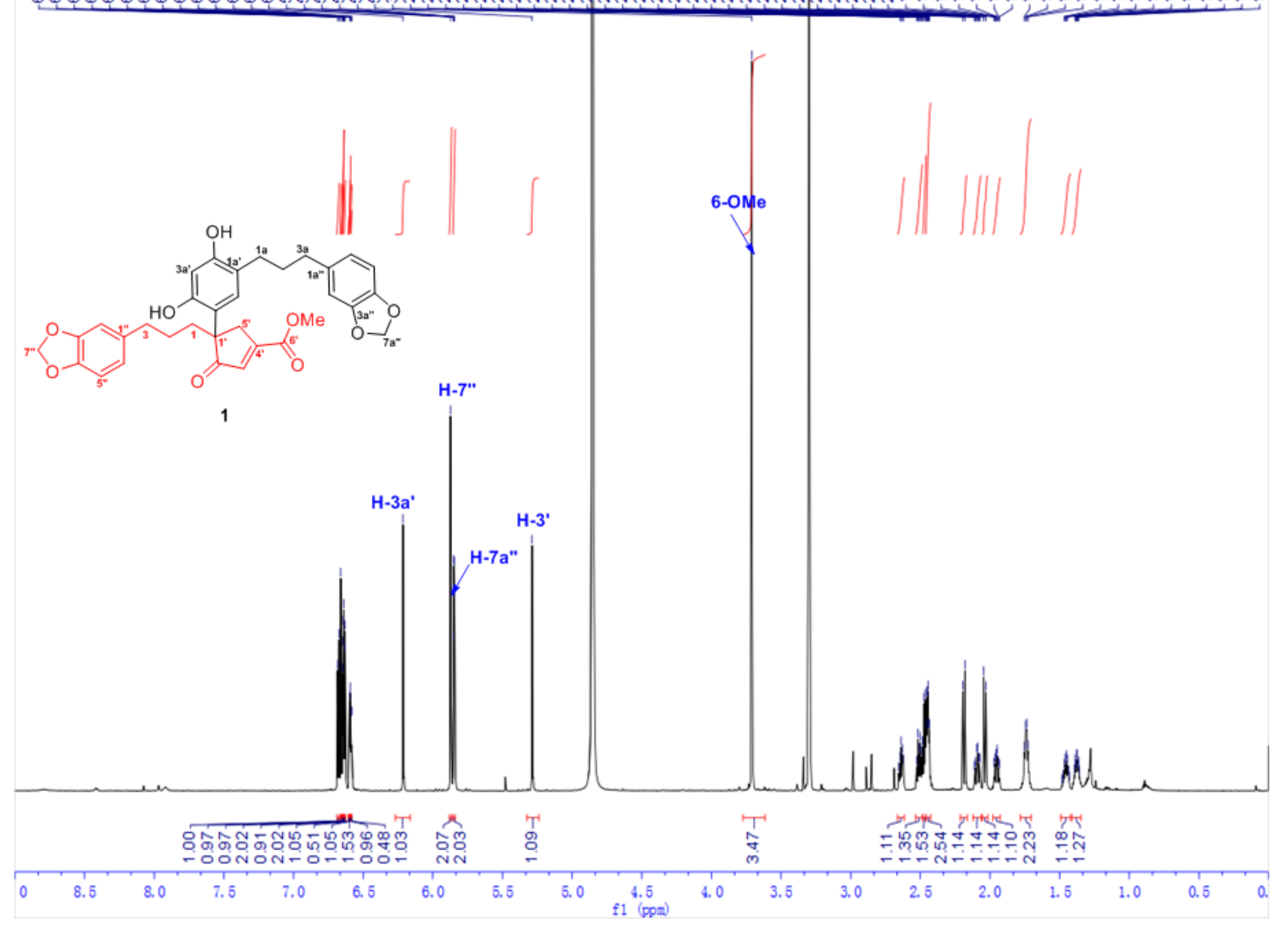

Figure S3. ${ }^{1} \mathrm{H}$ NMR spectrum $(0-9 \mathrm{ppm})$ of compound 1 

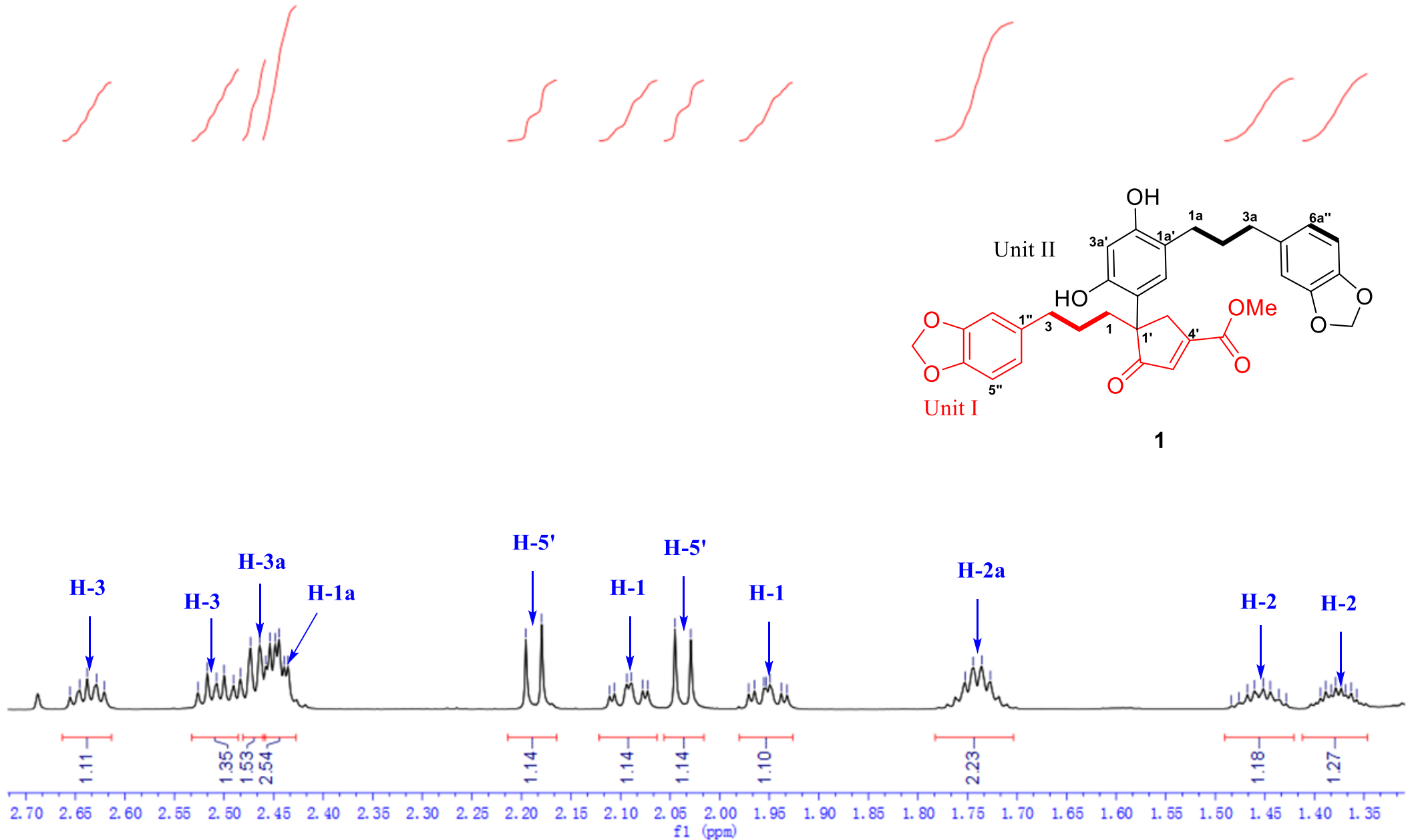

Figure S4. ${ }^{1} \mathrm{H}$ NMR spectrum (1.35-2.70 ppm) of compound 1 

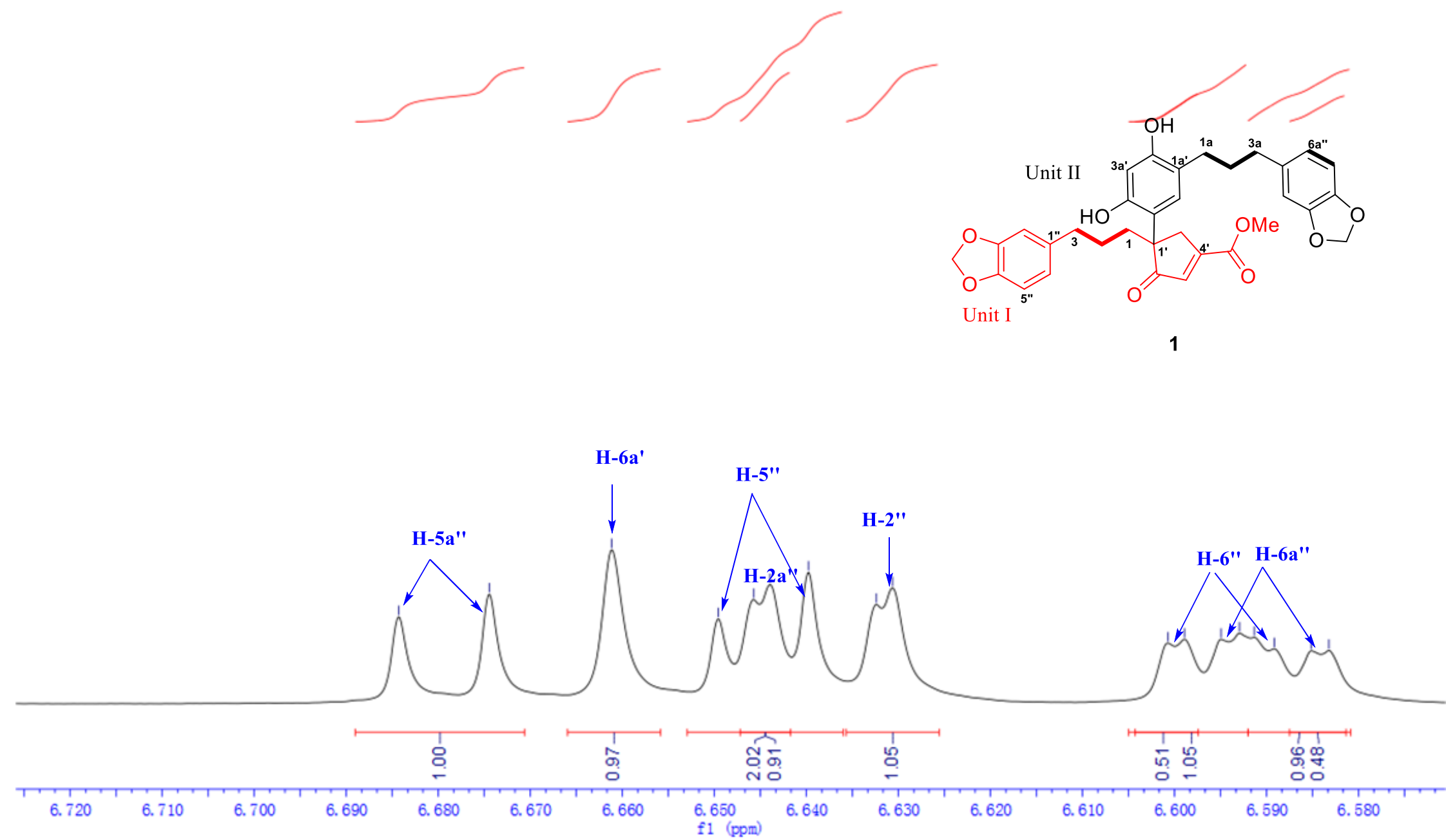

Figure S5. ${ }^{1} \mathrm{H}$ NMR spectrum (6.58-6.72 ppm) of compound 1 


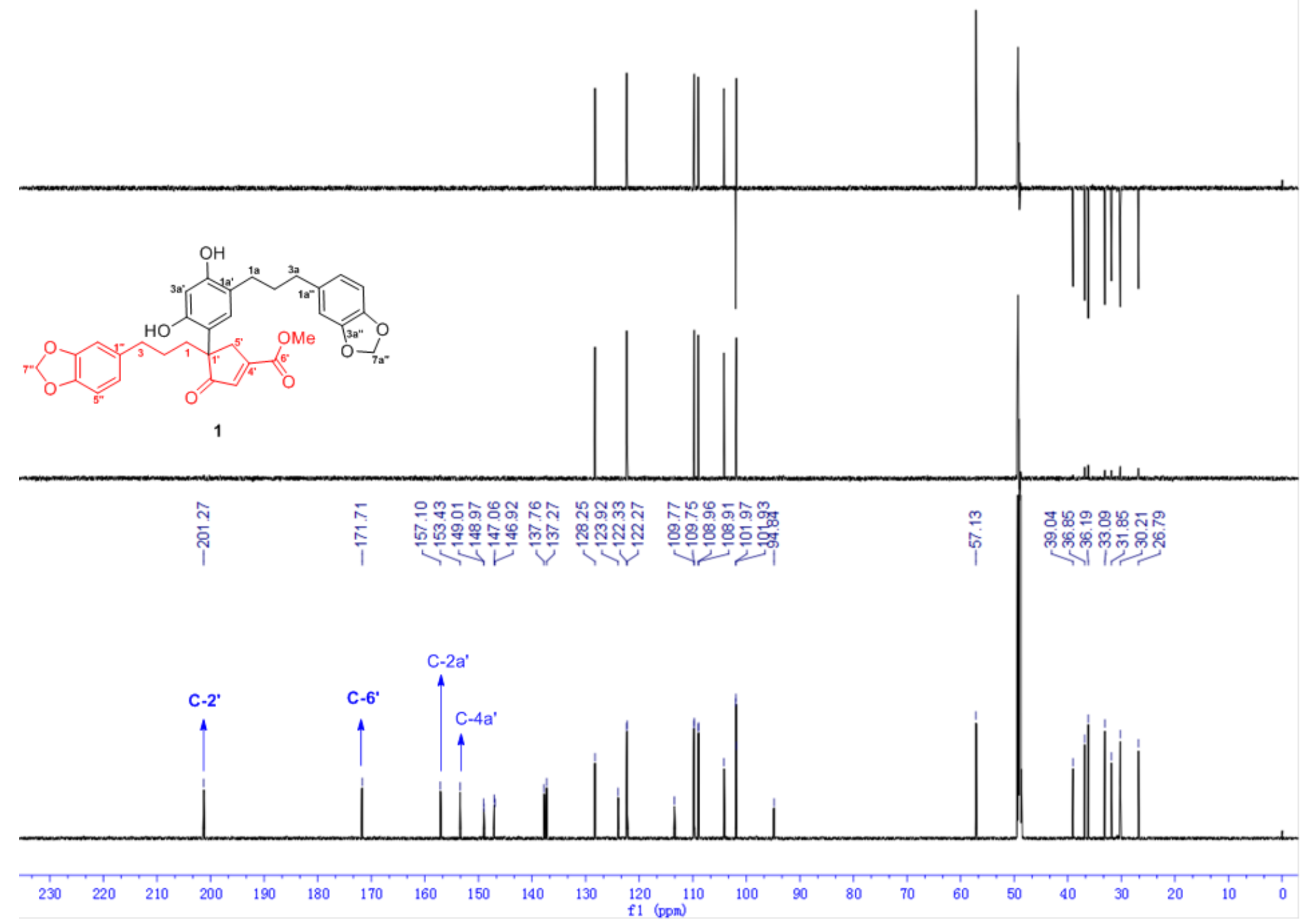

Figure S6. ${ }^{13} \mathrm{C}$ NMR spectra (0-230 ppm) of compound 1 


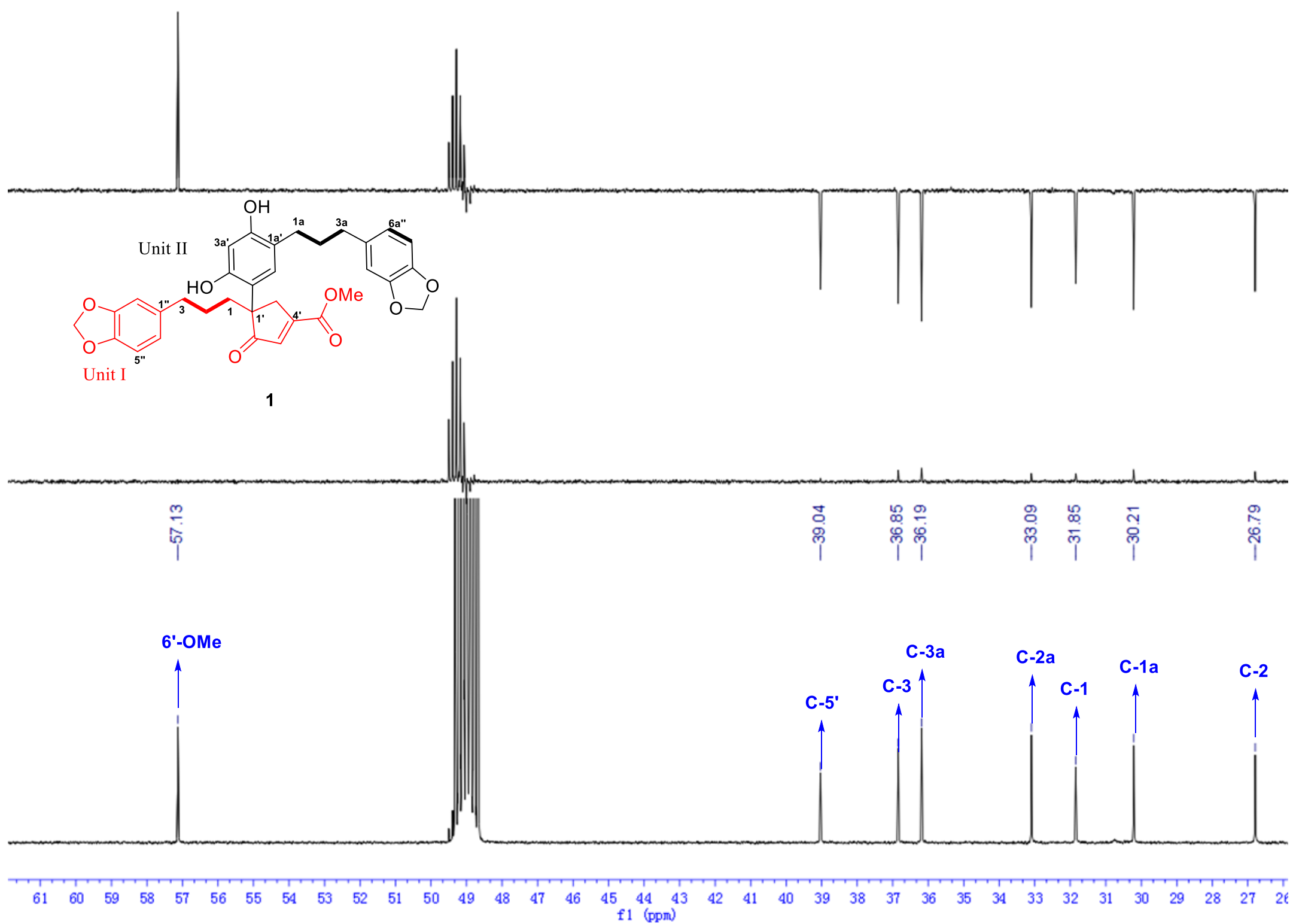

Figure S7. ${ }^{13} \mathrm{C}$ NMR spectra (20-61 ppm) of compound 1 

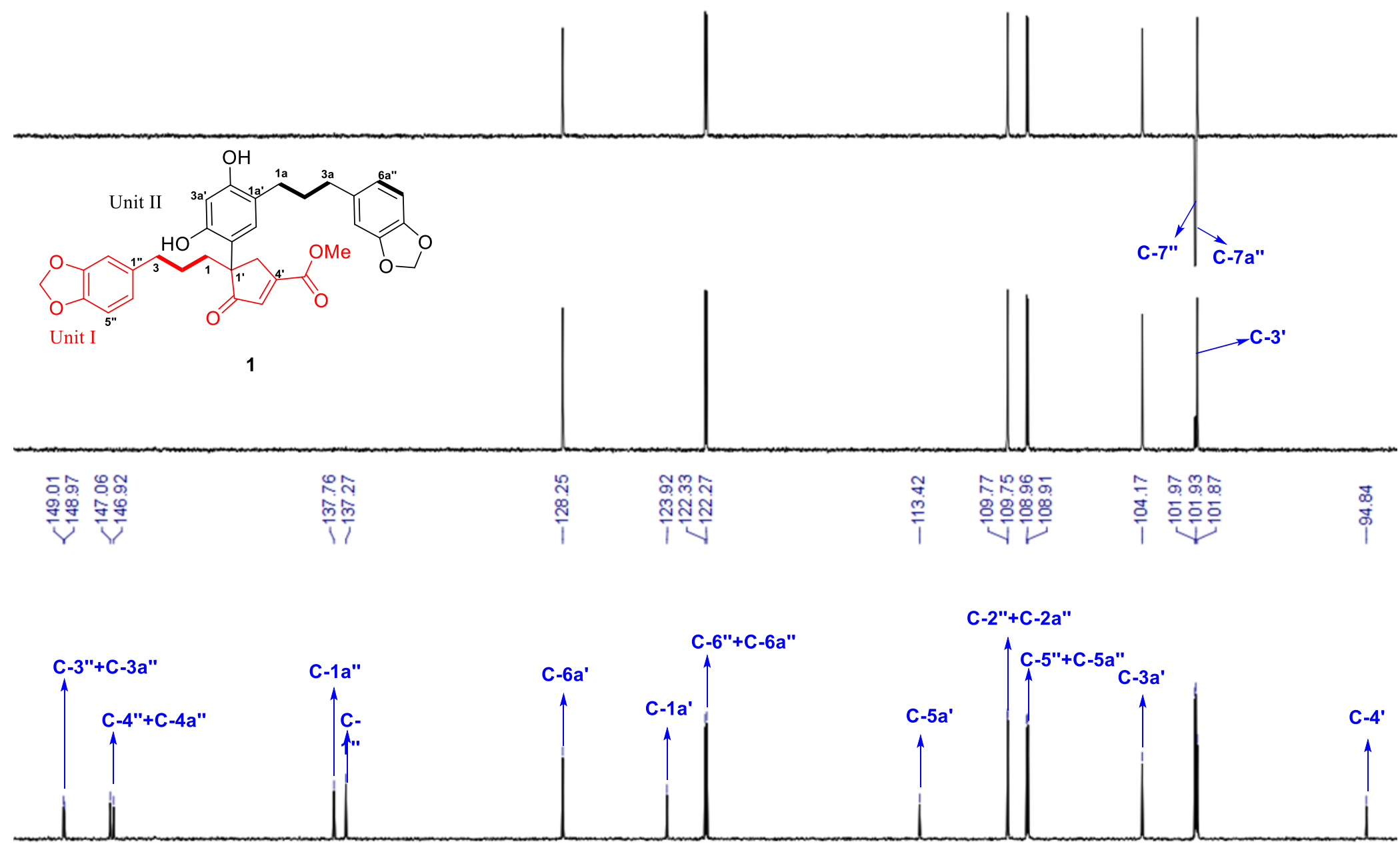

$\begin{array}{lllllllllllllllllllllllllllllllllll}150 & 148 & 146 & 144 & 142 & 140 & 138 & 136 & 134 & 132 & 130 & 128 & 126 & 124 & 122 & 120 & 118 & 116 & 114 & 112 & 110 & 108 & 106 & 104 & 102 & 100 & 98 & 96 & 94\end{array}$

Figure S8. ${ }^{13} \mathrm{C}$ NMR spectra (94-170 ppm) of compound 1 

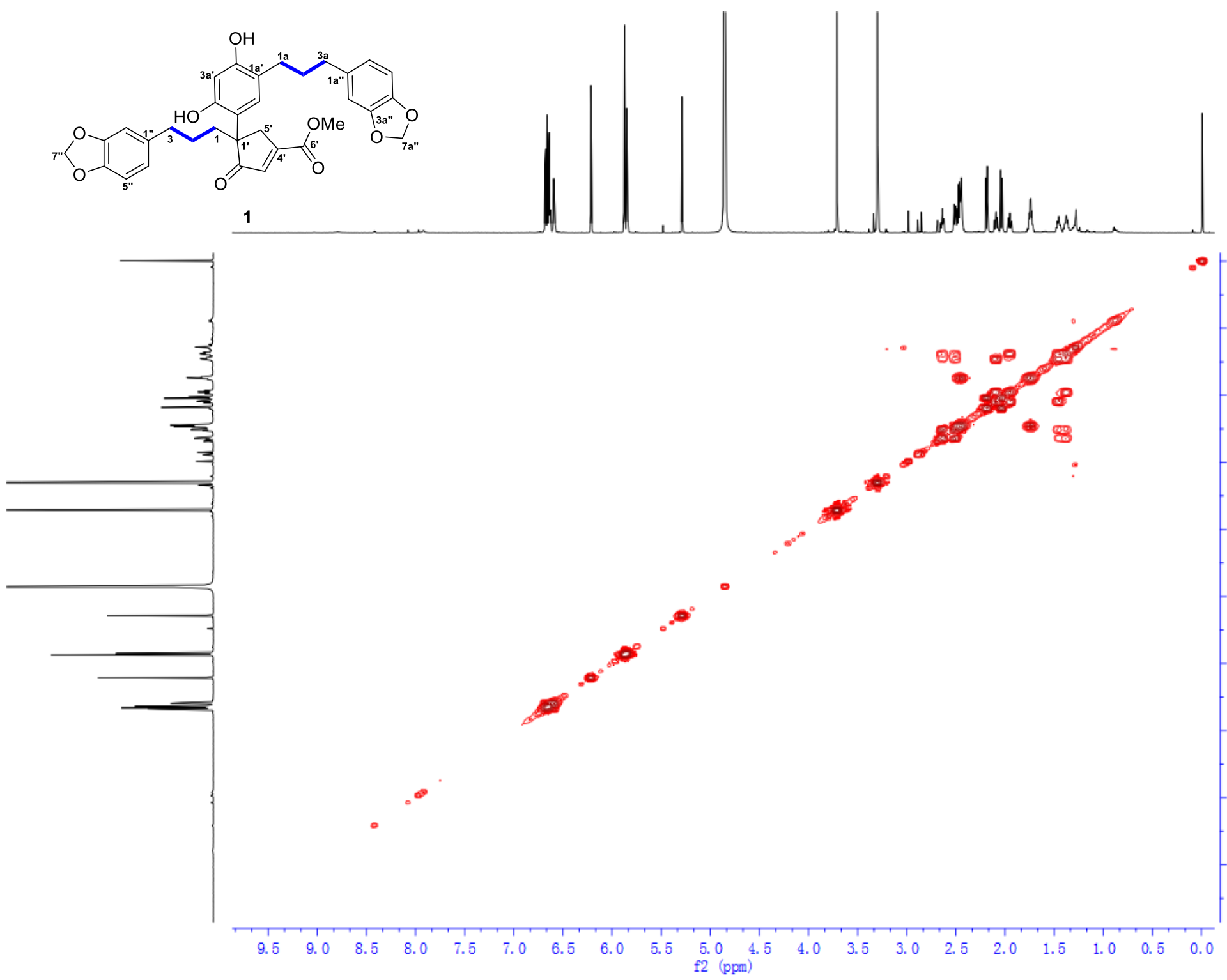

Figure S9. ${ }^{1} \mathrm{H}-{ }^{1} \mathrm{H}$ COSY spectrum of compound 1 


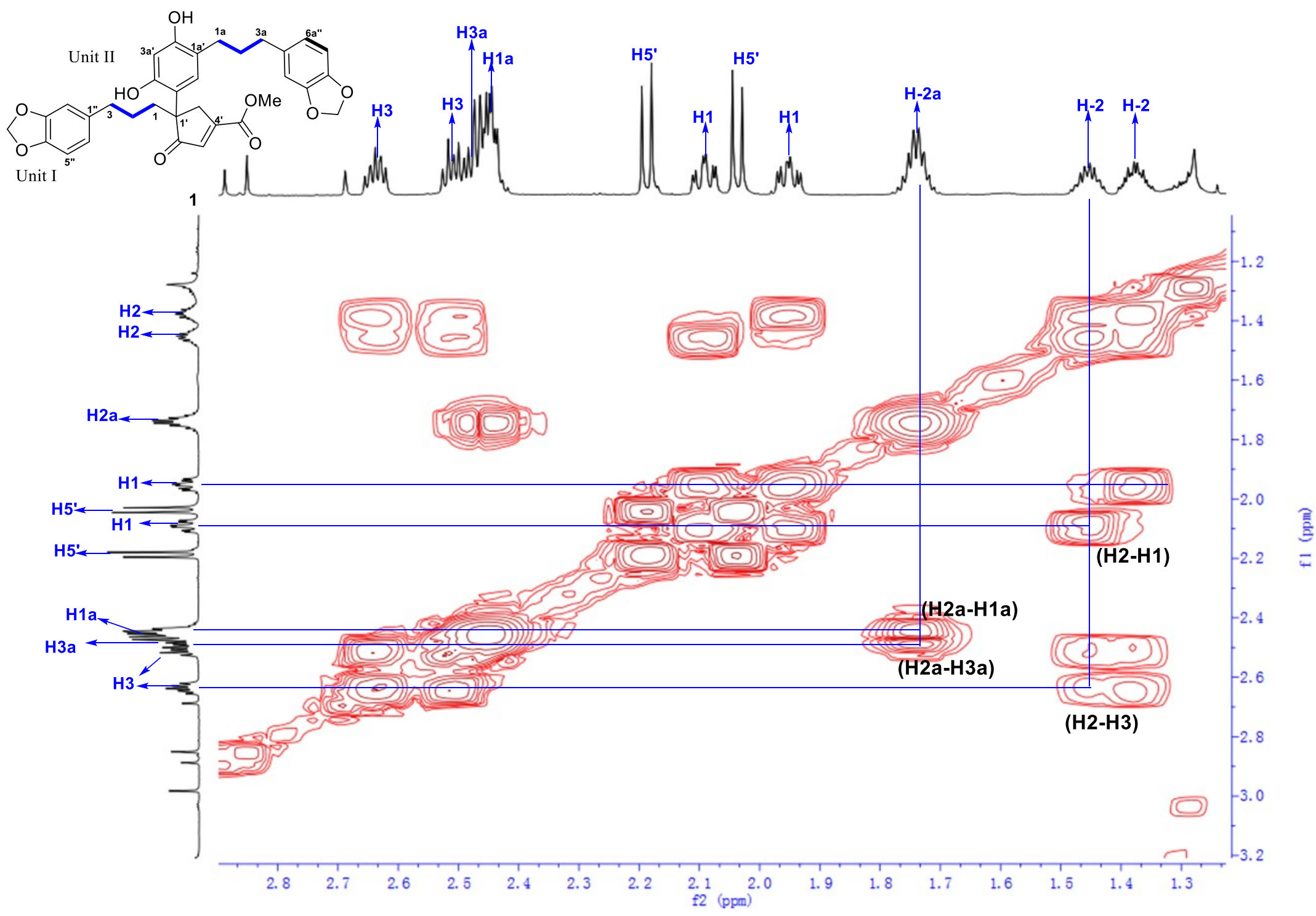

Figure S10. Key ${ }^{1} \mathrm{H}-{ }^{1} \mathrm{H}$ COSY spectrum of compound 1 


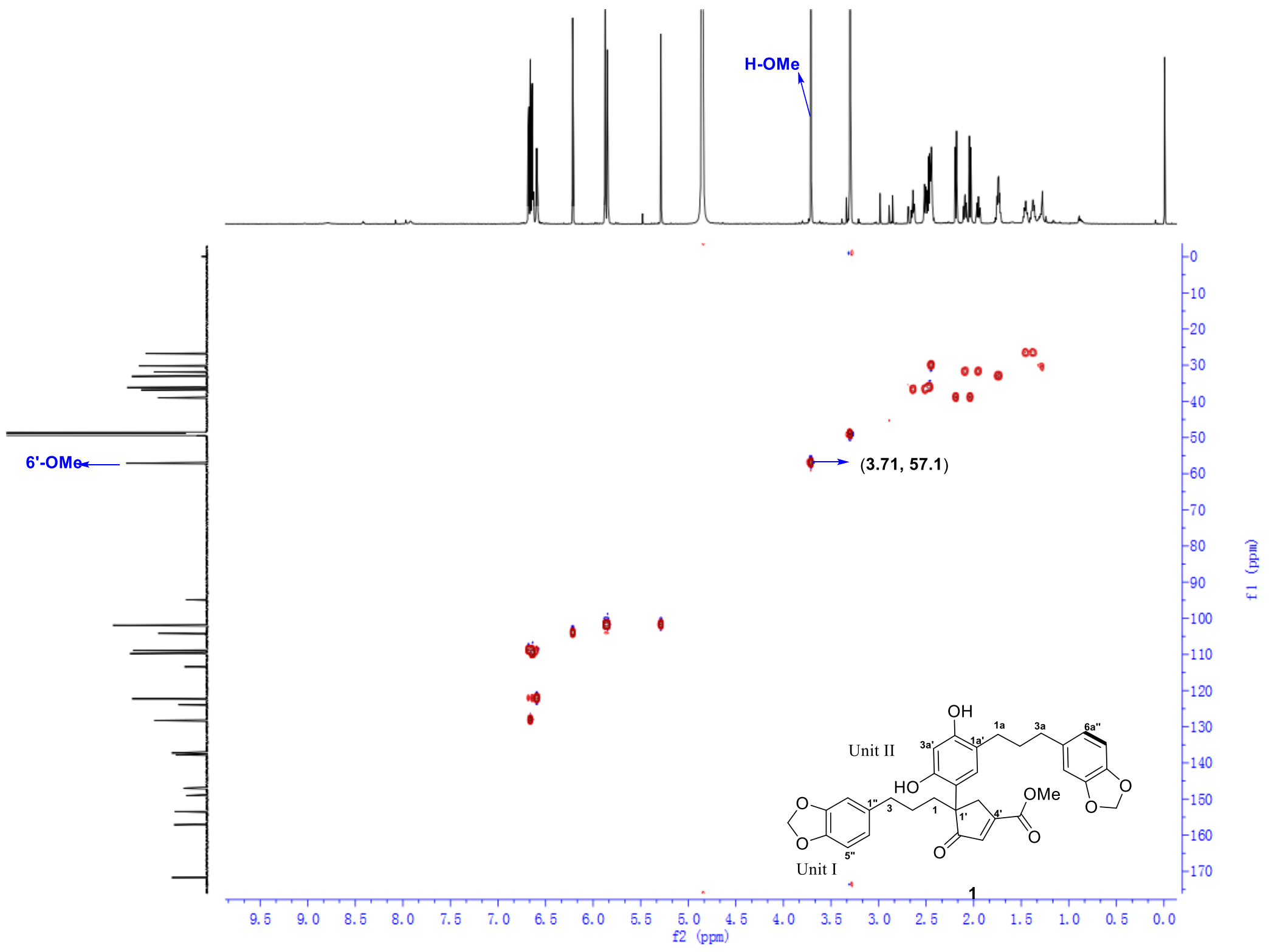

Figure S11. HSQC spectrum of compound 1 


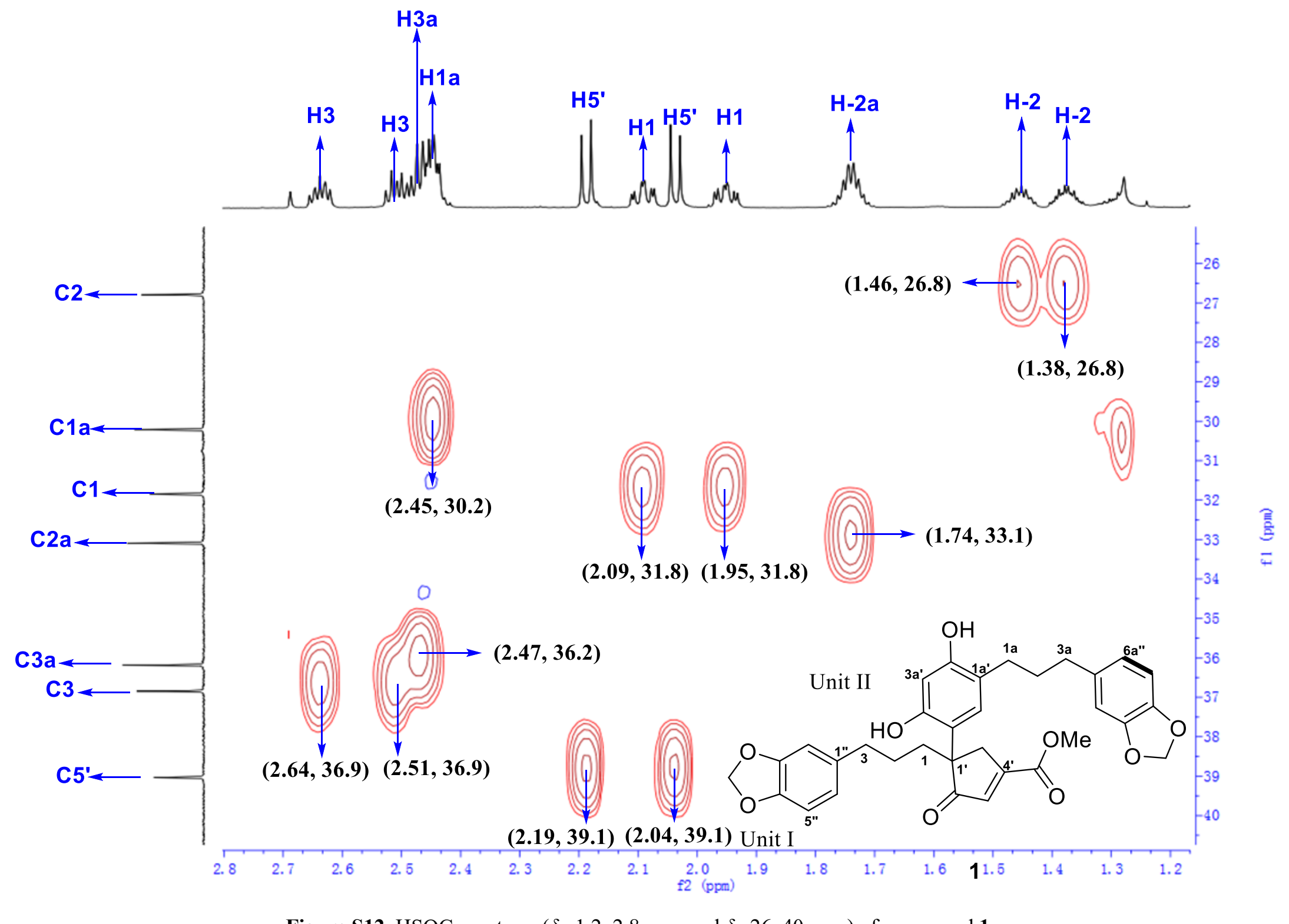

Figure S12. HSQC spectrum $\left(\delta_{\mathrm{H}} 1.2-2.8 \mathrm{ppm}\right.$ and $\left.\delta_{\mathrm{C}} 26-40 \mathrm{ppm}\right)$ of compound 1 


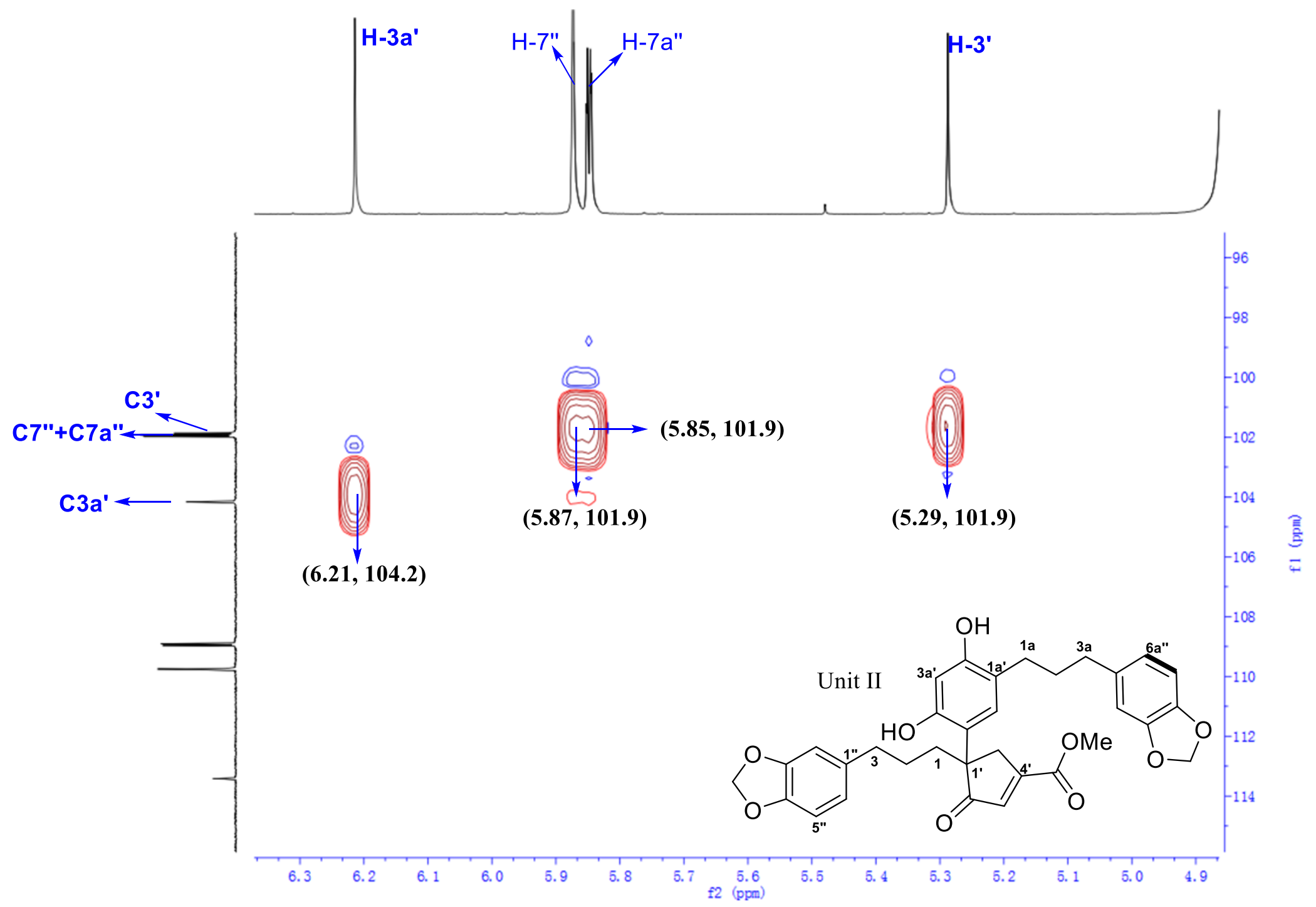

Figure S13. HSQC spectrum ( $\delta_{\mathrm{H}} 4.9-6.5 \mathrm{ppm}$ and $\left.\delta_{\mathrm{C}} 96-114 \mathrm{ppm}\right)$ of compound 1 
Supporting Information

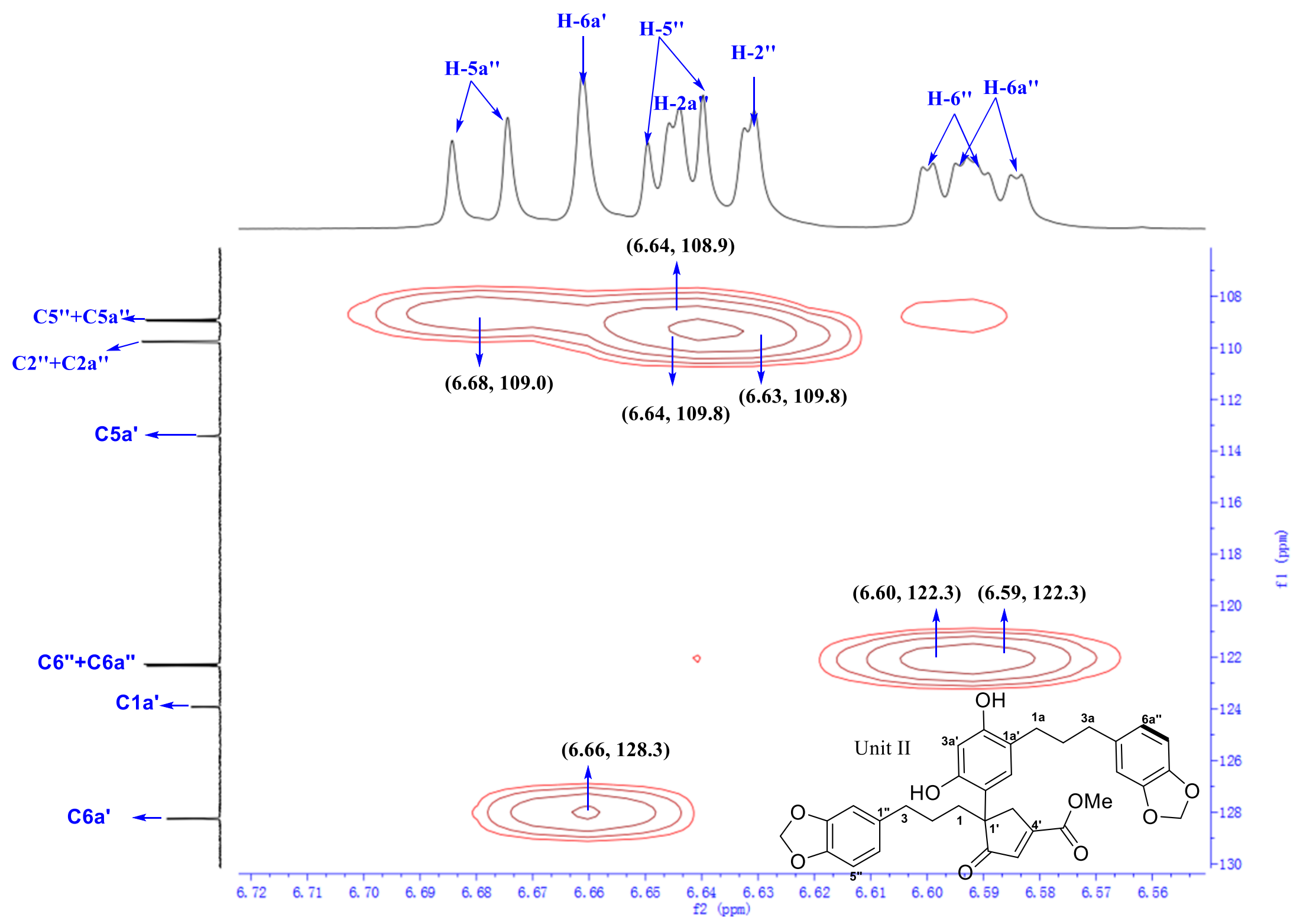

Figure S14. HSQC spectrum $\left(\delta_{\mathrm{H}} 6.56-6.72 \mathrm{ppm}\right.$ and $\left.\delta_{\mathrm{C}} 108-130 \mathrm{ppm}\right)$ of compound 1 
Supporting Information

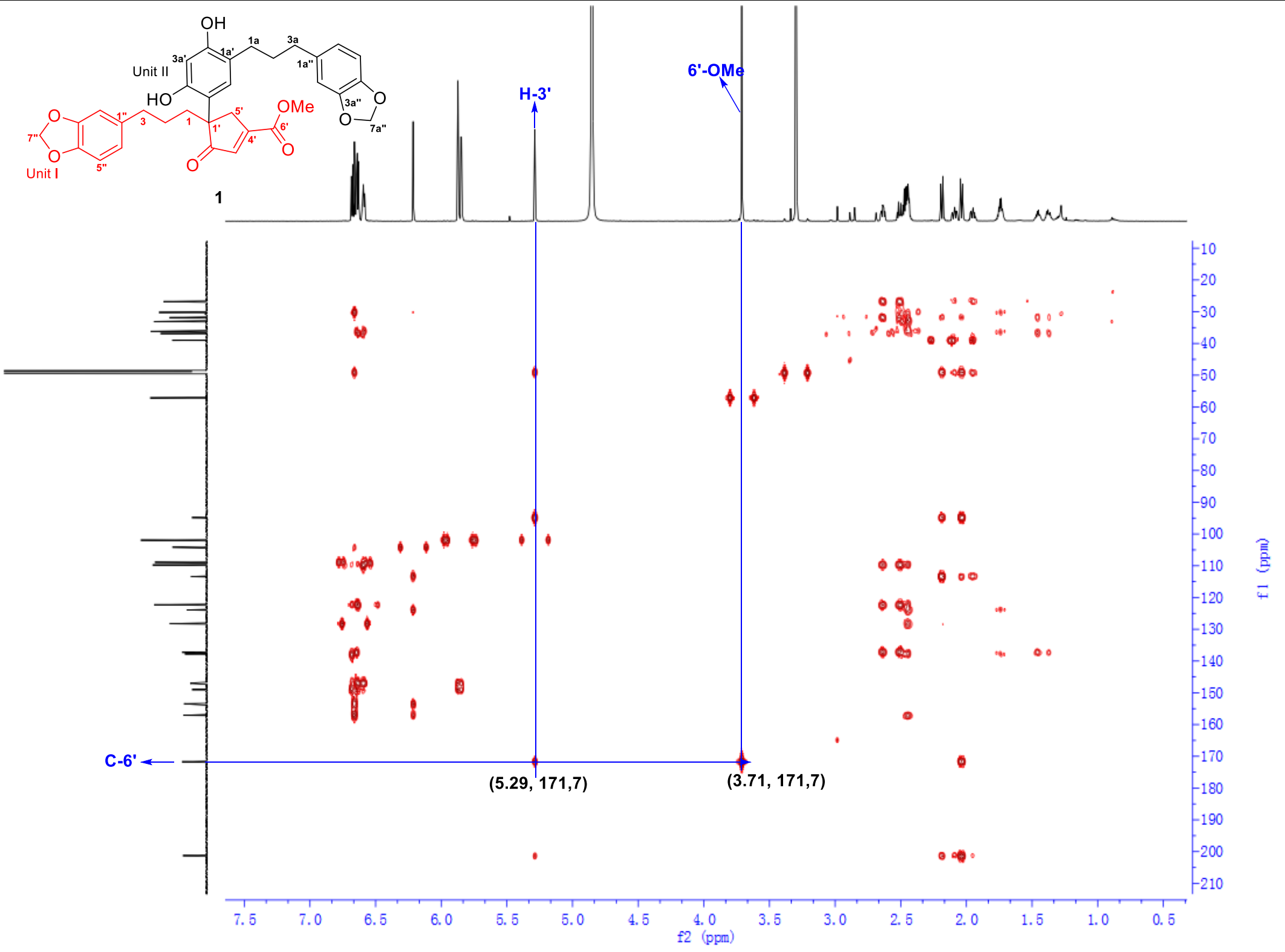

Figure S15. HMBC spectrum of compound 1 


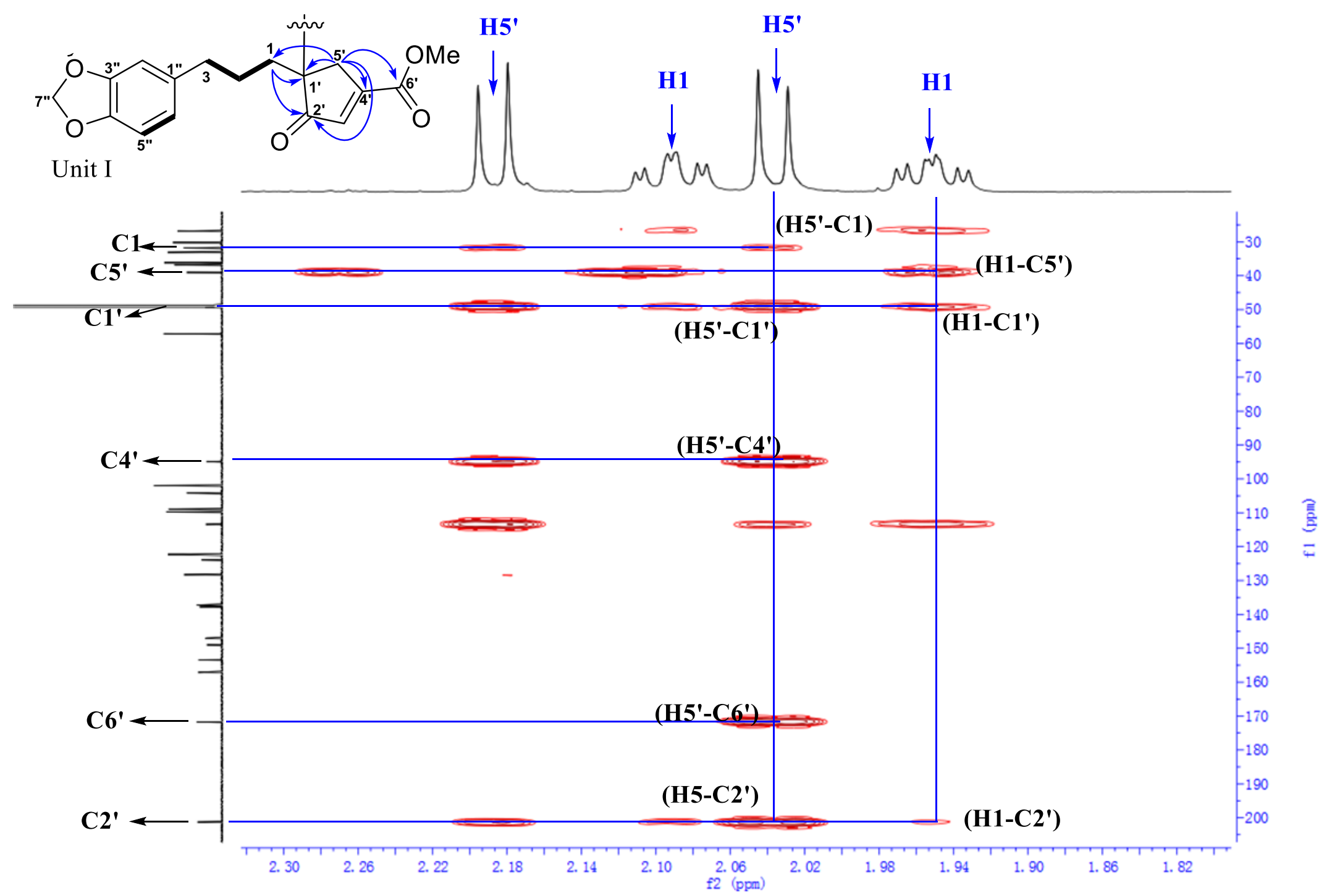

Figure S16. Key HMBC spectrum $\left(\delta_{\mathrm{H}} 1.82-2.30 \mathrm{ppm}\right.$ and $\left.\delta_{\mathrm{C}} 30-200 \mathrm{ppm}\right)$ of unit I in compound 1 


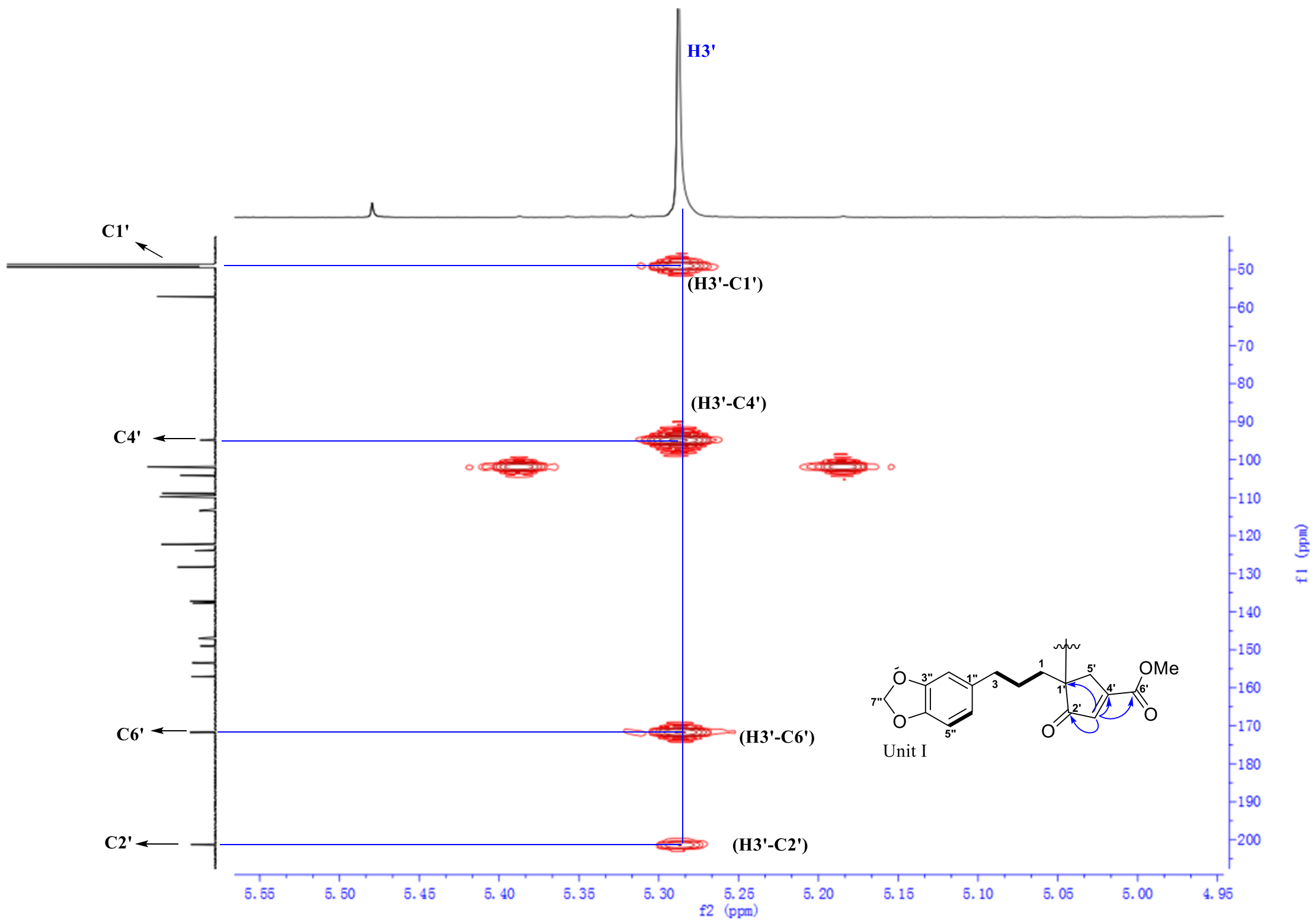

Figure S17. Key HMBC spectrum ( $\delta_{\mathrm{H}} 4.9-5.9 \mathrm{ppm}$ and $\left.\delta_{\mathrm{C}} 40-200 \mathrm{ppm}\right)$ of unit I in compound 1 


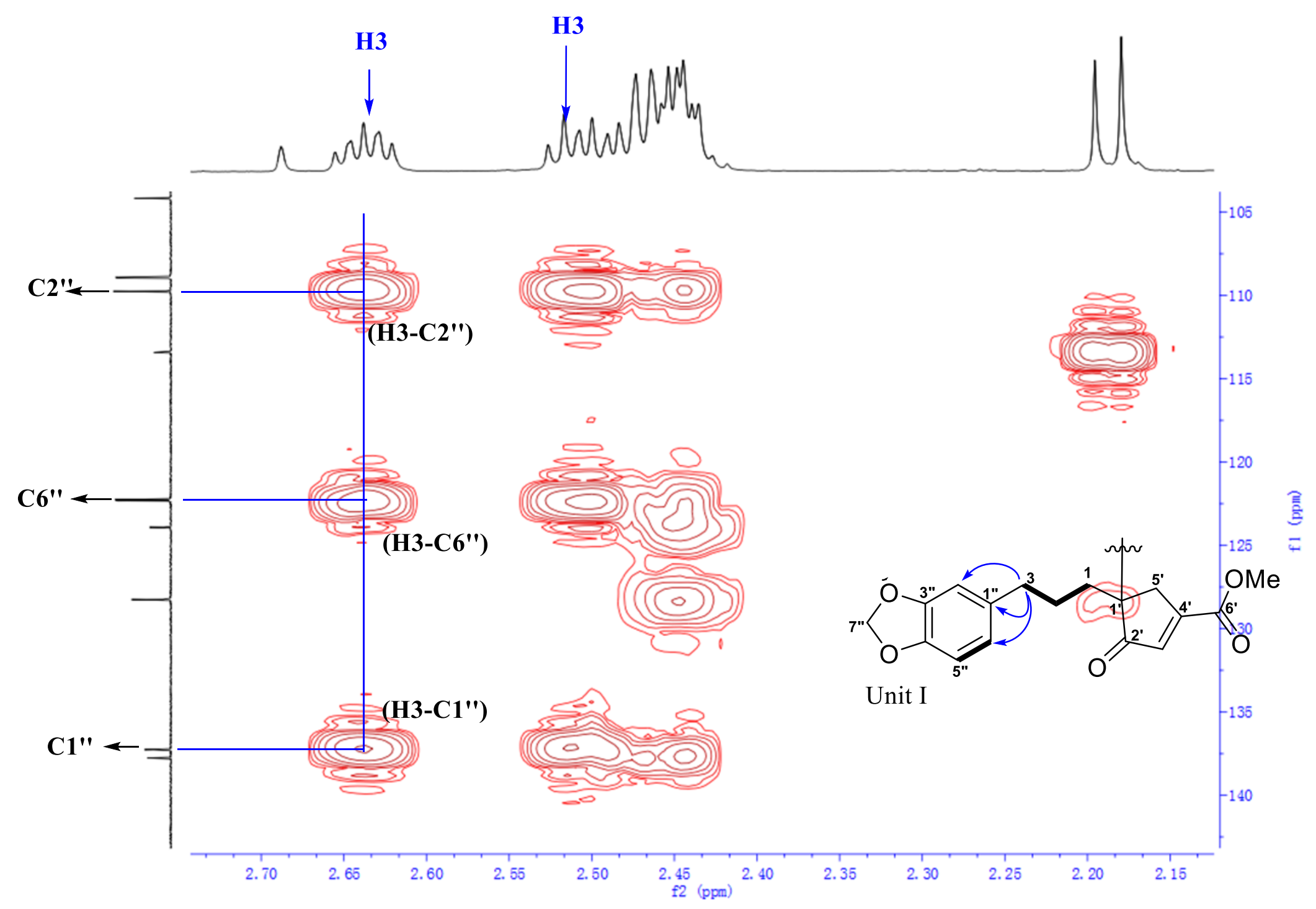

Figure S18. Key HMBC spectrum $\left(\delta_{\mathrm{H}} 2.15-2.70 \mathrm{ppm}\right.$ and $\left.\delta_{\mathrm{C}} 105-140 \mathrm{ppm}\right)$ of unit I in compound 1 


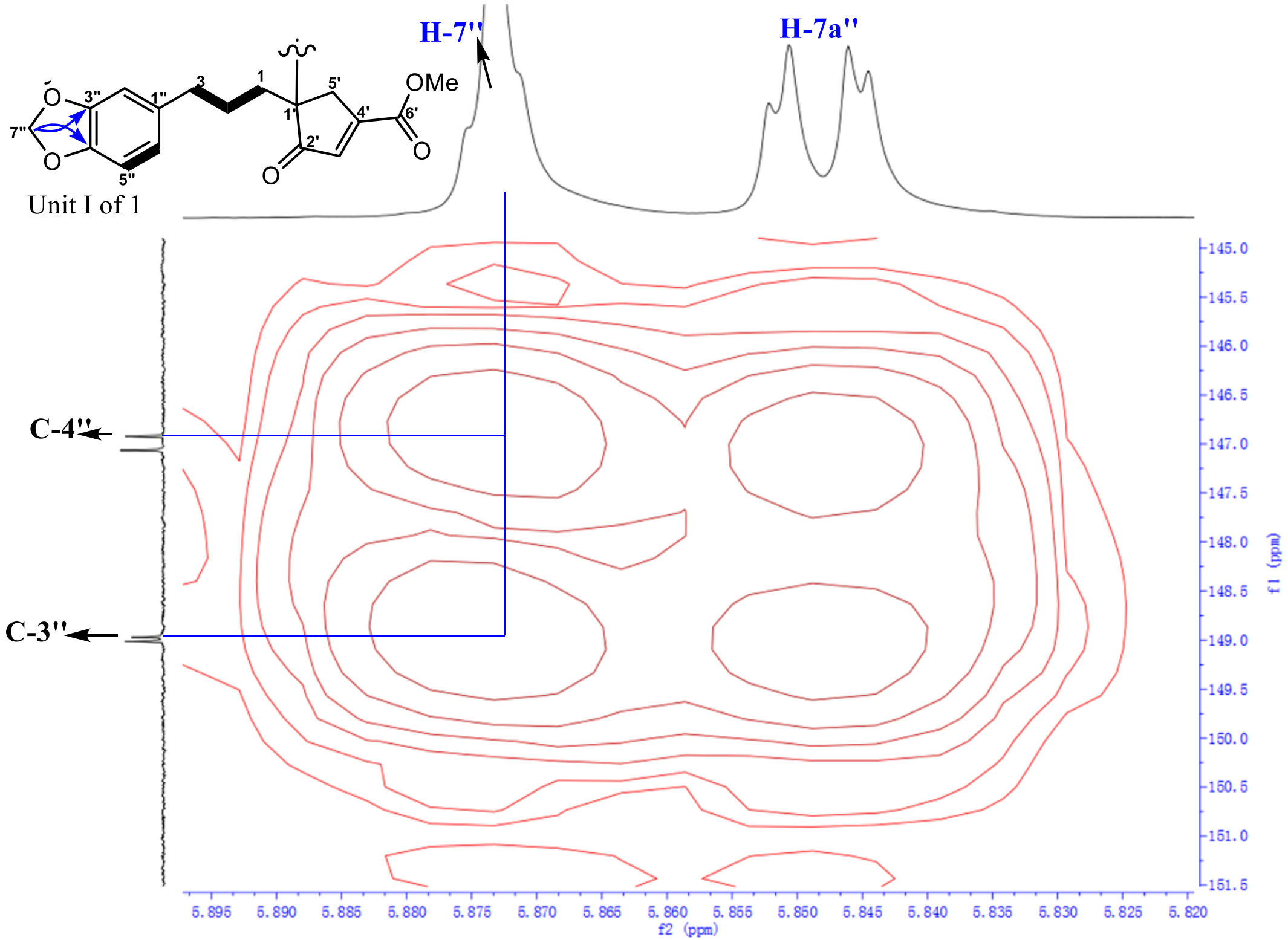

Figure S19. Key HMBC spectrum $\left(\delta_{\mathrm{H}} 5.82-5.90 \mathrm{ppm}\right.$ and $\left.\delta_{\mathrm{C}} 145-151.5 \mathrm{ppm}\right)$ of unit I in compound $\mathbf{1}$ 


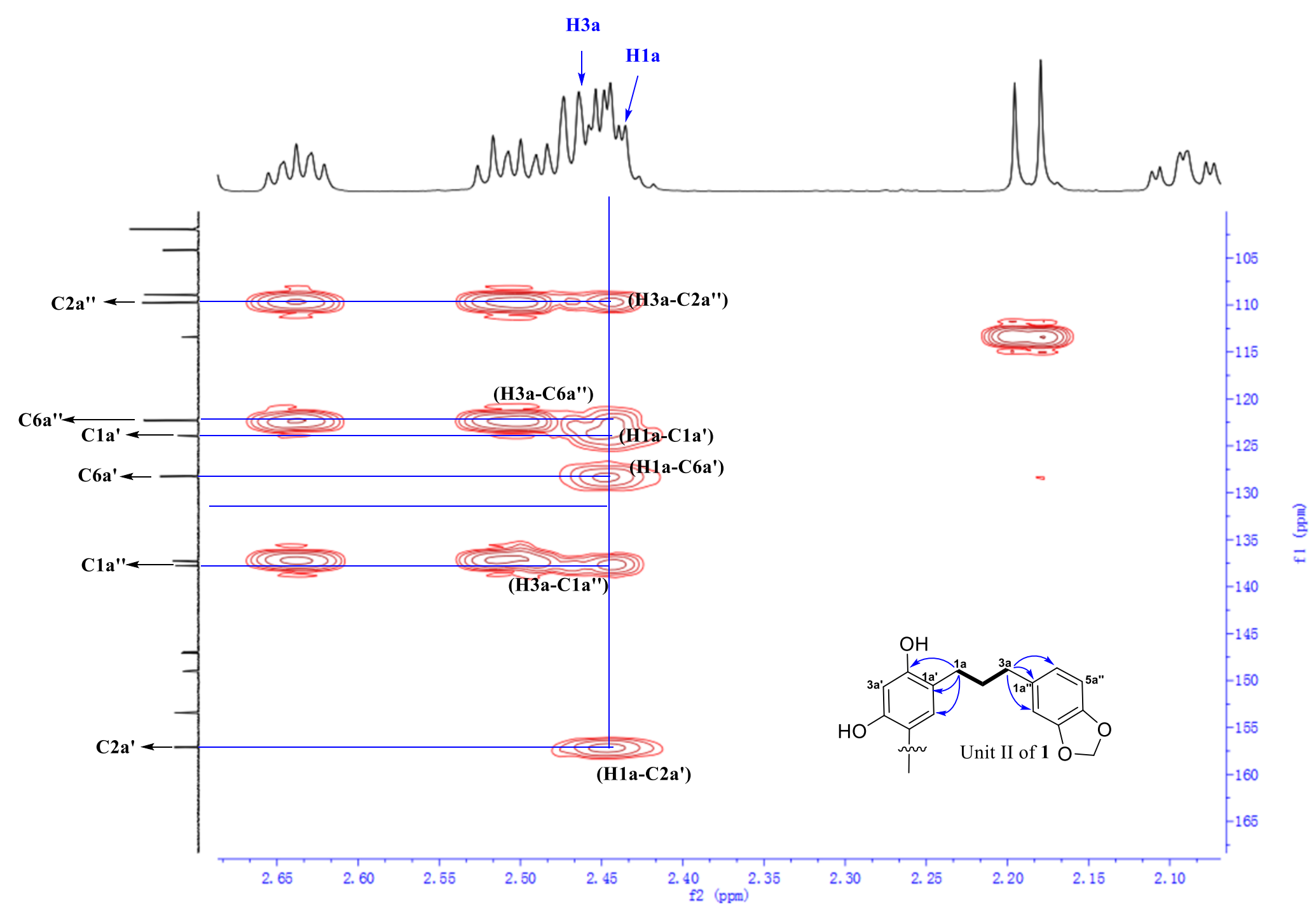

Figure S20. Key HMBC spectrum $\left(\delta_{\mathrm{H}} 2.10-2.65 \mathrm{ppm}\right.$ and $\left.\delta_{\mathrm{C}} 145-165 \mathrm{ppm}\right)$ of unit II in compound 1 

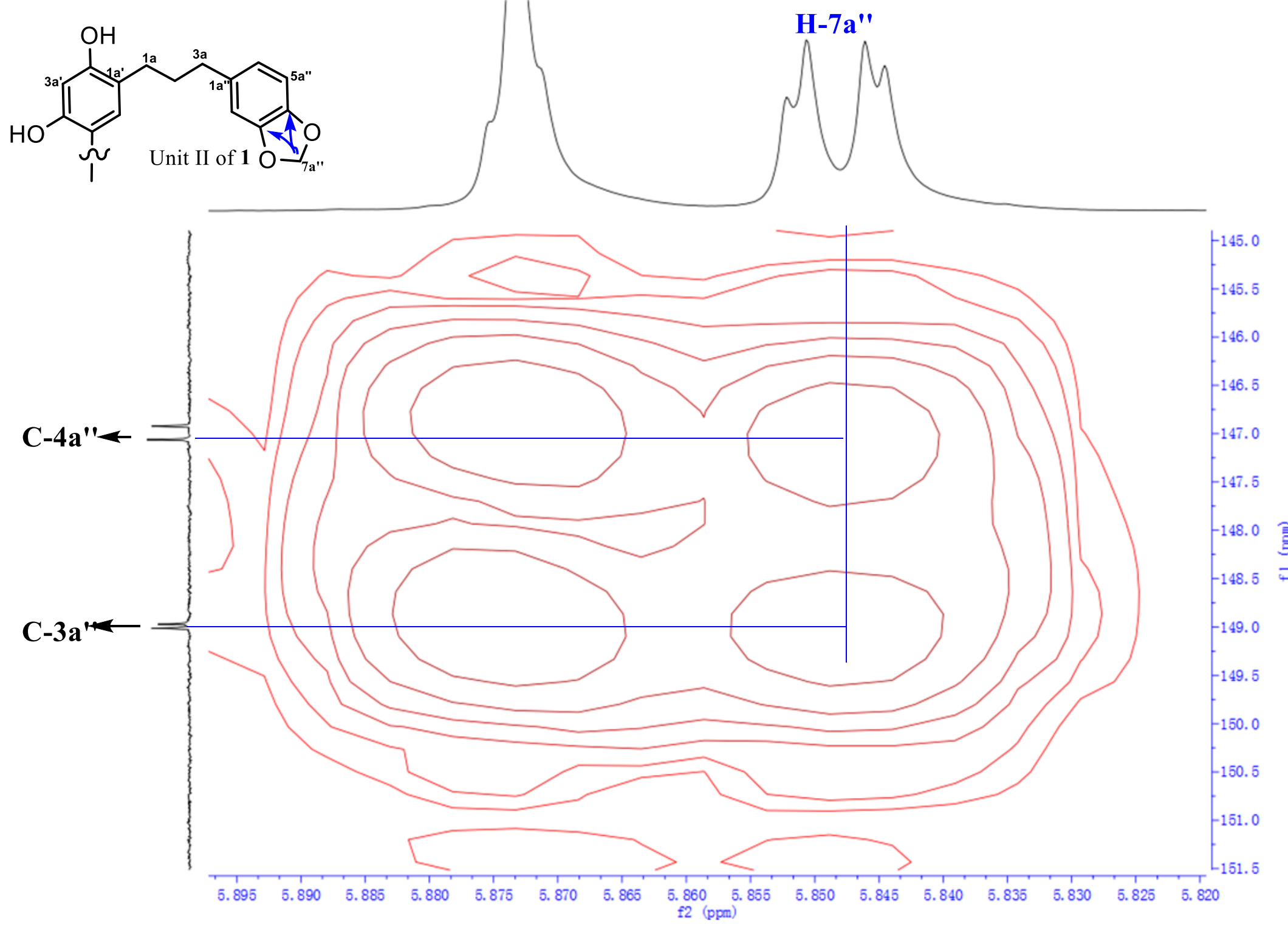

Figure S21. Key HMBC spectrum $\left(\delta_{\mathrm{H}} 5.82-5.895 \mathrm{ppm}\right.$ and $\left.\delta_{\mathrm{C}} 145-150 \mathrm{ppm}\right)$ of unit II in compound 1 


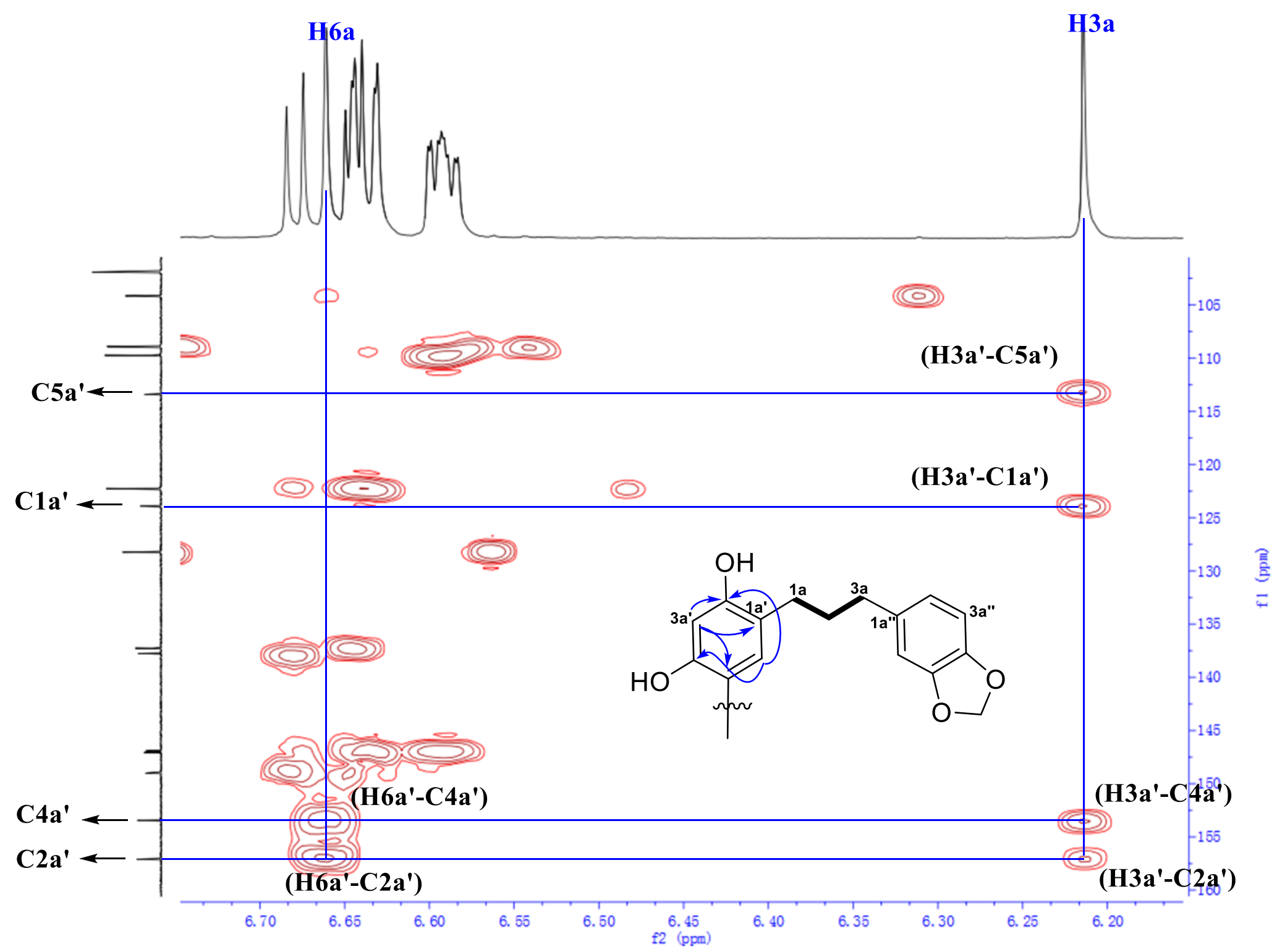

Figure S22. Key HMBC spectrum $\left(\delta_{\mathrm{H}} 6.20-6.70 \mathrm{ppm}\right.$ and $\left.\delta_{\mathrm{C}} 105-160 \mathrm{ppm}\right)$ of unit II in compound 1 


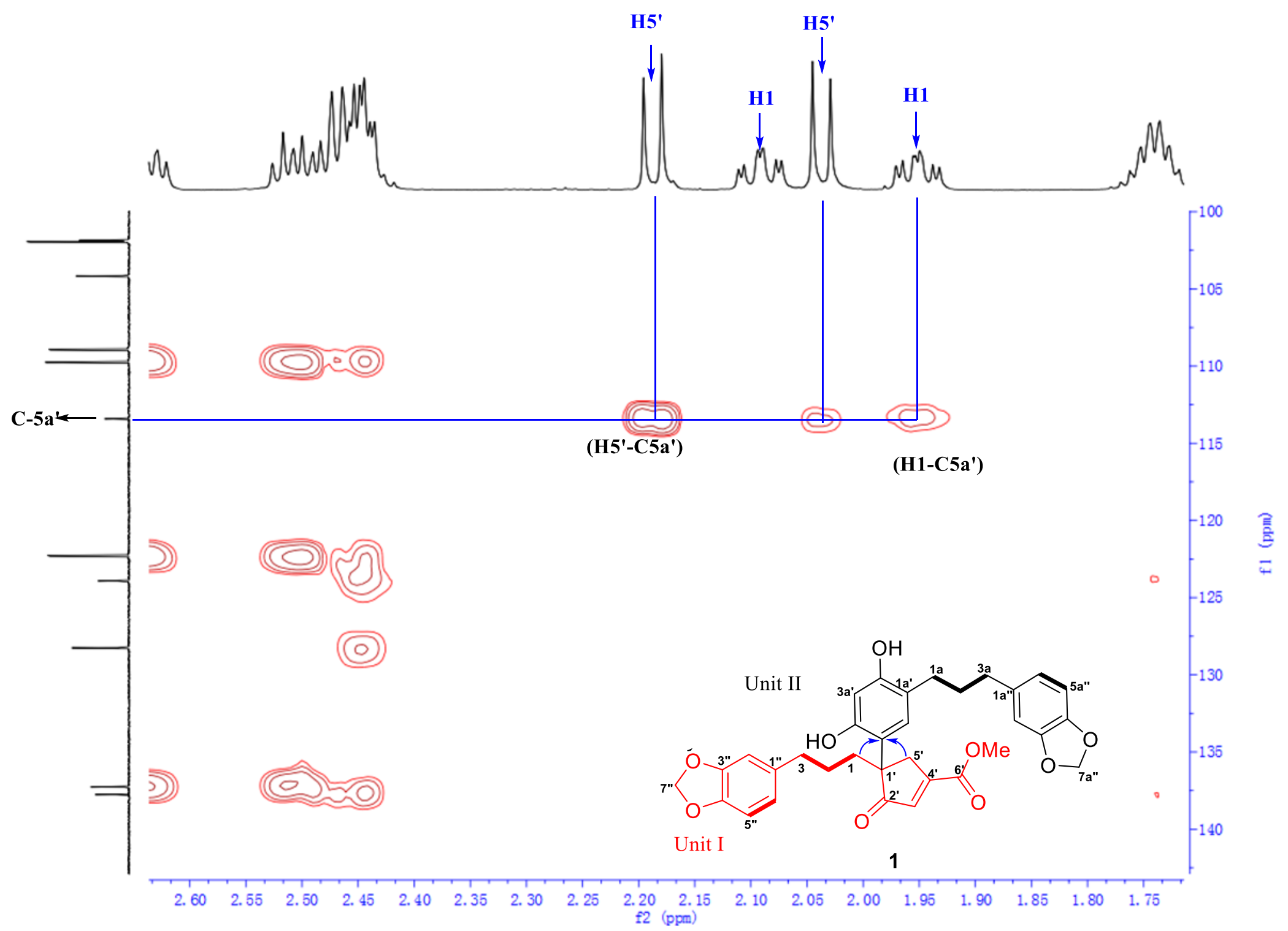

Figure S23. Key HMBC spectrum $\left(\delta_{\mathrm{H}} 1.75-2.00 \mathrm{ppm}\right.$ and $\left.\delta_{\mathrm{C}} 100-140 \mathrm{ppm}\right)$ ofcompound 1 
Supporting Information

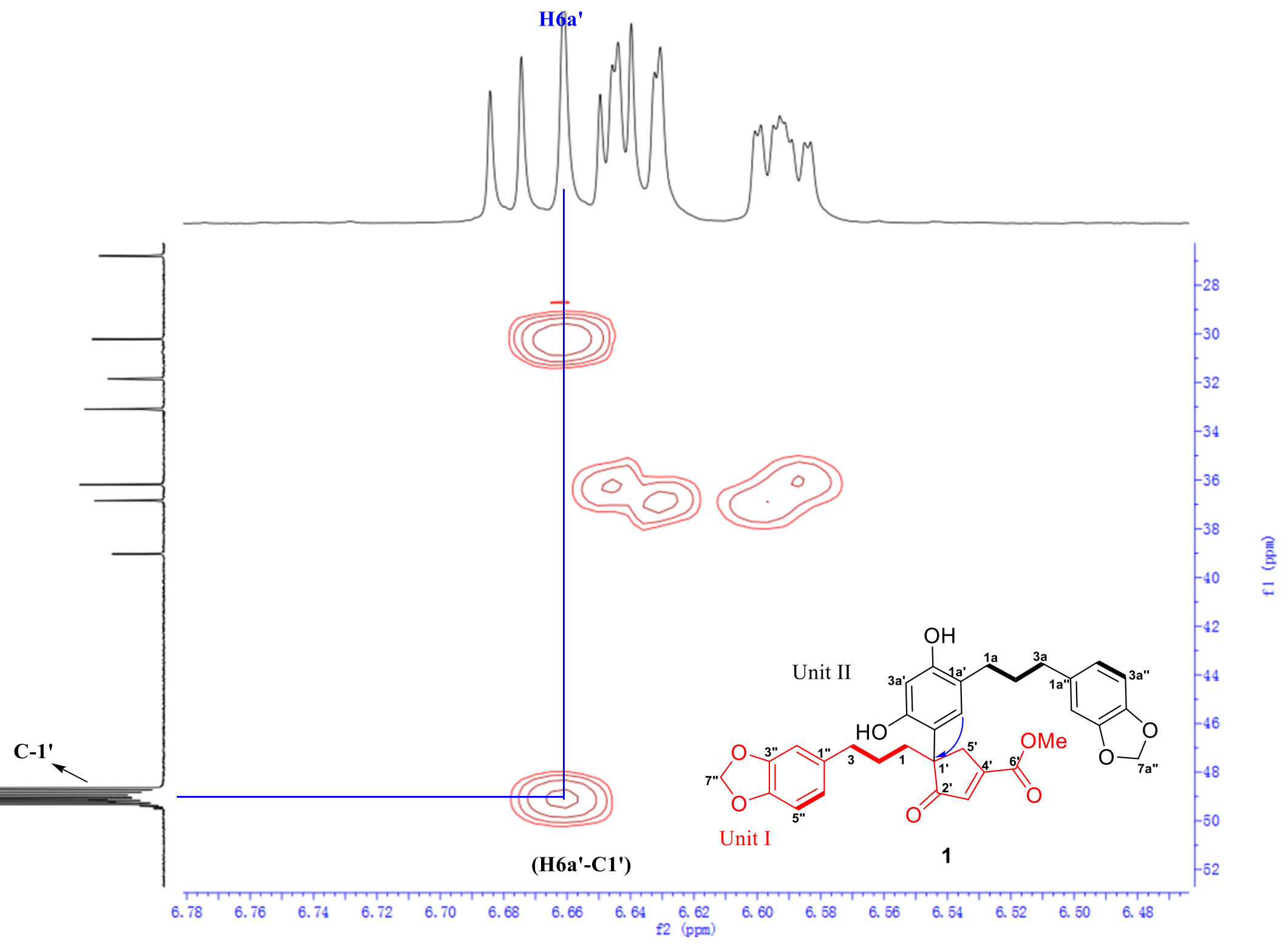

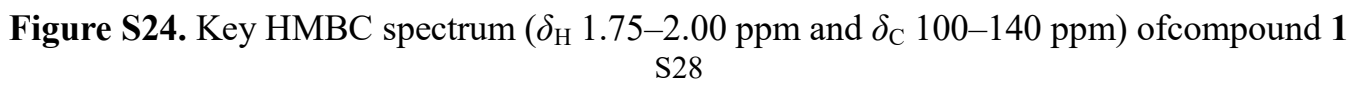


Supporting Information

User Spectra

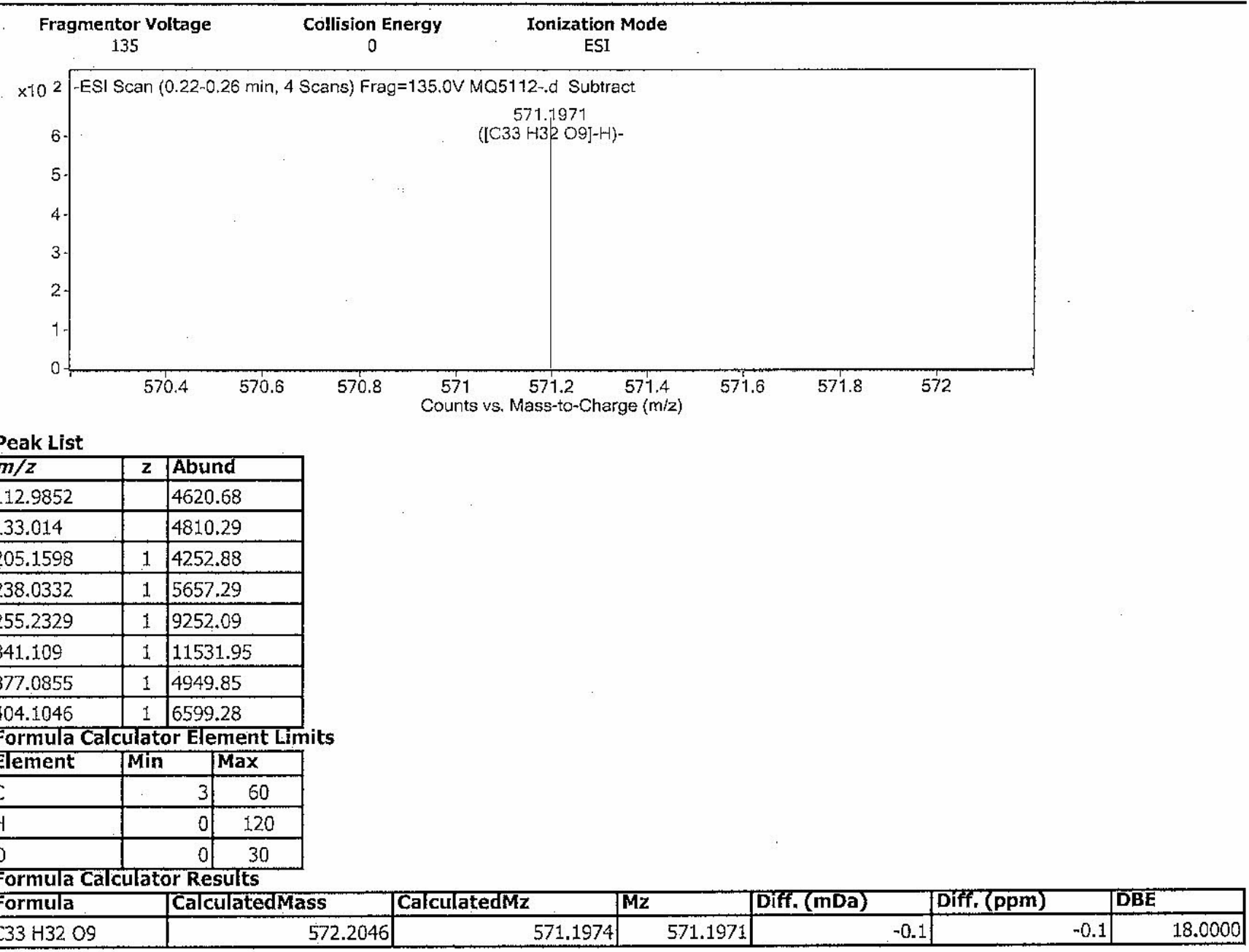

--- End Of Report -..

Figure S25. HR-ESIMS spectrum of compound 1

S29 
Supporting Information

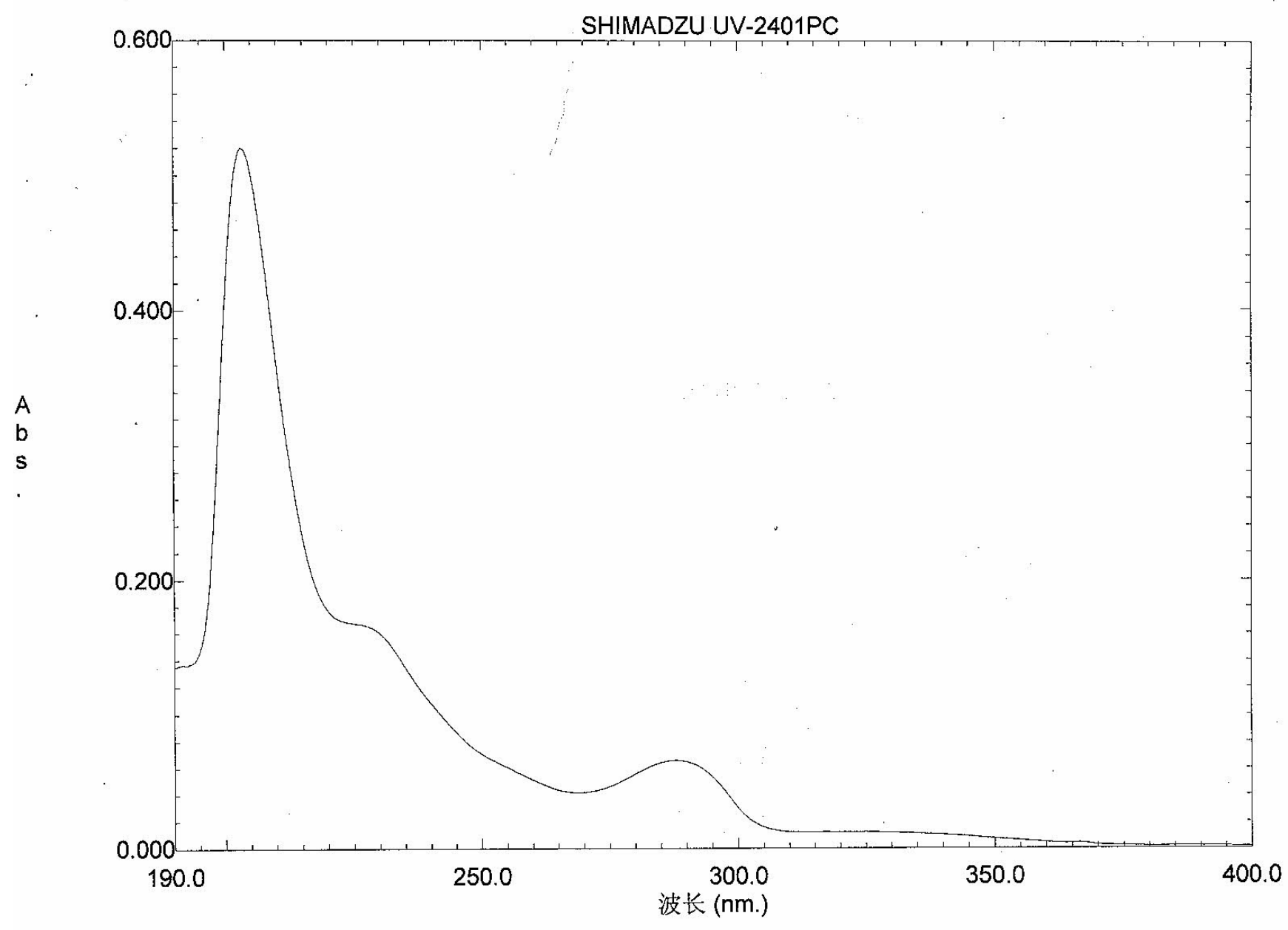

Figure S26. UV spectrum of compound 1 
Optical rotation measuremen

\begin{tabular}{|c|c|c|c|c|c|c|c|c|}
\hline \multirow{2}{*}{$\begin{array}{l}\text { Model } \\
\text { No. }\end{array}$} & \multicolumn{2}{|r|}{38} & \multirow[b]{2}{*}{ Data } & \multirow[b]{2}{*}{$\begin{array}{l}\text { Monitor } \\
\text { Blank }\end{array}$} & \multirow[b]{2}{*}{$\begin{array}{l}\text { Temp. } \\
\text { Cell } \\
\text { Temp Point }\end{array}$} & \multirow[b]{2}{*}{$\begin{array}{l}\text { Date } \\
\text { Comment } \\
\text { Sample Name }\end{array}$} & \multirow[b]{2}{*}{$\begin{array}{l}\text { Light } \\
\text { Filter } \\
\text { Operator }\end{array}$} & \multirow[b]{2}{*}{$\begin{array}{l}\text { Cycle Time } \\
\text { Integ Time }\end{array}$} \\
\hline & Sample & Mode & & & & & & \\
\hline No.1 & $83(1 / 3)$ & Sp.Rot & 134.6670 & $\begin{array}{l}0.0404 \\
0.0000\end{array}$ & $\begin{array}{l}19.2 \\
50.00 \\
\text { Cell }\end{array}$ & $\begin{array}{c}\text { Thu Jan } 18 \text { 16:19:57 } 2018 \\
0.00060 \mathrm{~g} / \mathrm{mL} \mathrm{MeOH} \\
5112-1\end{array}$ & $\begin{array}{l}\mathrm{Na} \\
589 \mathrm{~nm}\end{array}$ & $\begin{array}{l}2 \mathrm{sec} \\
2 \mathrm{sec}\end{array}$ \\
\hline No. 2 & $83(2 / 3)$ & Sp.Rot & 136.3330 & $\begin{array}{l}0.0409 \\
0.0000\end{array}$ & $\begin{array}{l}19.1 \\
50.00 \\
\text { Cell }\end{array}$ & $\begin{array}{c}\text { Thu Jan } 18 \text { 16:20:03 } 2018 \\
0.00060 \mathrm{~g} / \mathrm{mL} \mathrm{MeOH} \\
5112-1\end{array}$ & $\begin{array}{l}\mathrm{Na} \\
589 \mathrm{~nm}\end{array}$ & $\begin{array}{l}2 \mathrm{sec} \\
2 \mathrm{sec}\end{array}$ \\
\hline No. 3 & $83(3 / 3)$ & Sp.Rot & 143.6670 & $\begin{array}{l}0.0431 \\
0.0000\end{array}$ & $\begin{array}{l}19.1 \\
50.00 \\
\text { Cell }\end{array}$ & $\begin{array}{c}\text { Thu Jan } 18 \text { 16:20:08 } 2018 \\
0.00060 \mathrm{~g} / \mathrm{mL} \mathrm{MeOH} \\
5112-1\end{array}$ & $\begin{array}{l}\mathrm{Na} \\
589 \mathrm{~nm}\end{array}$ & $\begin{array}{l}2 \mathrm{sec} \\
2 \mathrm{sec}\end{array}$ \\
\hline No.4 & $84(1 / 3)$ & Sp.Rot & 147.6670 & $\begin{array}{l}0.0443 \\
0.0000\end{array}$ & $\begin{array}{l}19.1 \\
50.00 \\
\text { Cell }\end{array}$ & $\begin{array}{l}\text { Thu Jan } 18 \text { 16:20:24 } 2018 \\
0.00060 \mathrm{~g} / \mathrm{mL} \mathrm{MeOH} \\
5112-1\end{array}$ & $\begin{array}{l}\mathrm{Na} \\
589 \mathrm{~nm}\end{array}$ & $\begin{array}{l}2 \mathrm{sec} \\
2 \mathrm{sec}\end{array}$ \\
\hline No. 5 & $84(2 / 3)$ & Sp.Rot & 129.6670 & $\begin{array}{l}0.0389 \\
0.0000\end{array}$ & $\begin{array}{l}19.0 \\
50.00 \\
\text { Cell }\end{array}$ & $\begin{array}{c}\text { Thu Jan } 18 \text { 16:20:30 } 2018 \\
0.00060 \mathrm{~g} / \mathrm{mL} \mathrm{MeOH} \\
5112-1\end{array}$ & $\begin{array}{l}\mathrm{Na} \\
589 \mathrm{~nm}\end{array}$ & $\begin{array}{l}2 \mathrm{sec} \\
2 \mathrm{sec}\end{array}$ \\
\hline No.6 & $84(3 / 3)$ & Sp.Rot & 139.3330 & $\begin{array}{l}0.0418 \\
0.0000\end{array}$ & $\begin{array}{l}19.0 \\
50.00 \\
\text { Cell }\end{array}$ & $\begin{array}{l}\text { Thu Jan } 18 \text { 16:20:35 } 2018 \\
0.00060 \mathrm{~g} / \mathrm{mL} \mathrm{MeOH} \\
5112-1\end{array}$ & $\begin{array}{l}\mathrm{Na} \\
589 \mathrm{~nm}\end{array}$ & $\begin{array}{l}2 \mathrm{sec} \\
2 \mathrm{sec}\end{array}$ \\
\hline
\end{tabular}

Figure S27. ORD spectrum of compound (+)-1 
Optical rotation measurement

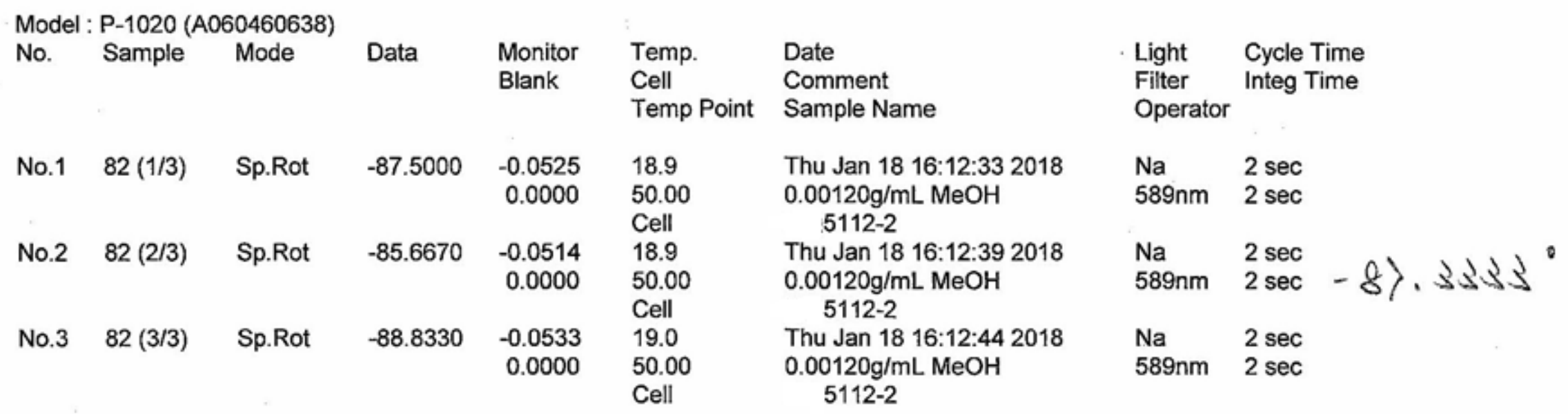

Figure S28. ORD spectrum of compound (-)-1 

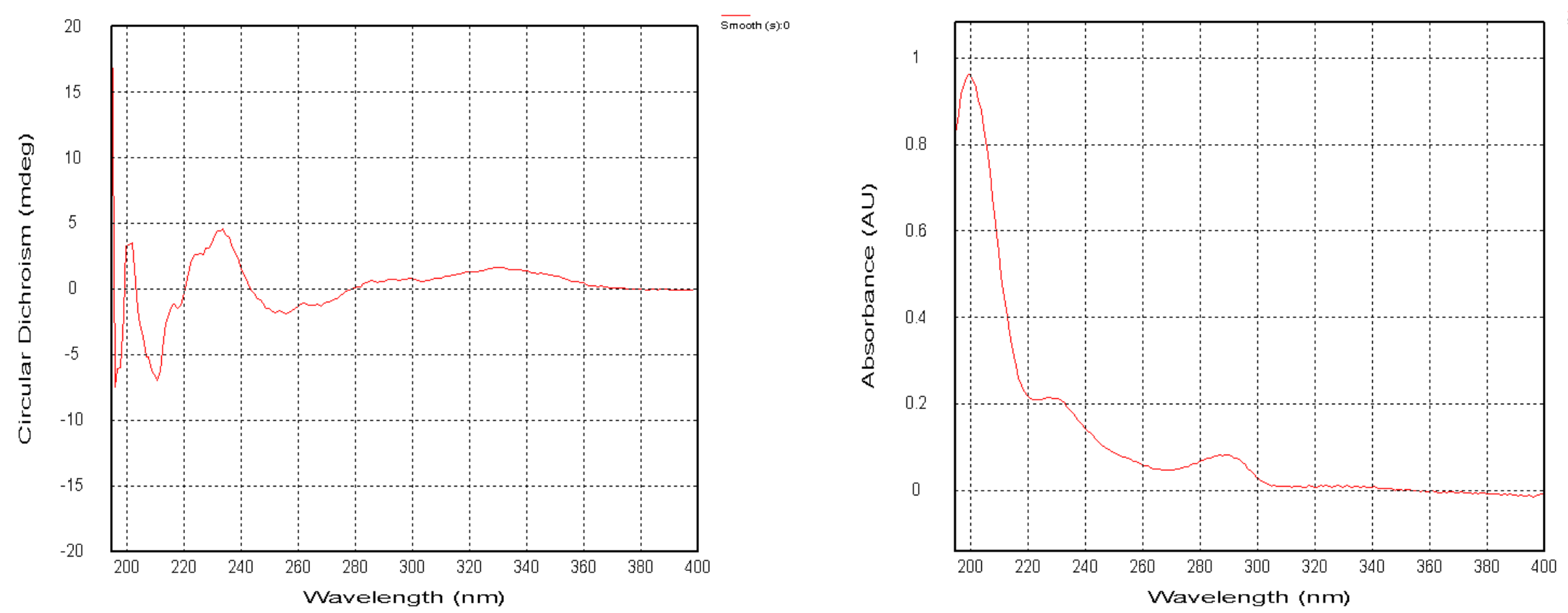

Figure S29. CD spectrum of compound (+)-1 

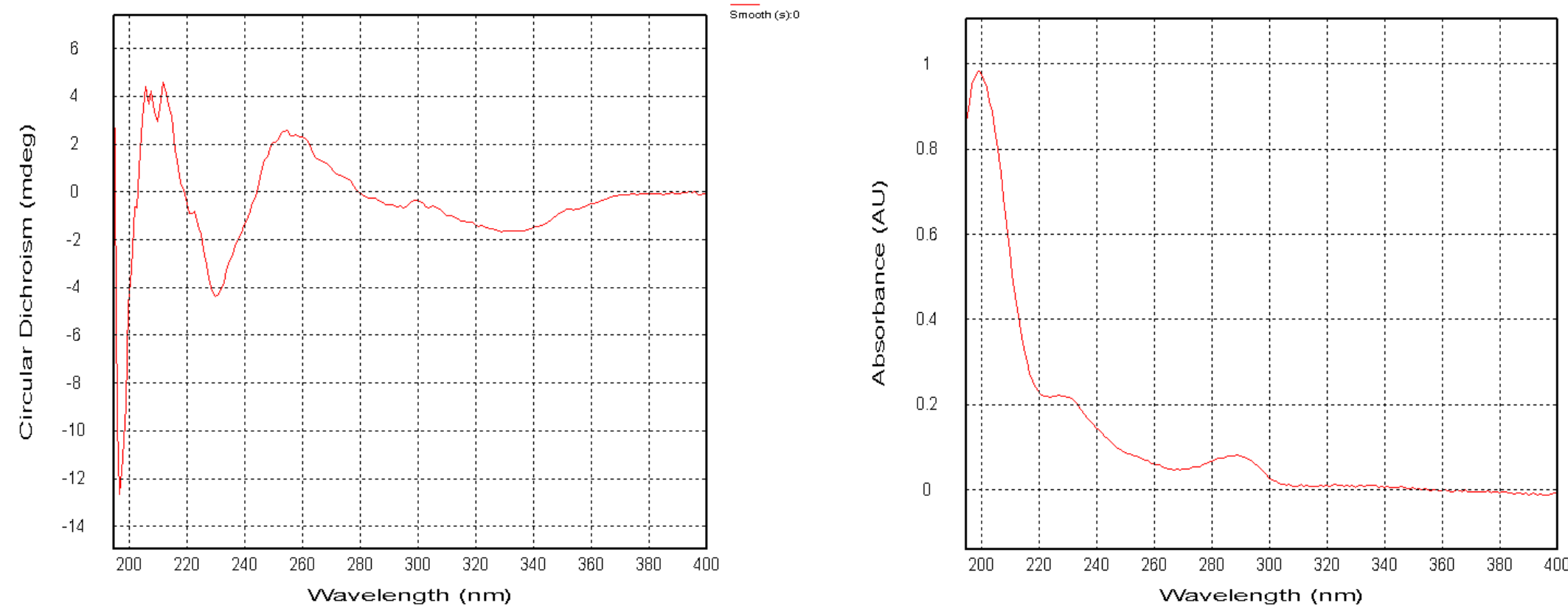

Figure S30. CD spectrum of compound (-)-1 
Supporting Information

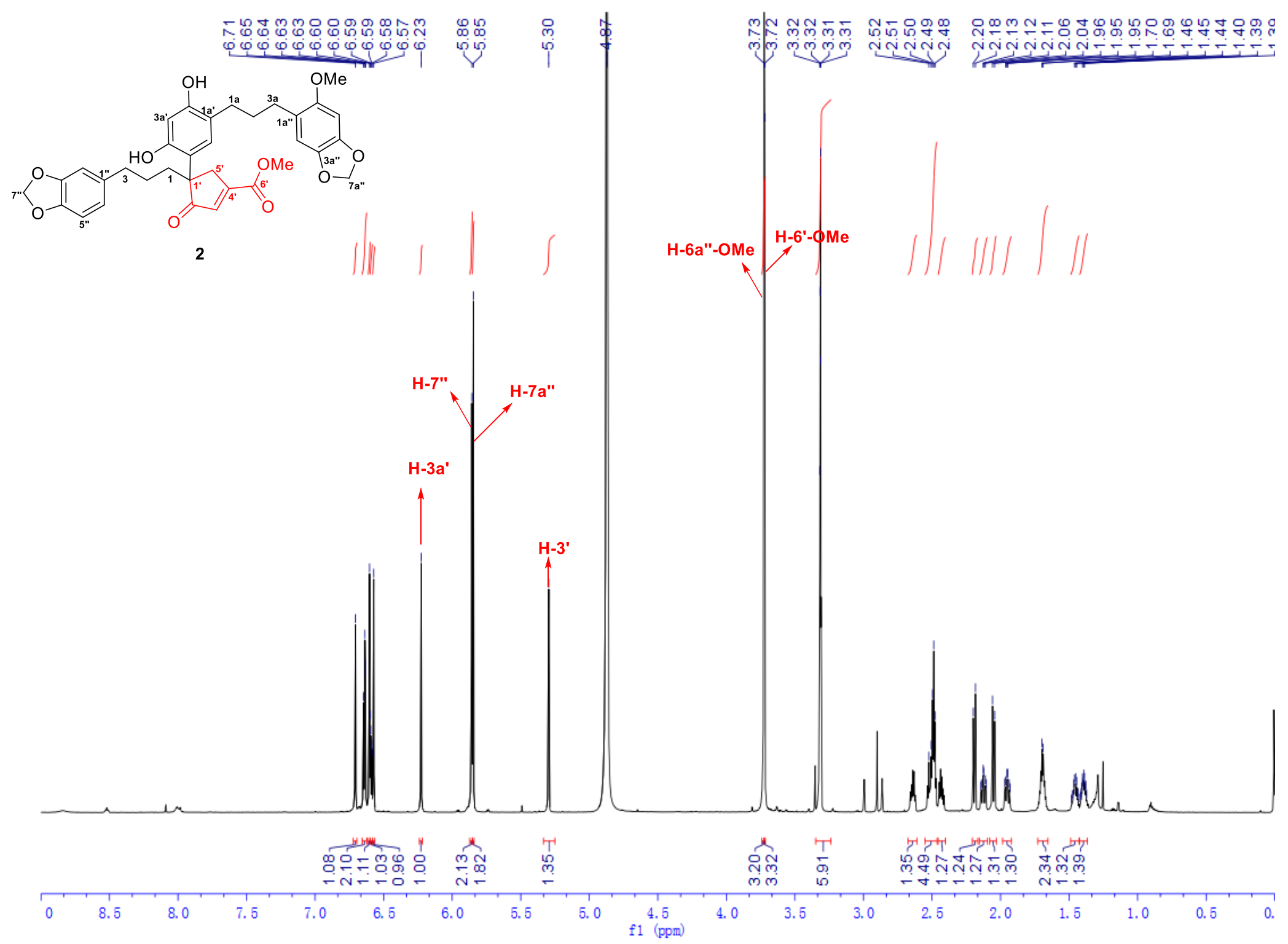

Figure S31. ${ }^{1} \mathrm{H}$ NMR spectrum (0-9 ppm) of compound 2

$$
\text { S35 }
$$




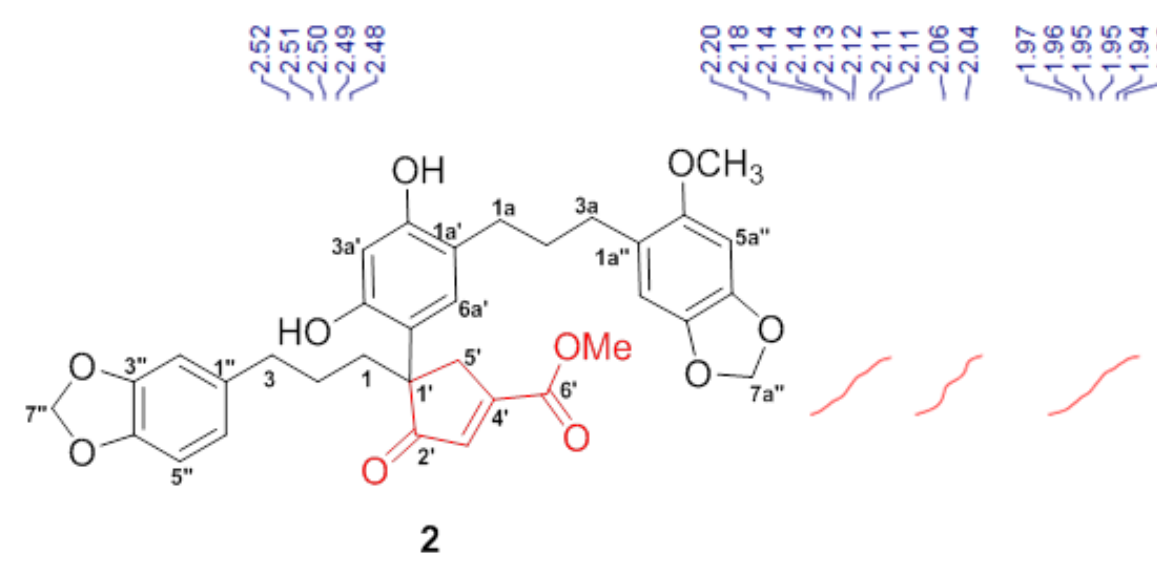

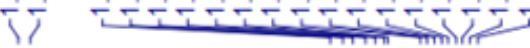

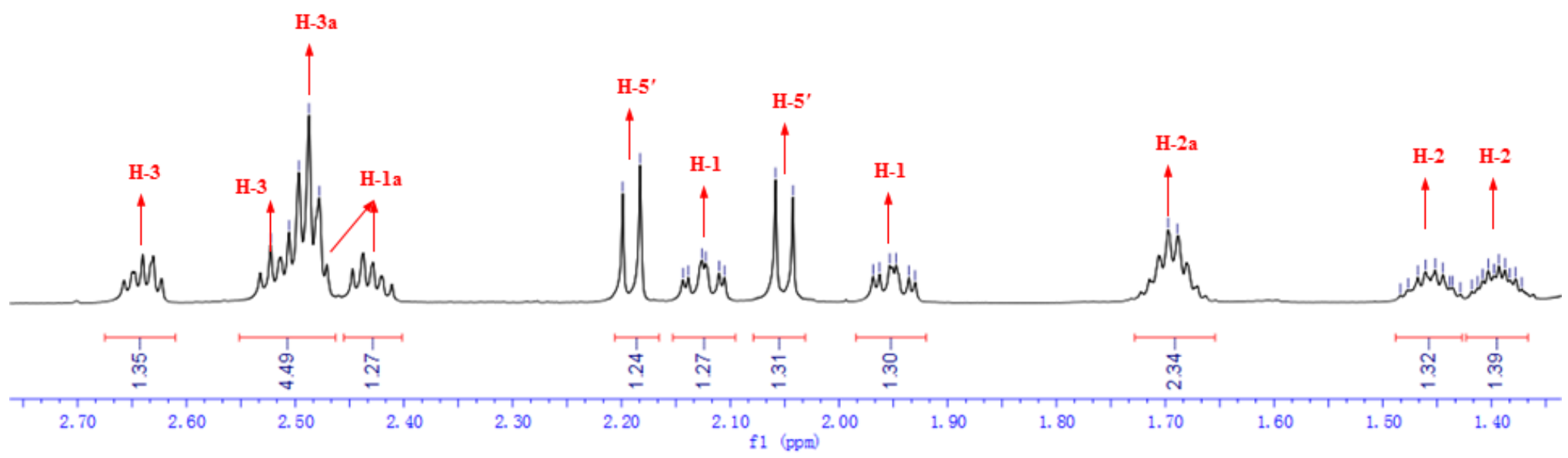

Figure S32. ${ }^{1} \mathrm{H}$ NMR spectrum $(1.40-2.70 \mathrm{ppm}) \quad$ of compound 2 

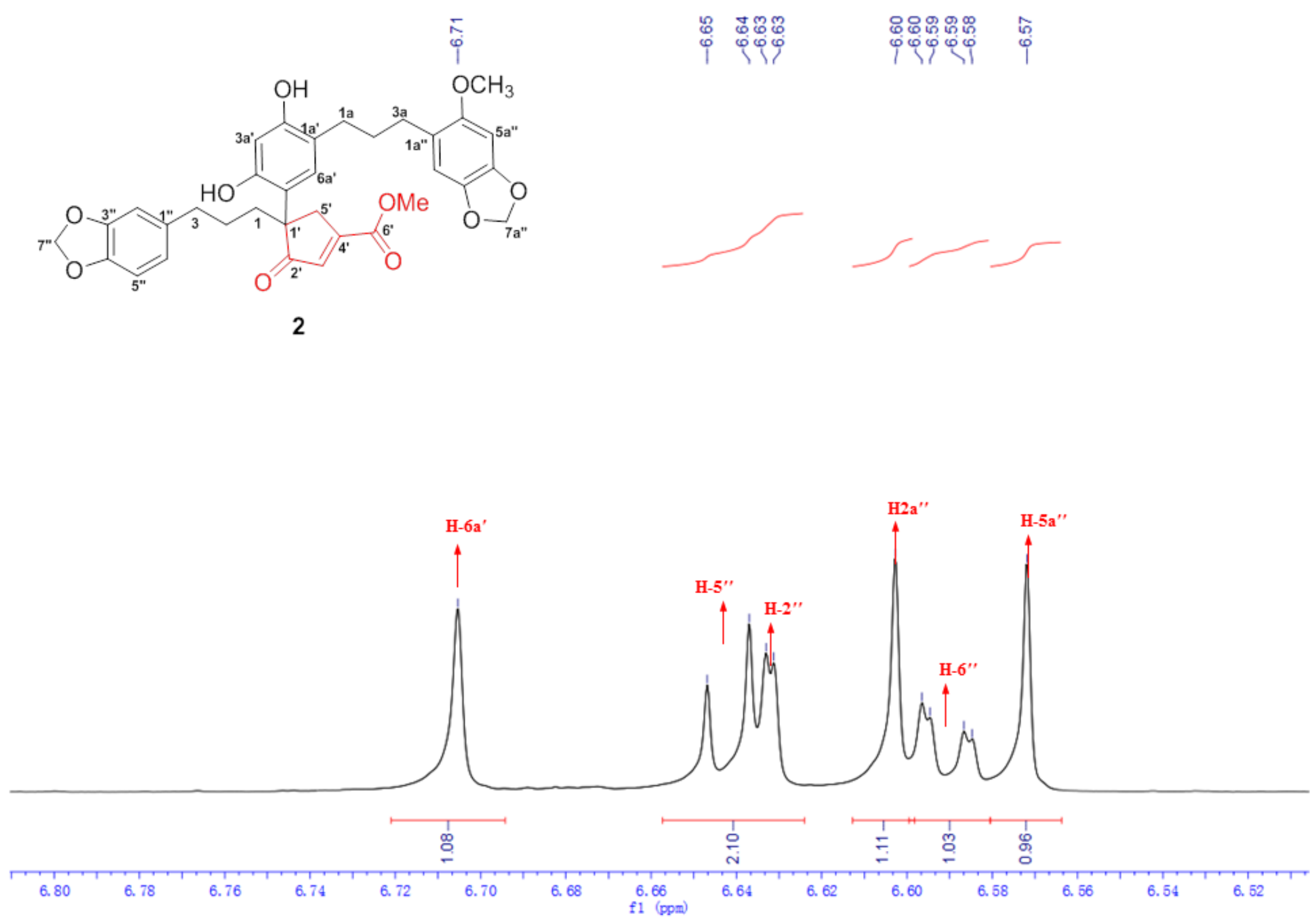

Figure S33. ${ }^{1} \mathrm{H}$ NMR spectrum (6.52-6.80 ppm) of compound 2 

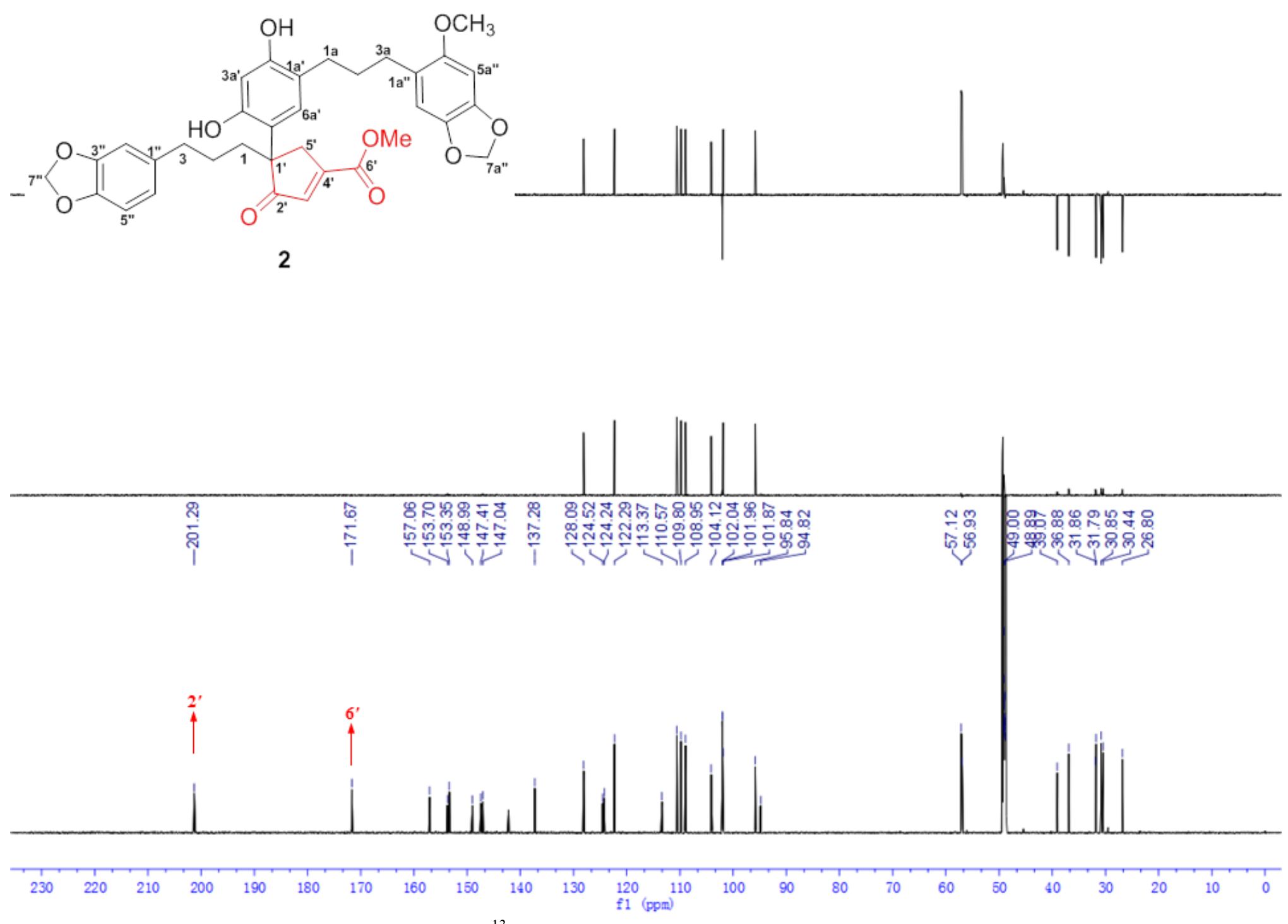

Figure S34. ${ }^{13} \mathrm{C}$ NMR spectra (0-230 ppm) of compound 2 

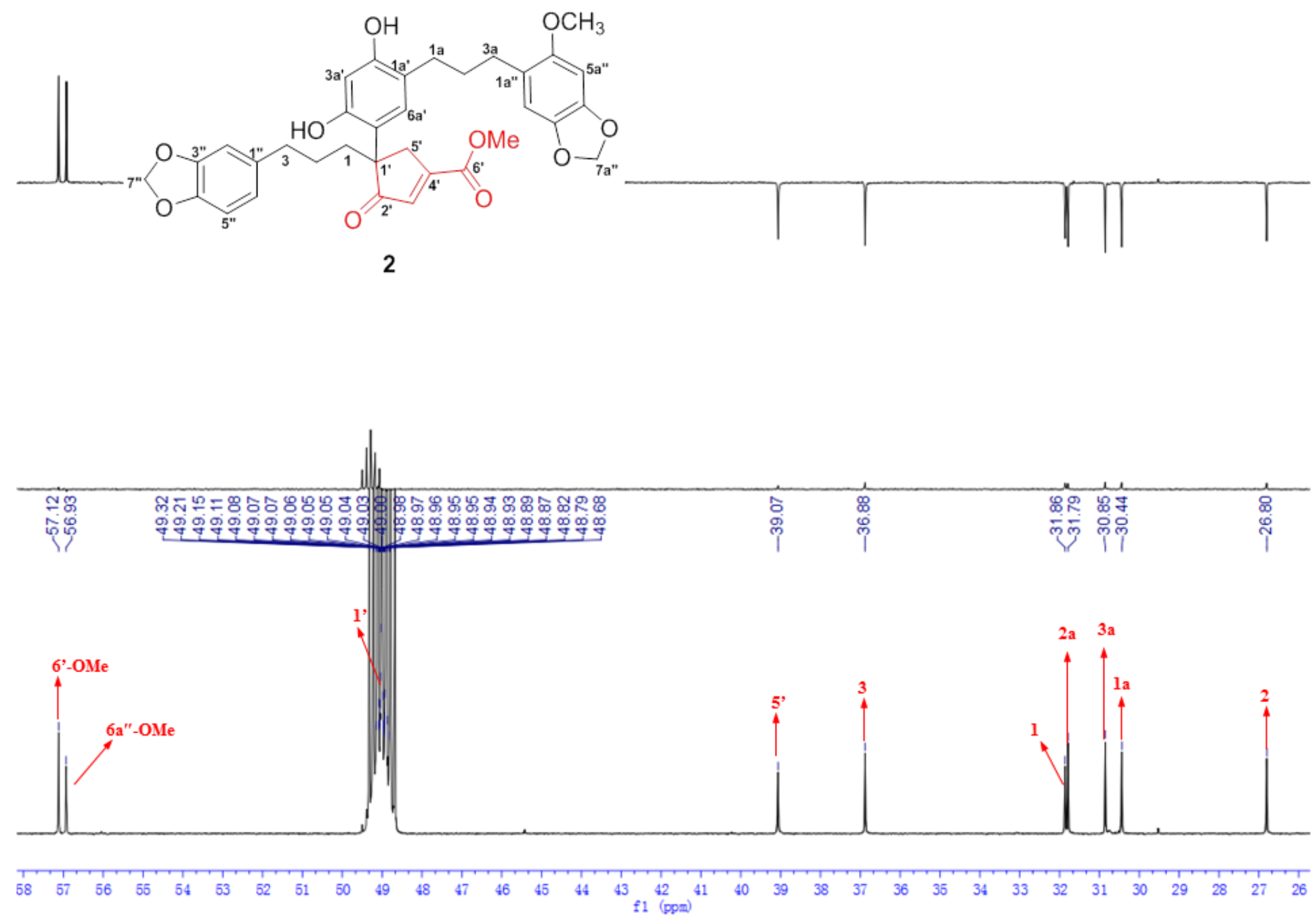

Figure S35. ${ }^{13} \mathrm{C}$ NMR spectra (26-58 ppm)of compound 2

$$
\text { S39 }
$$



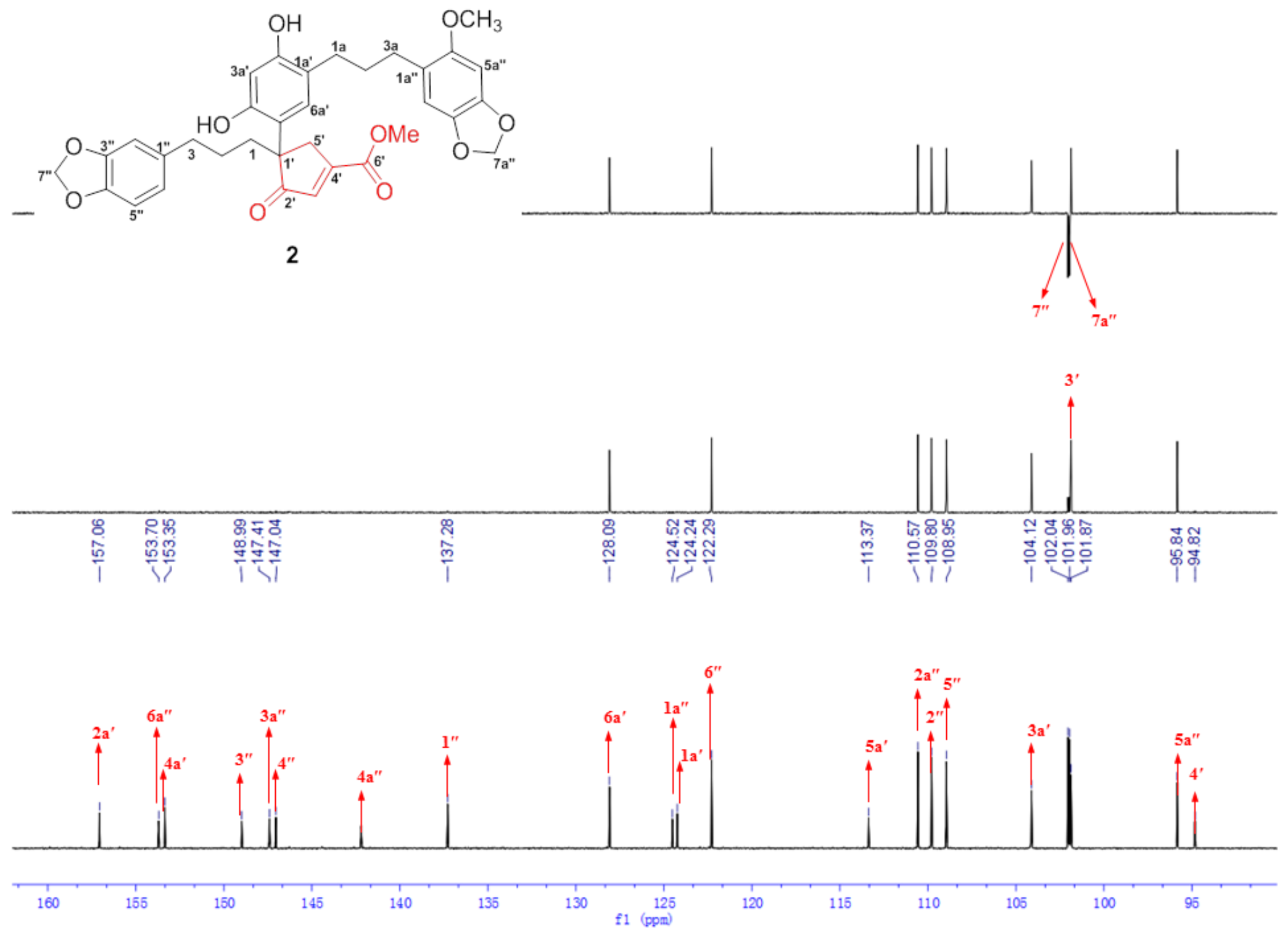

Figure S36. ${ }^{13} \mathrm{C}$ NMR spectra (93-160 ppm) of compound 2 


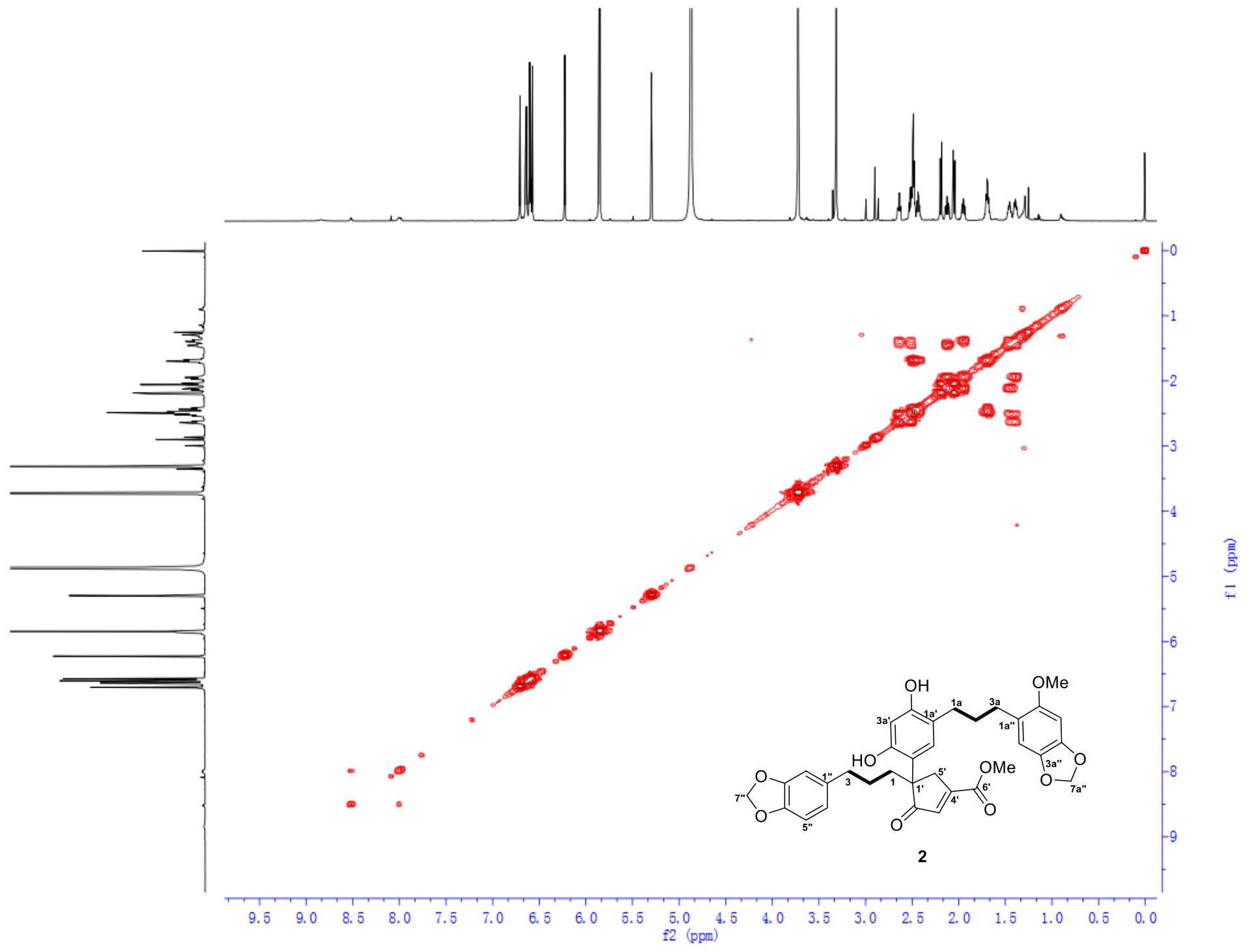

Figure S37. ${ }^{1} \mathrm{H}-{ }^{1} \mathrm{H}$ COSY spectrum of compound 2 


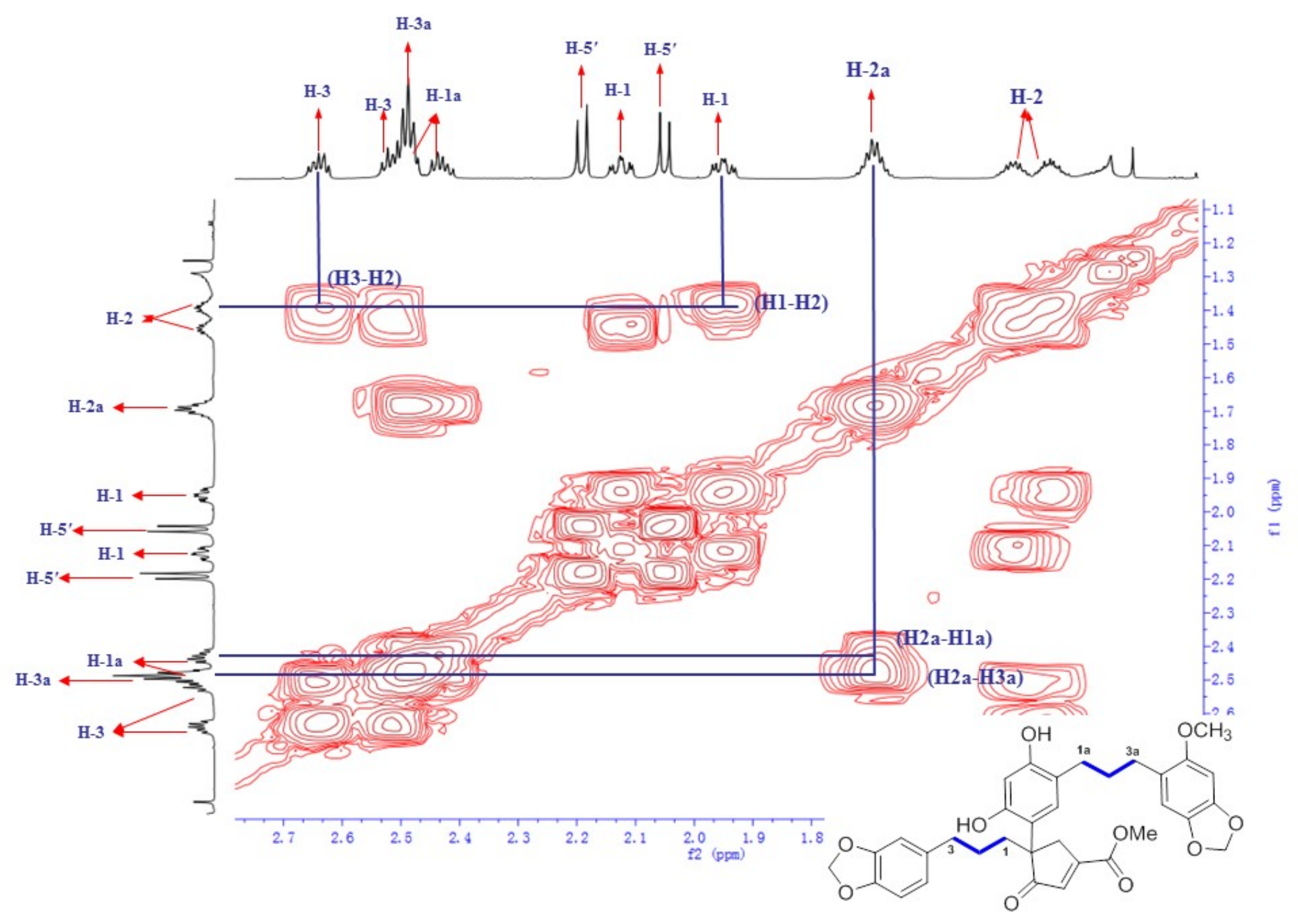

Figure S38. Key ${ }^{1} \mathrm{H}-{ }^{1} \mathrm{H}$ COSY spectrum of compound $\mathbf{2}$ 


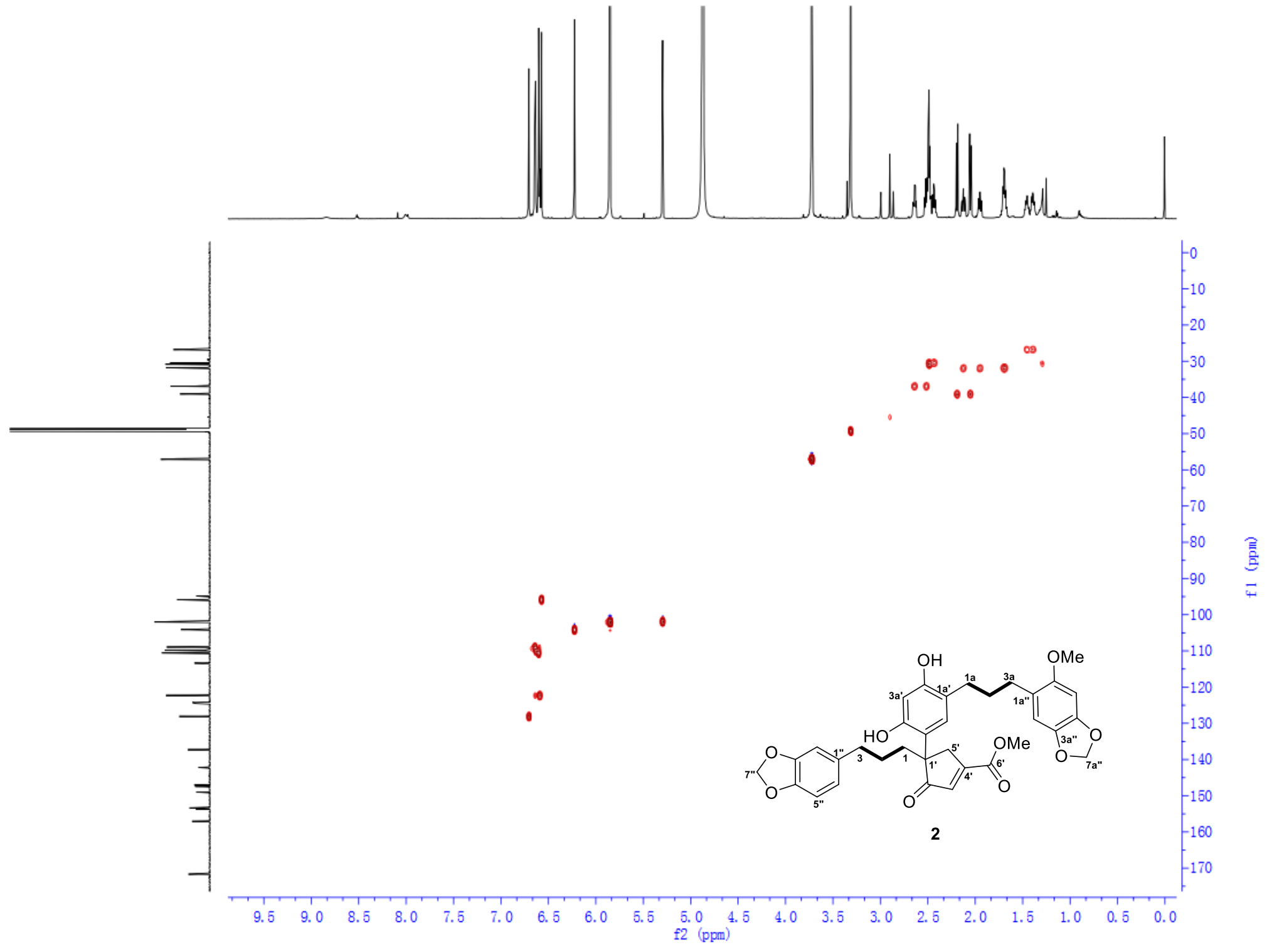

Figure S39. HSQC spectrum of compound 2 


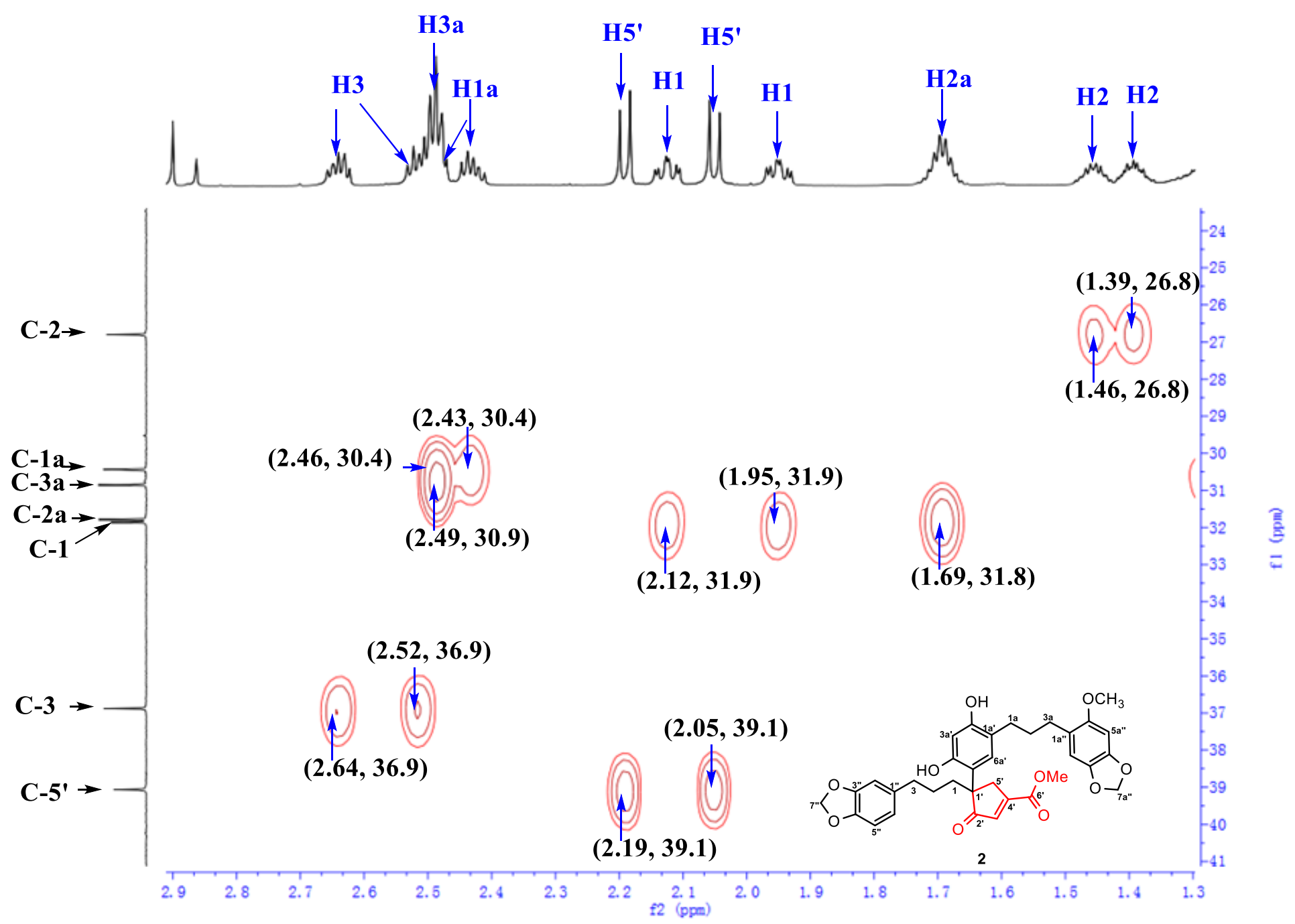

Figure S40. HSQC spectrum ( $\delta_{\mathrm{H}} 1.3-2.9$ and $\left.\delta_{\mathrm{C}} 24-41\right)$ of compound 2 


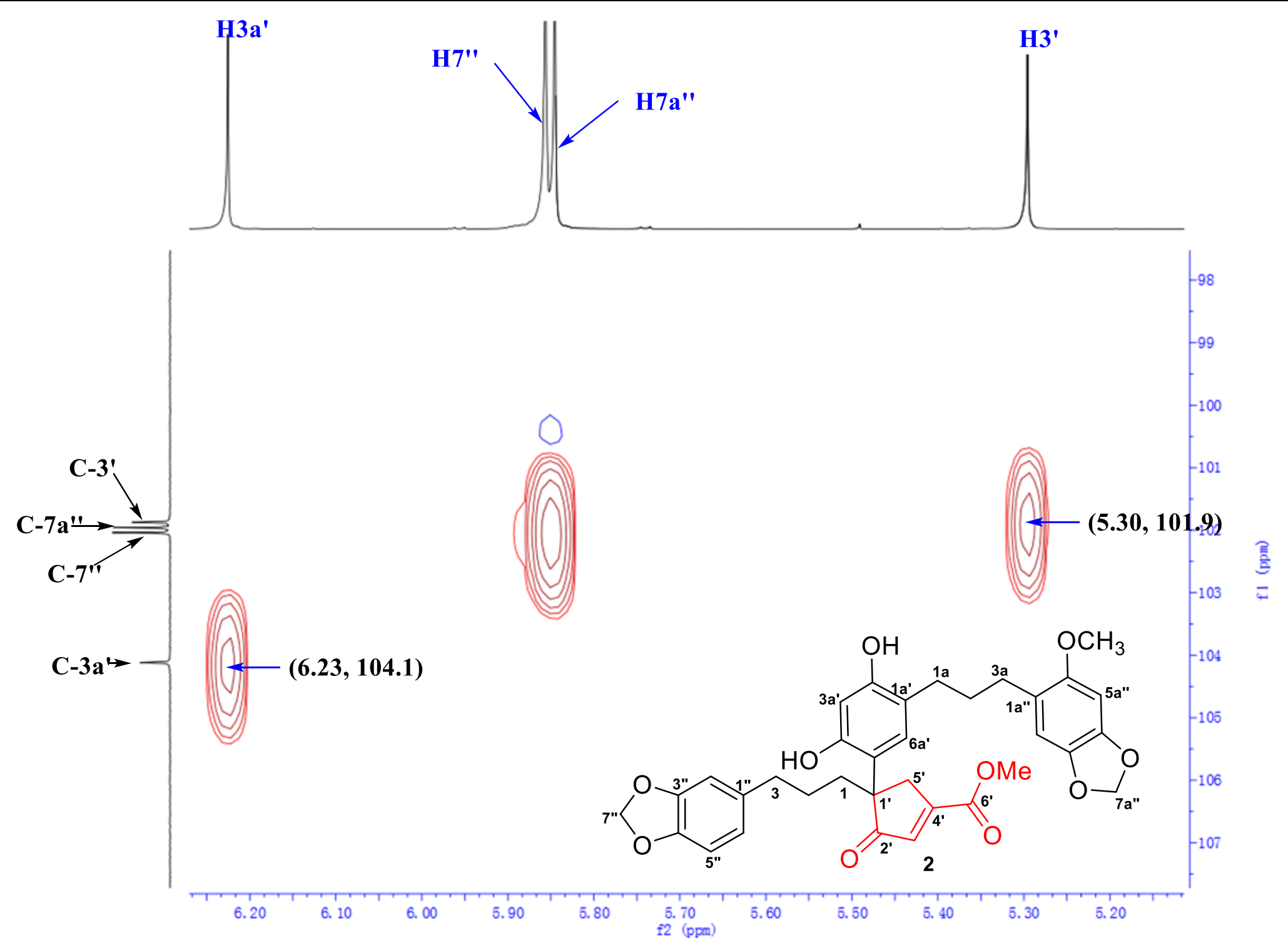

Figure S41. HSQC spectrum $\left(\delta_{\mathrm{H}} 5.2-6.2\right.$ and $\left.\left.\delta_{\mathrm{C}} 98-107\right)\right)$ of compound 2 


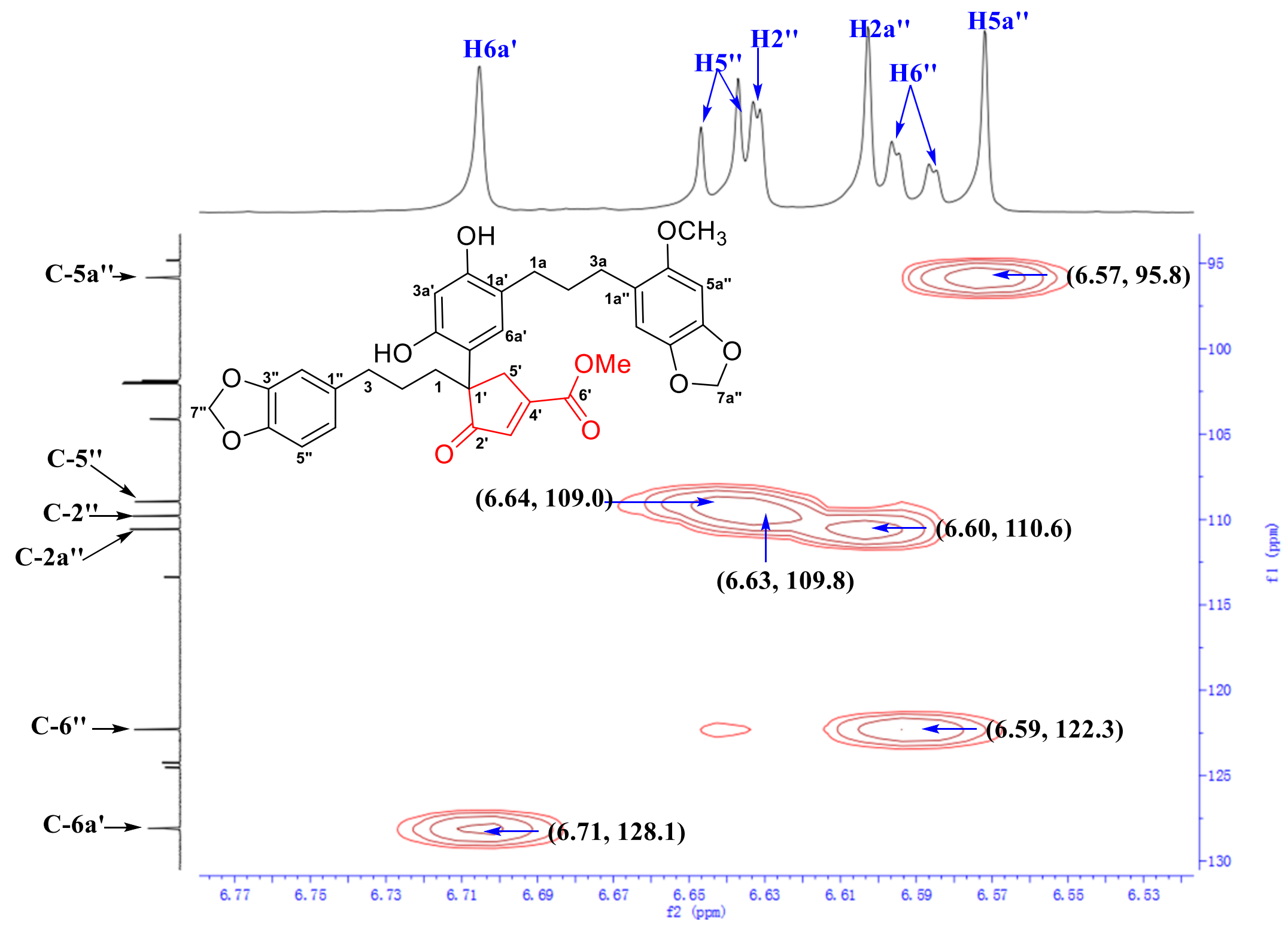

Figure S42. HSQC spectrum $\left(\delta_{\mathrm{H}} 6.53-6.77\right.$ and $\left.\left.\delta_{\mathrm{C}} 95-130\right)\right)$ of compound 2 

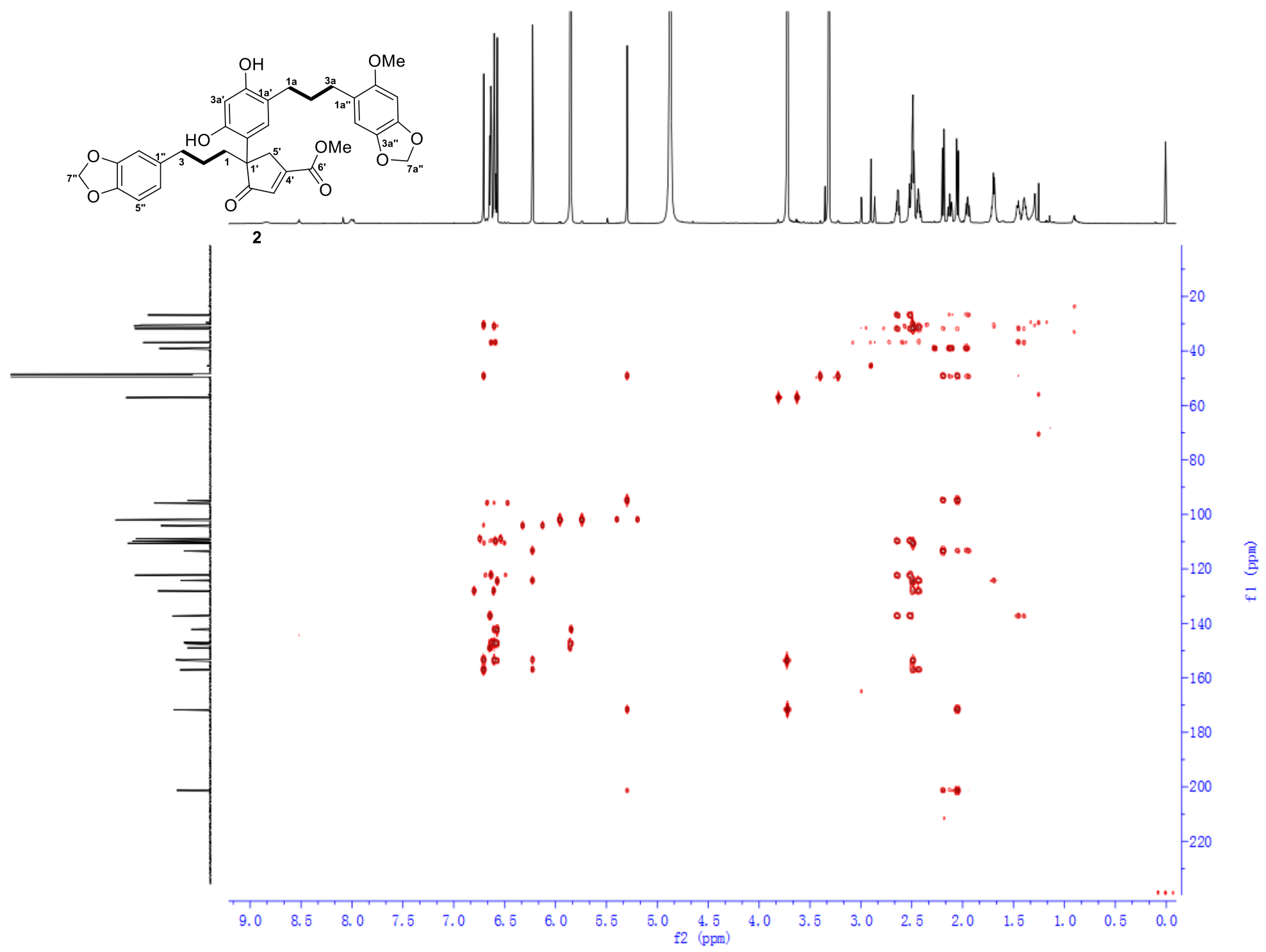

Figure S43. HMBC spectrum of compound 2 


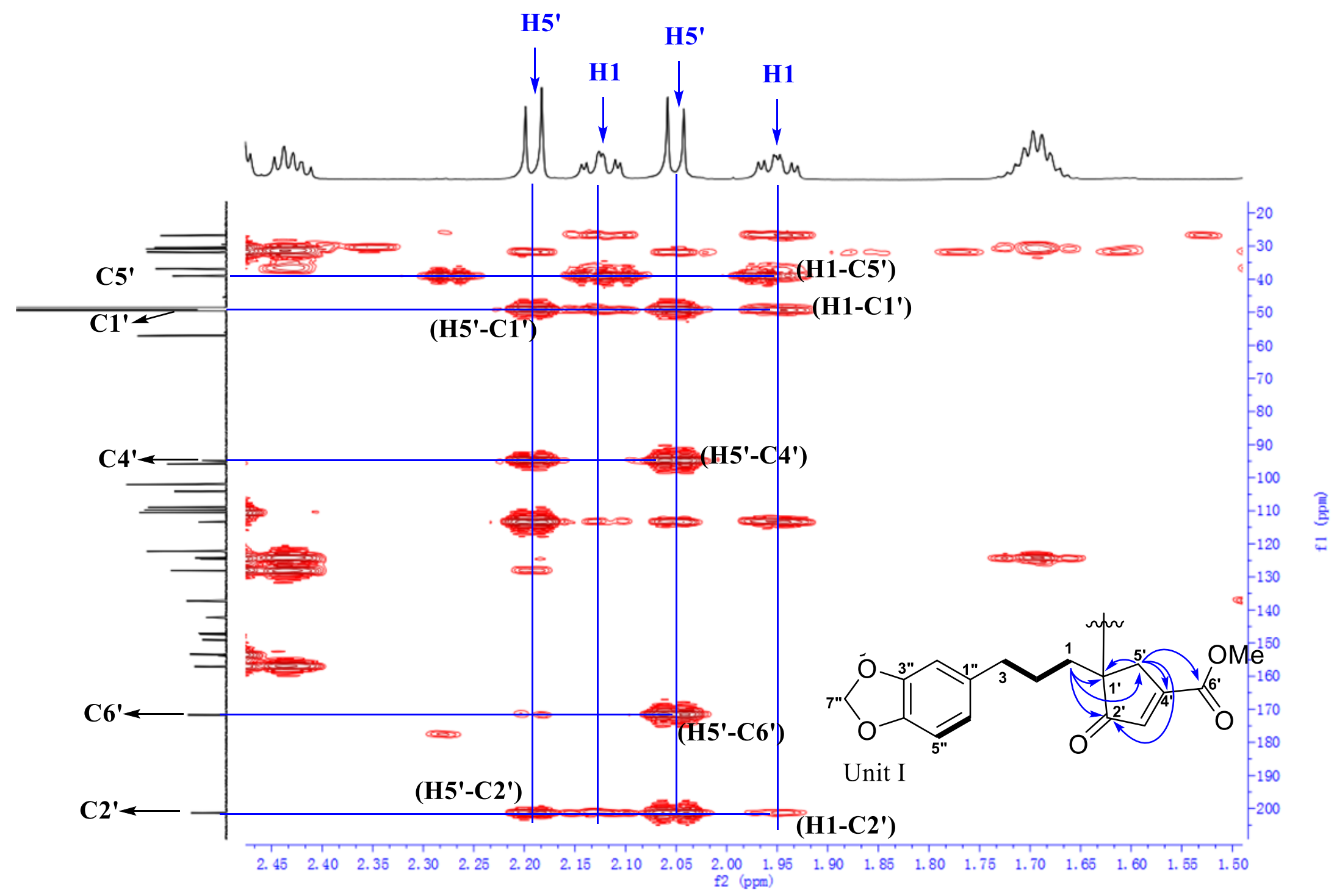

Figure S44. Key HMBC spectrum $\left(\delta_{\mathrm{H}} 1.50-2.45\right.$ and $\left.\delta_{\mathrm{C}} 20-200\right)$ of unit I in compound 2 


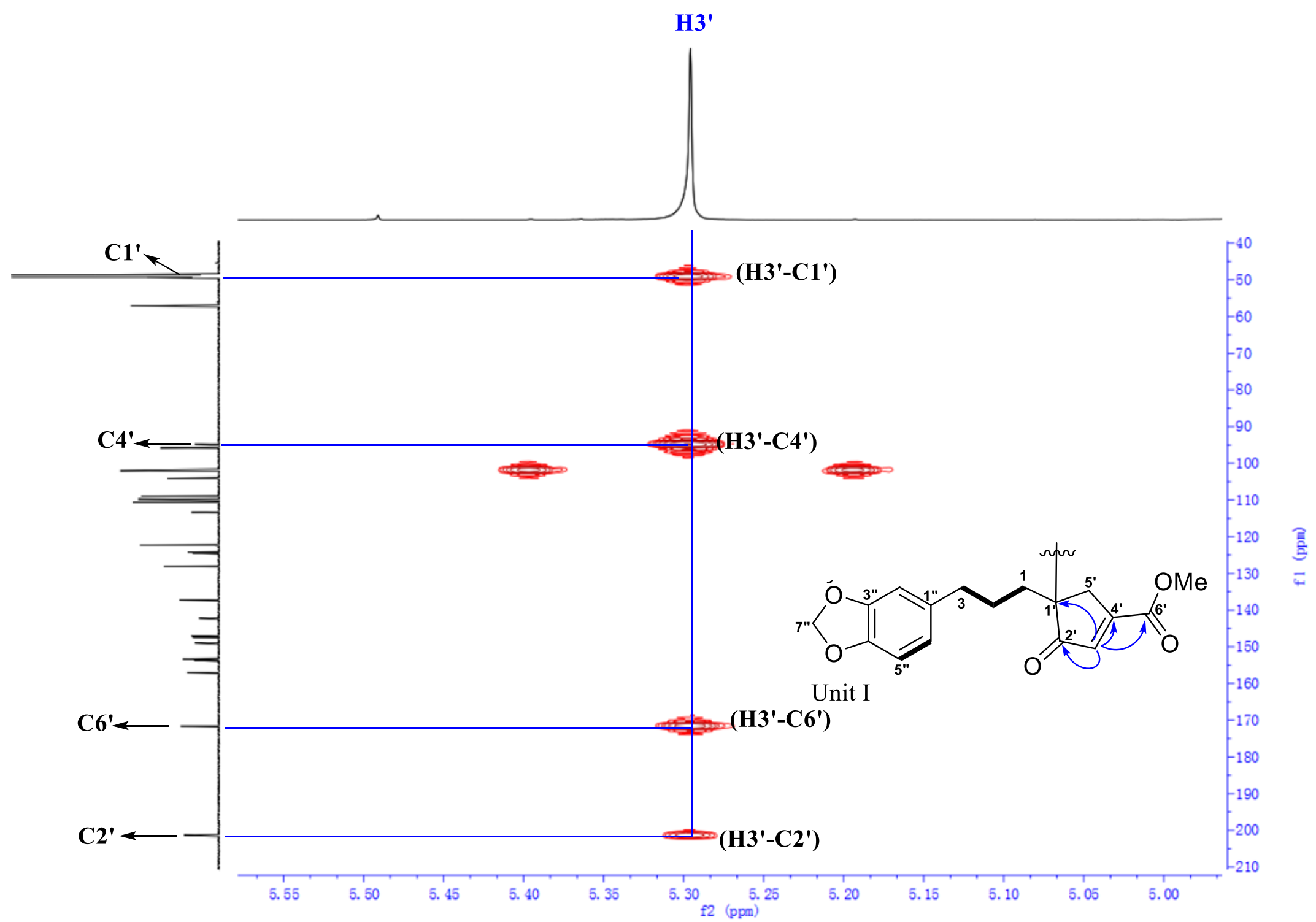

Figure S45. Key HMBC spectrum $\left(\delta_{\mathrm{H}} 5.00-5.55\right.$ and $\left.\delta_{\mathrm{C}} 40-210\right)$ of unit I in compound 2 


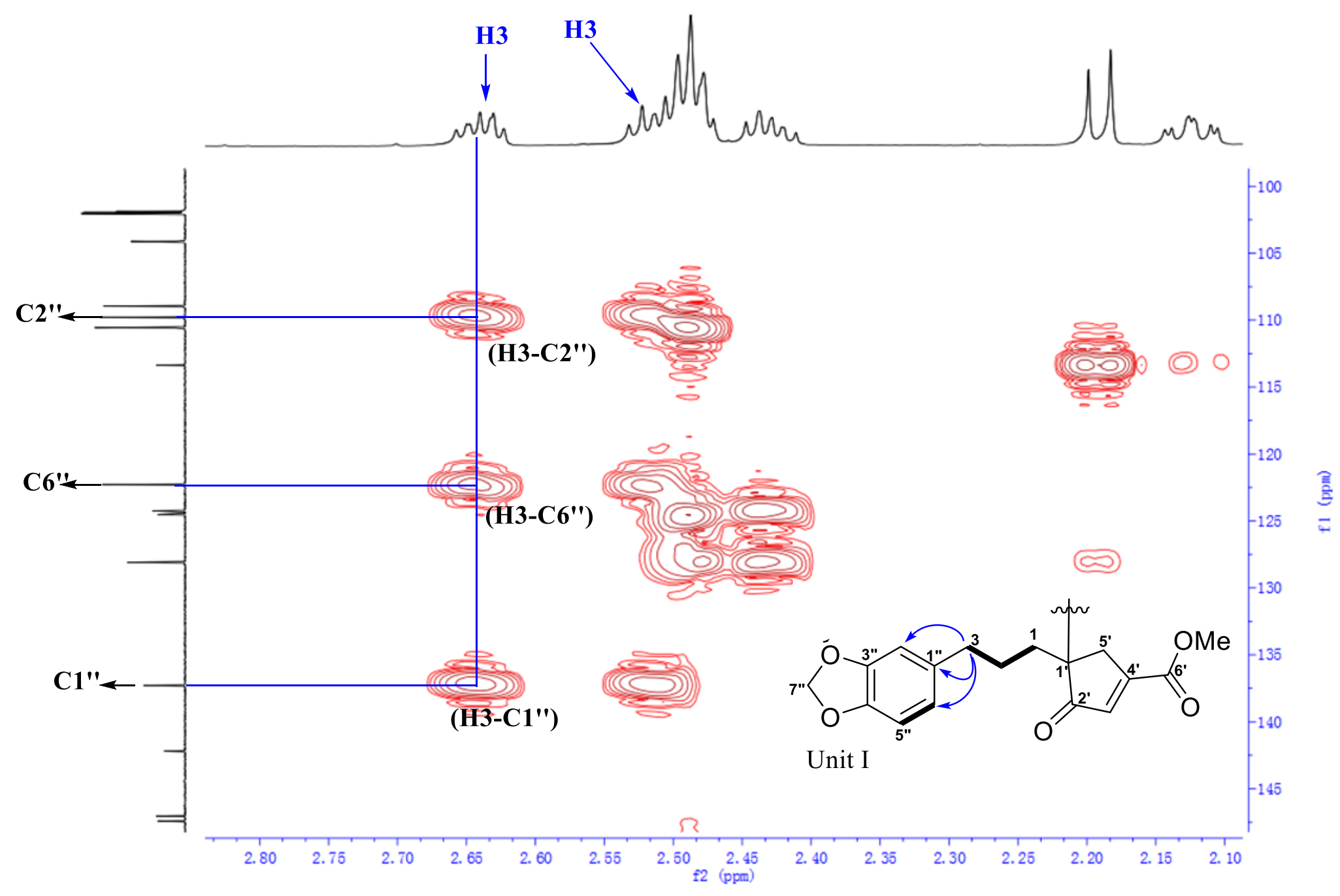

Figure S46. Key HMBC spectrum $\left(\delta_{\mathrm{H}} 2.10-2.80\right.$ and $\left.\delta_{\mathrm{C}} 100-145\right)$ of unit I in compound 2 


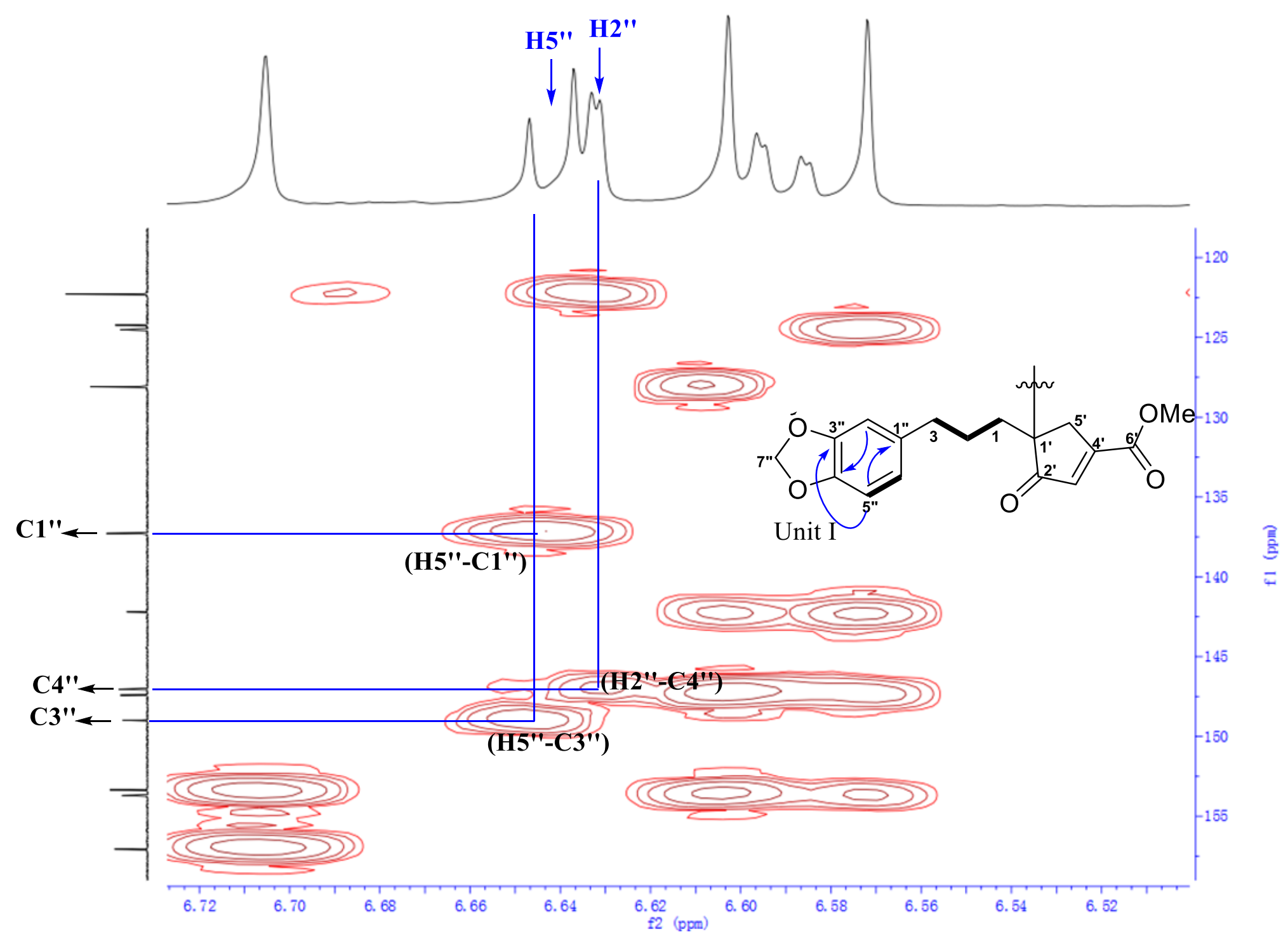

Figure S47. Key HMBC spectrum $\left(\delta_{\mathrm{H}} 6.52-6.72\right.$ and $\left.\delta_{\mathrm{C}} 120-160\right)$ of unit I in compound 2 


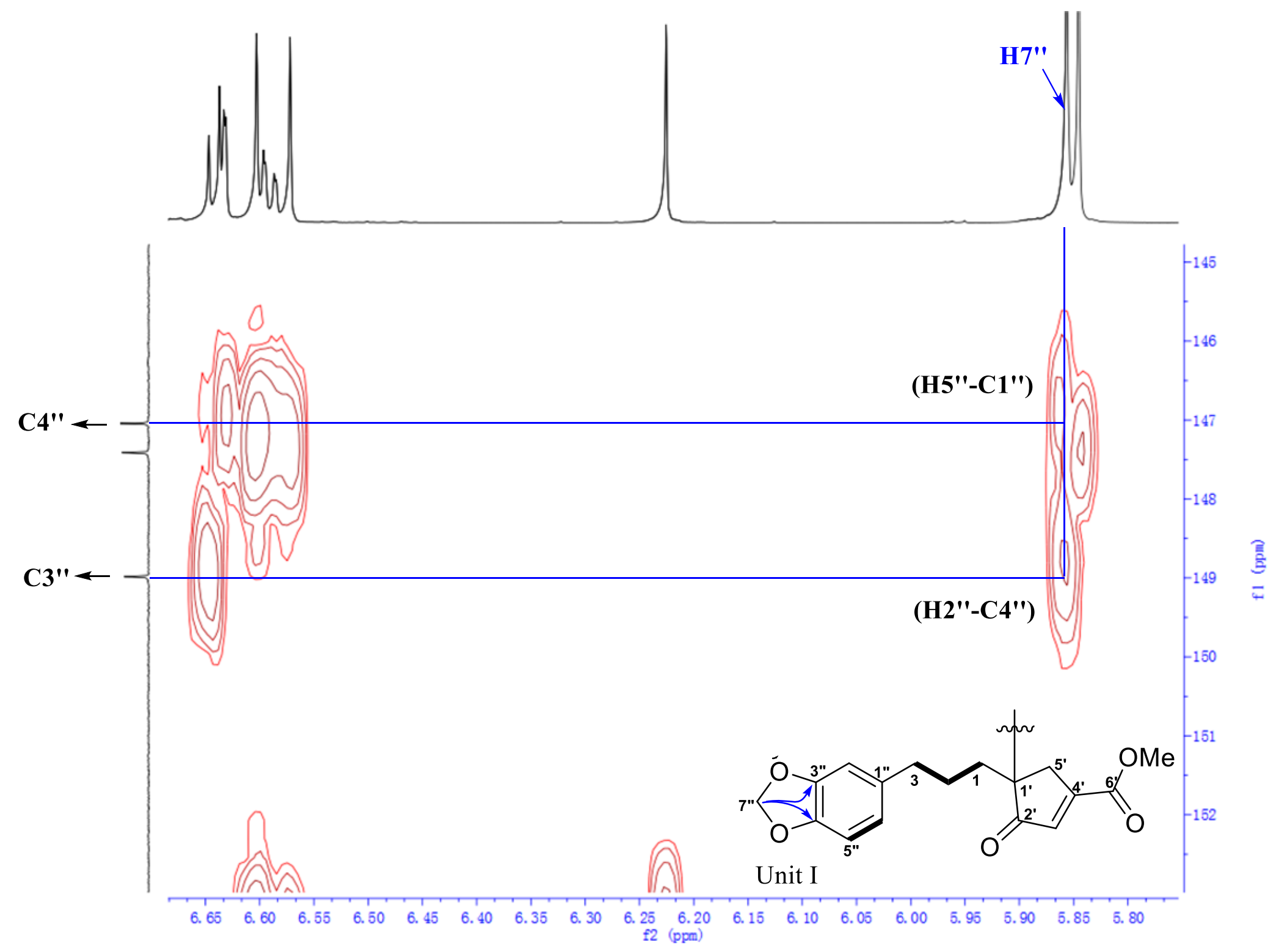

Figure S48. Key HMBC spectrum $\left(\delta_{\mathrm{H}} 5.80-6.65\right.$ and $\left.\delta_{\mathrm{C}} 145-152\right)$ of unit I in compound 2 


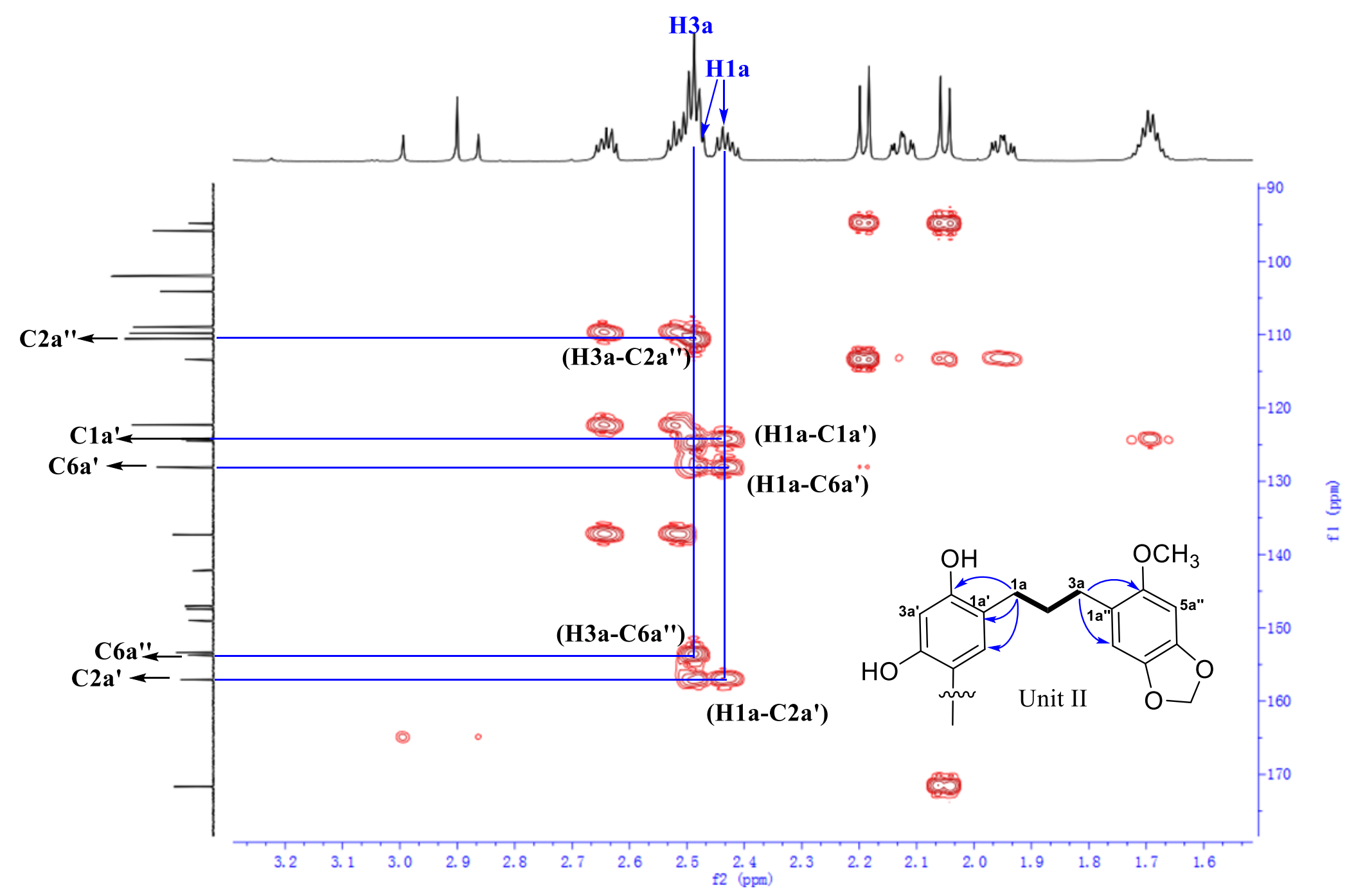

Figure S49. Key HMBC spectrum $\left(\delta_{\mathrm{H}} 1.60-3.20\right.$ and $\left.\delta_{\mathrm{C}} 90-170\right)$ of unit II in compound 2 


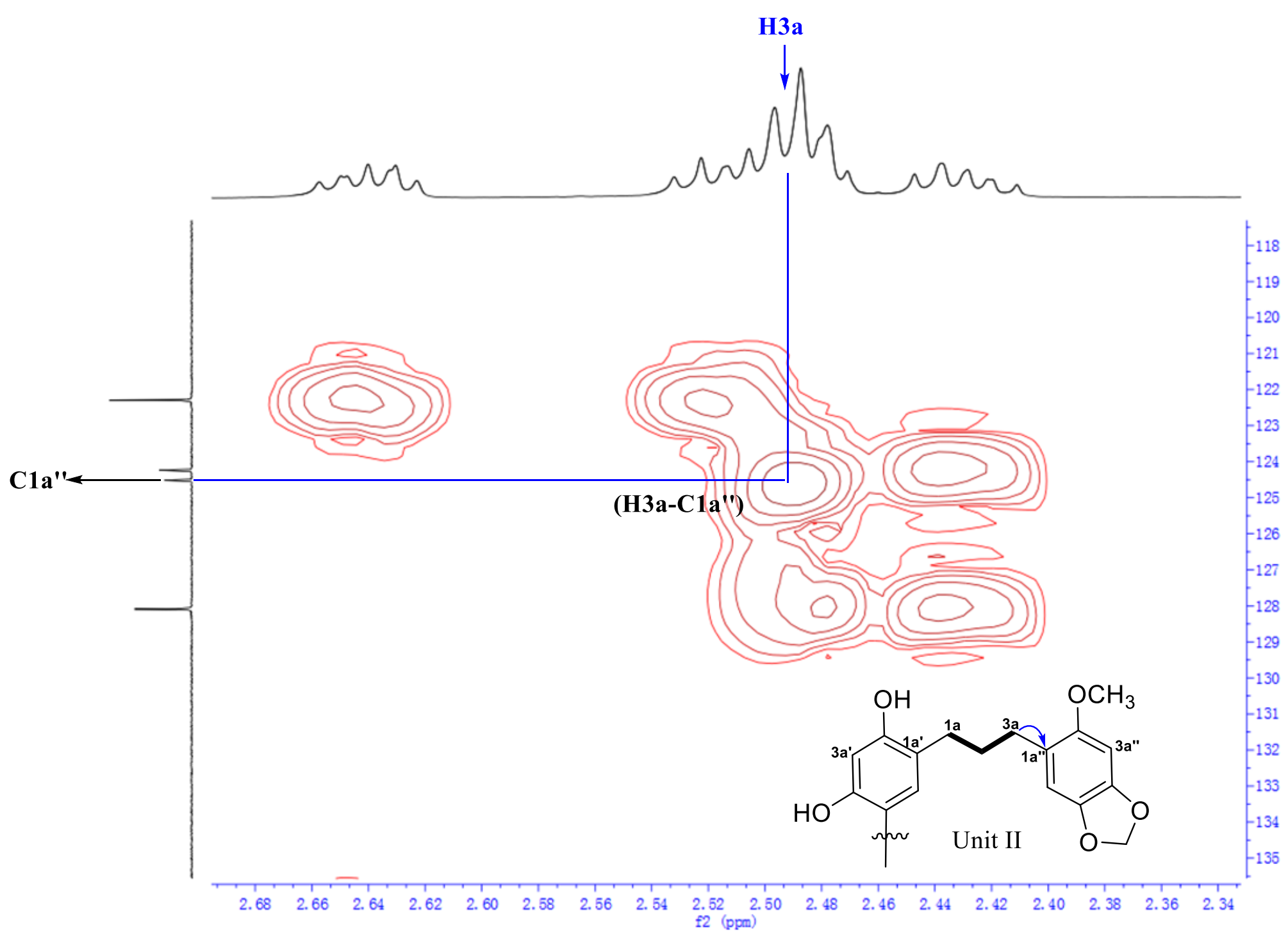

Figure S50. Key HMBC spectrum $\left(\delta_{\mathrm{H}} 2.34-2.68\right.$ and $\left.\delta_{\mathrm{C}} 118-135\right)$ of unit II in compound 2 


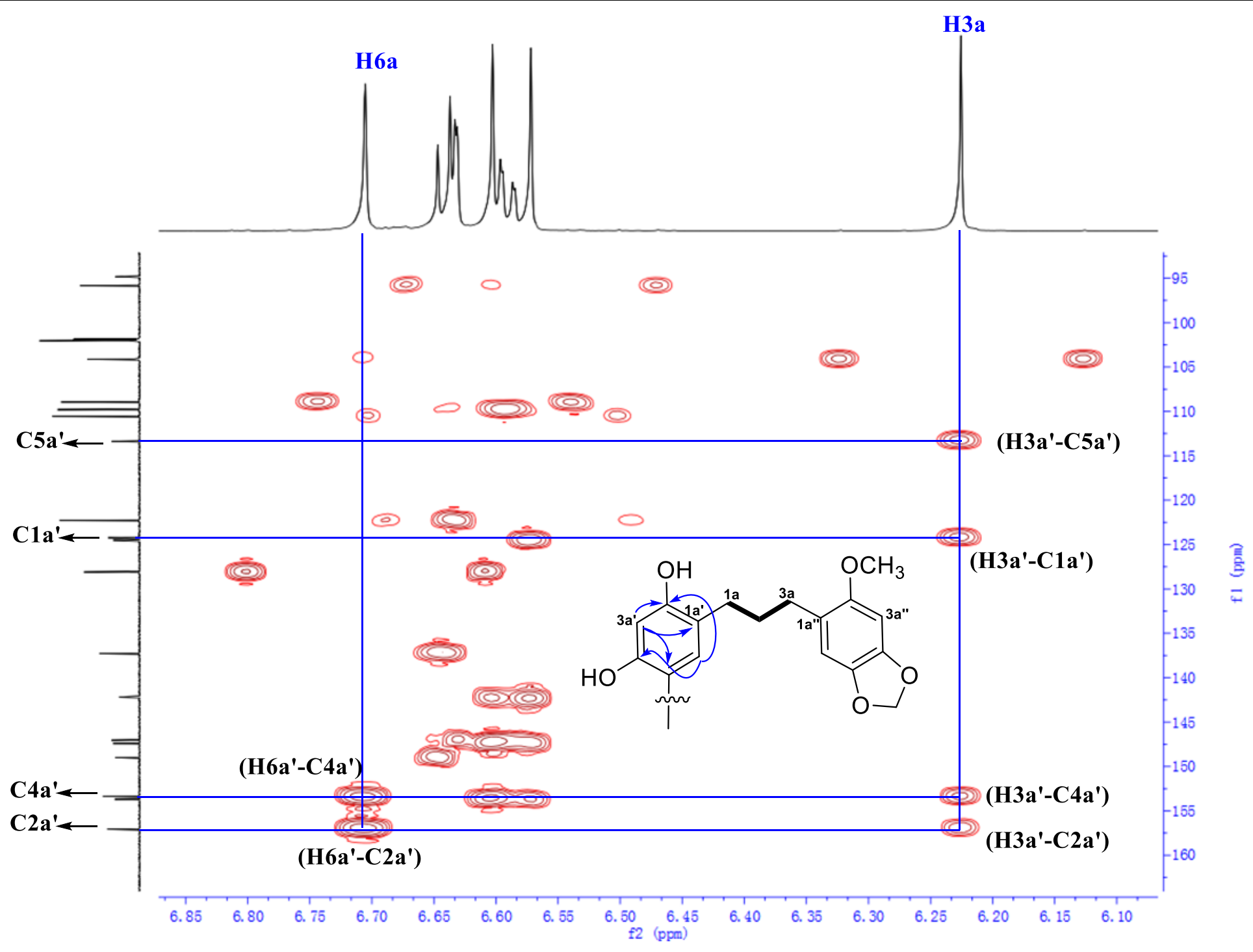

Figure S51. Key HMBC spectrum $\left(\delta_{\mathrm{H}} 6.10-6.85\right.$ and $\left.\delta_{\mathrm{C}} 95-160\right)$ of unit II in compound 2 


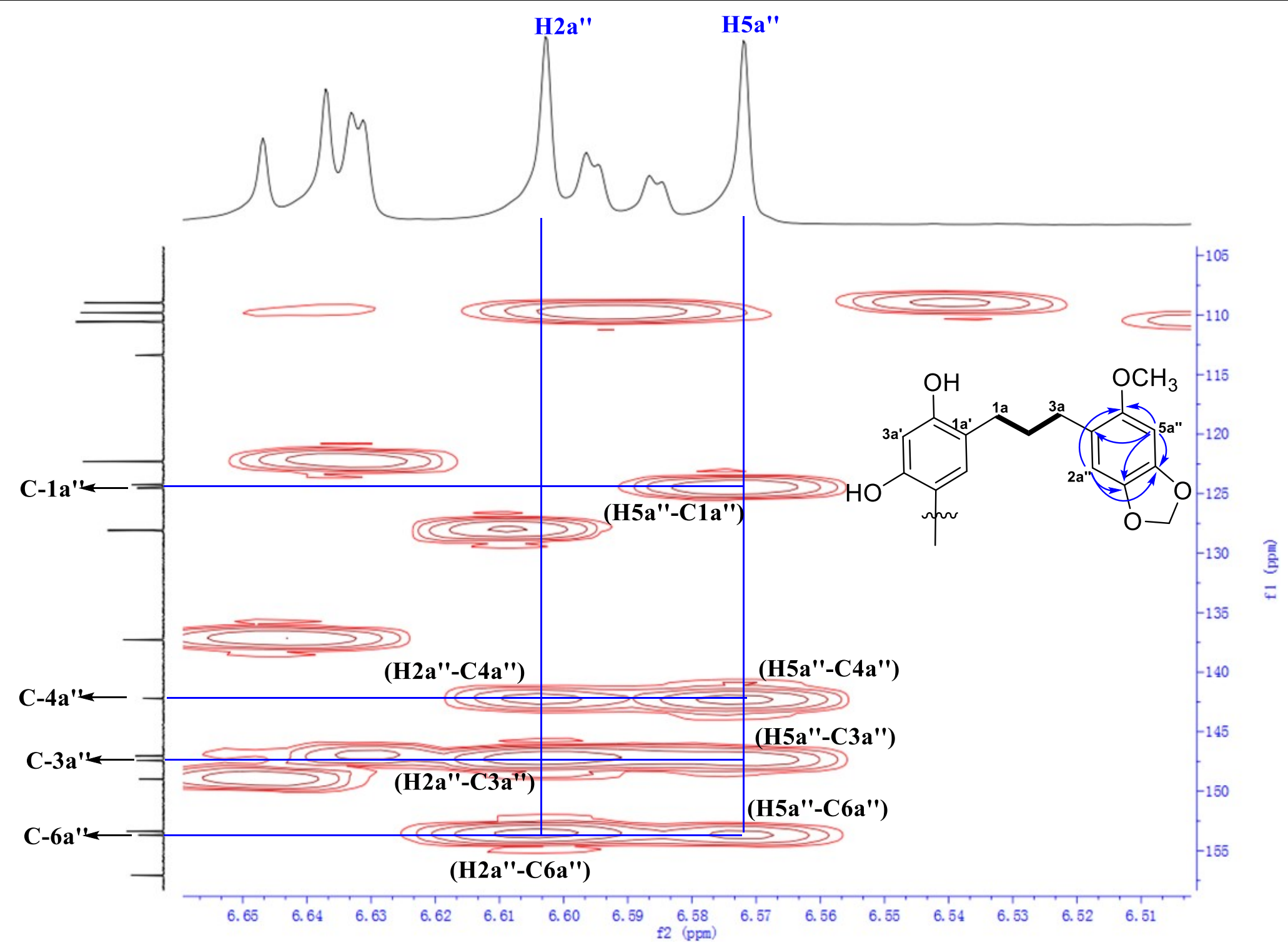

Figure S52. Key HMBC spectrum $\left(\delta_{\mathrm{H}} 6.51-6.65\right.$ and $\left.\delta_{\mathrm{C}} 105-155\right)$ of unit II in compound 2 


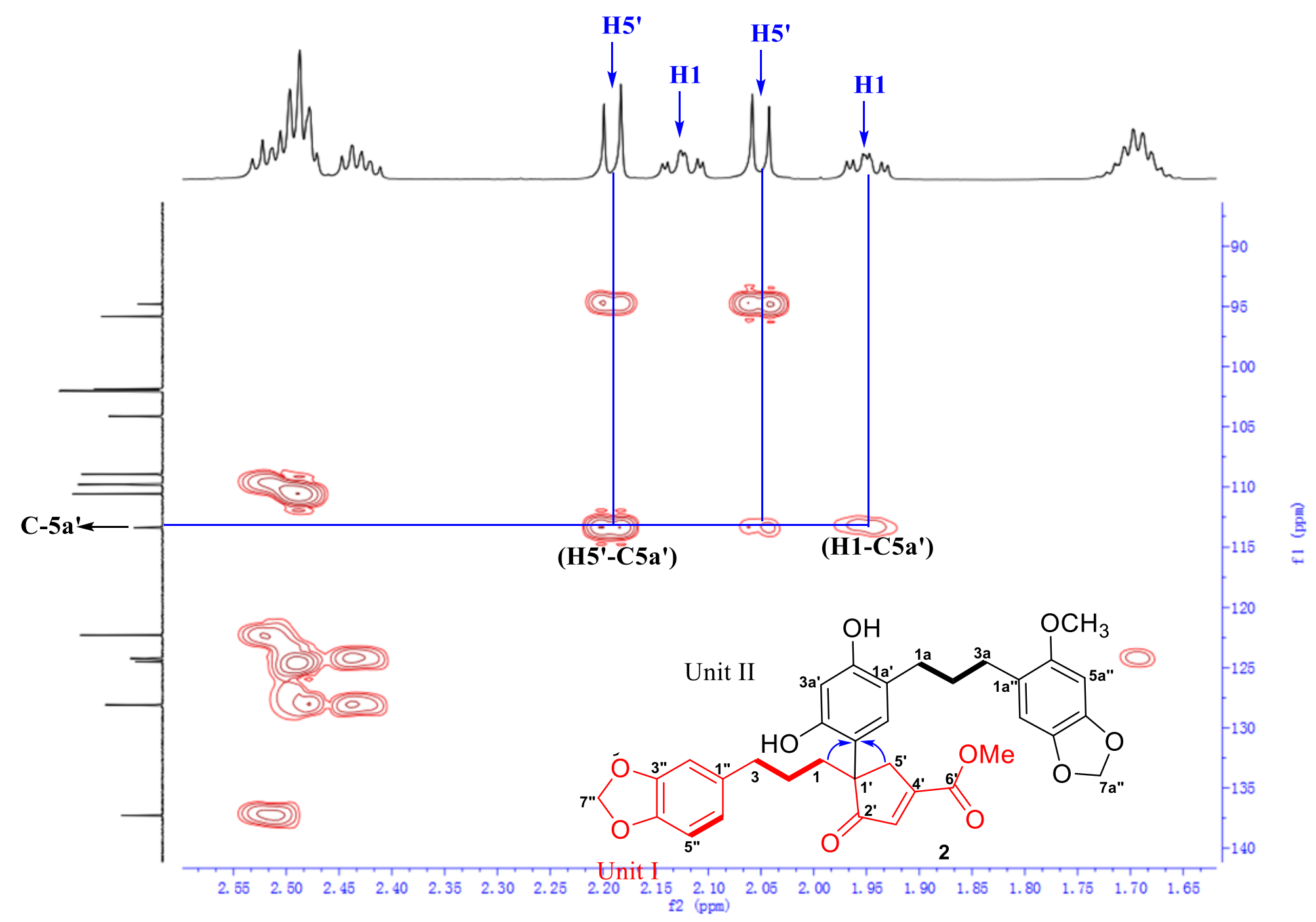

Figure S53. Key HMBC spectrum $\left(\delta_{\mathrm{H}} 1.65-2.55\right.$ and $\left.\delta_{\mathrm{C}} 90-140\right)$ of compound 2 


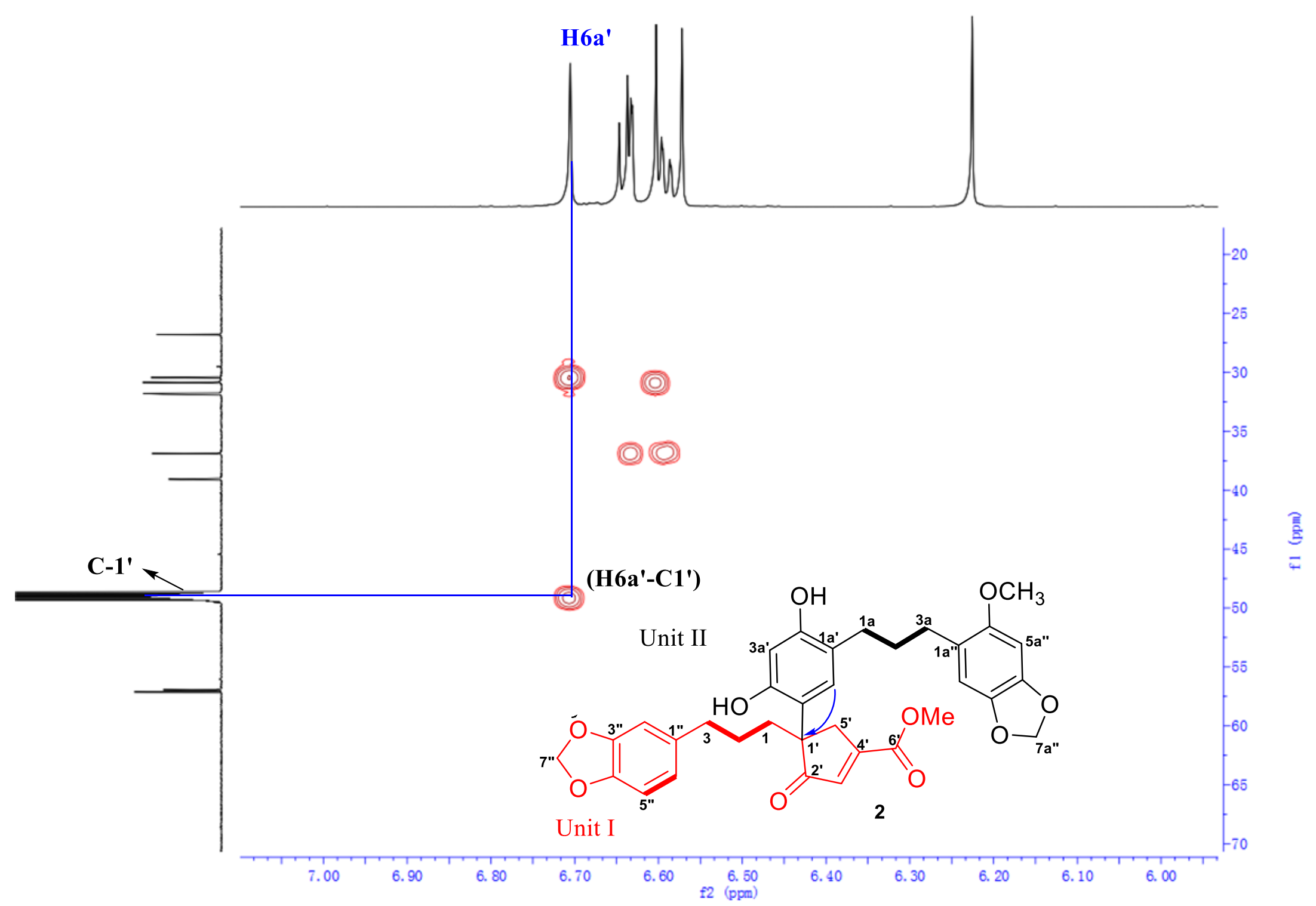

Figure S54. Key HMBC spectrum $\left(\delta_{\mathrm{H}} 6.00-7.00\right.$ and $\left.\delta_{\mathrm{C}} 20-70\right)$ of compound 2

$$
\text { S58 }
$$




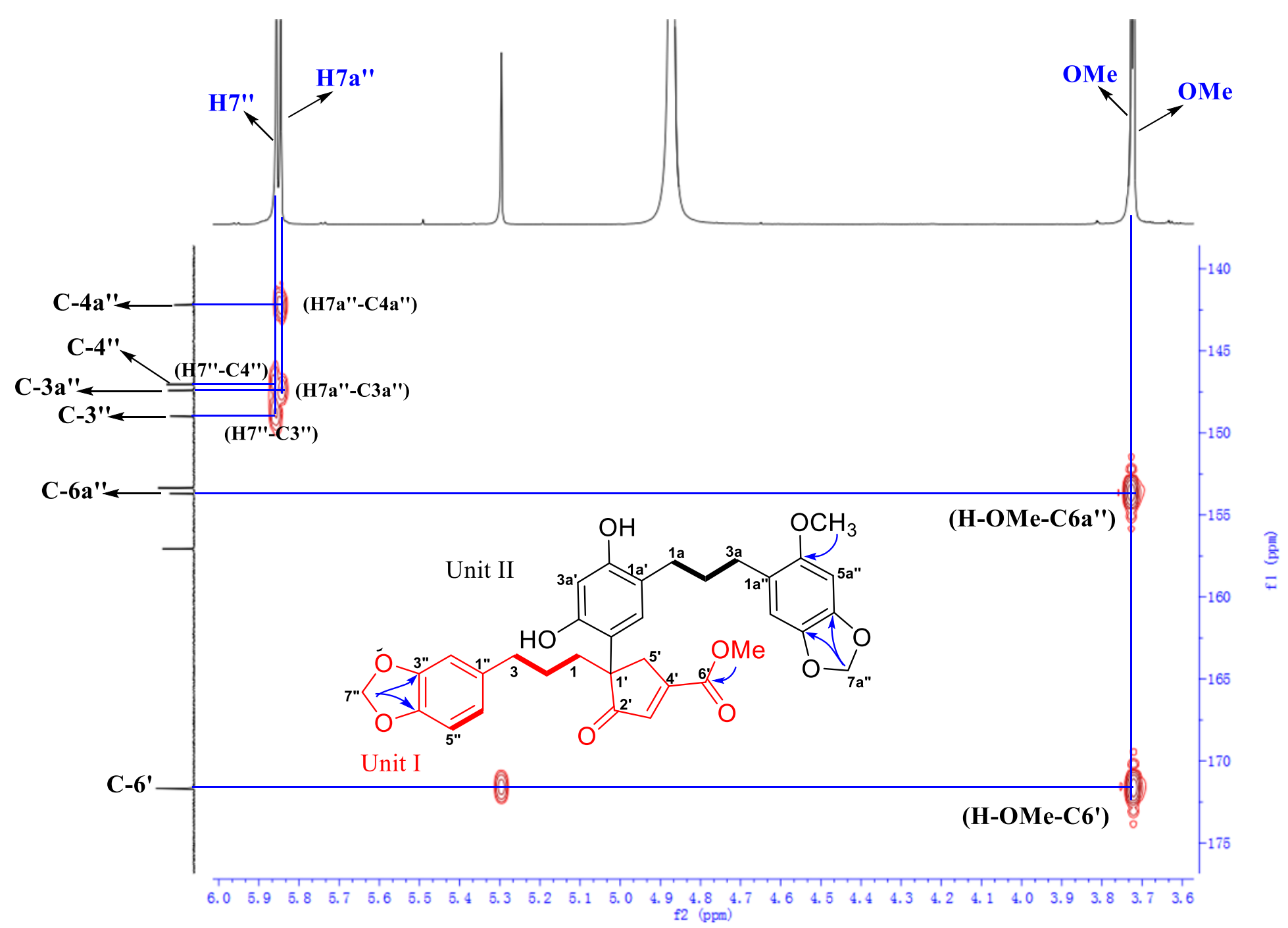

Figure S55. Key HMBC spectrum $\left(\delta_{\mathrm{H}} 3.60-6.00\right.$ and $\left.\delta_{\mathrm{C}} 140-175\right)$ of compound 2 
Supporting Information

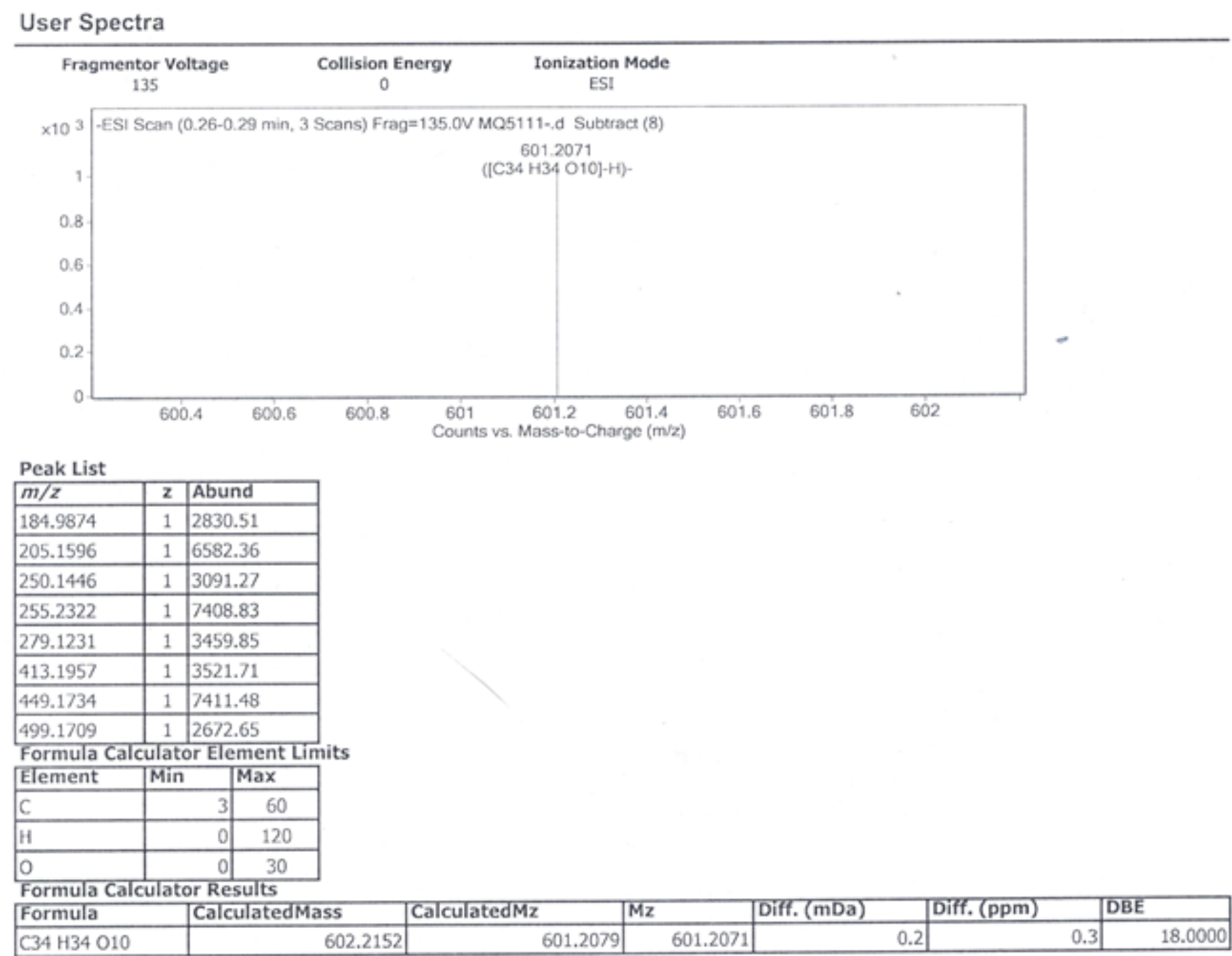

... End Of Report -..

Figure S56. HRESI of compound 2

S60 


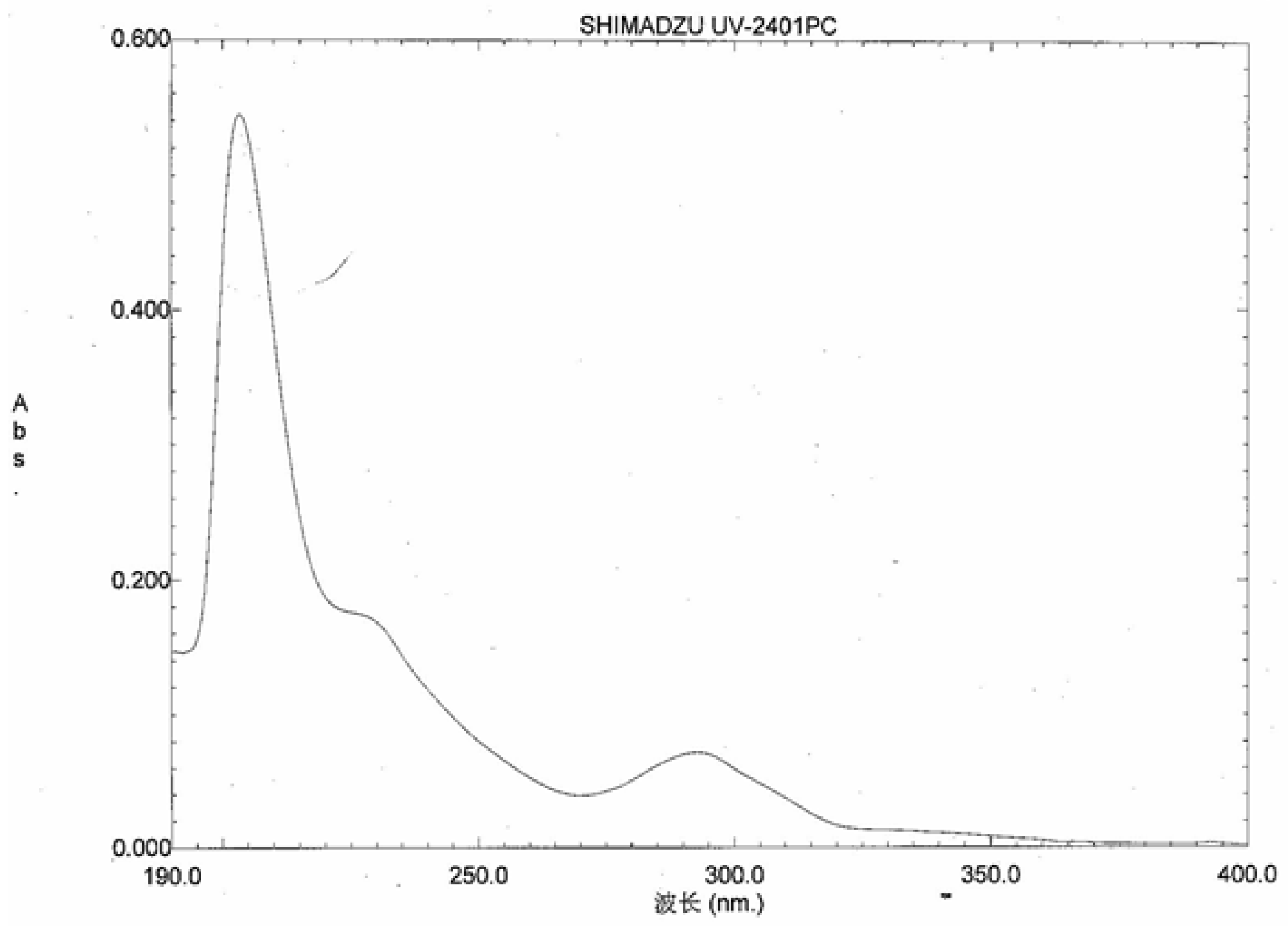

Figure S57. UV spectrum of compound 2 
Optical rotation measurement

Model : P-1020 (A060460638)

No. Sample Mode

Data

Monitor

Blank

Tem
Cell
Tem

Temp Point

Date

Comment

Sample Name

$\begin{array}{llllll}\text { No.1 } & 79(1 / 3) & \text { Sp.Rot } & 87.0590 & 0.0740 & 19.0 \\ & & & & 0.0000 & \begin{array}{l}50.00 \\ \text { Cell }\end{array} \\ \text { No.2 } & 79(2 / 3) & \text { Sp.Rot } & 84.8240 & 0.0721 & 19.0 \\ & & & & 0.0000 & 50.00 \\ & & & & & \text { Cell } \\ \text { No.3 } & 79(3 / 3) & \text { Sp.Rot } & 87.4120 & 0.0743 & 19.0 \\ & & & & 0.0000 & 50.00 \\ & & & & & \text { Cell }\end{array}$

Thu Jan 18 15:48:47 2018 $0.00170 \mathrm{~g} / \mathrm{mL} \mathrm{MeOH}$ 5111-1

Thu Jan 18 15:48:53 2018 $0.00170 \mathrm{~g} / \mathrm{mL} \mathrm{MeOH}$ 5111-1

Thu Jan 18 15:48:58 2018 $0.00170 \mathrm{~g} / \mathrm{mL} \mathrm{MeOH}$ 5111-1

Figure S58. ORD of compound (+)-2
Light Cycle Time Filter Integ Time

Operator

$\mathrm{Na} \quad 2 \mathrm{sec}$

$589 \mathrm{~nm} 2 \mathrm{sec}$

$\mathrm{Na} \quad 2 \mathrm{sec}$

$589 \mathrm{~nm} 2 \mathrm{sec}+86,43,4$

$\mathrm{Na} \quad 2 \mathrm{sec}$

$589 \mathrm{~nm} 2 \mathrm{sec}$ 
Optical rotation measurement

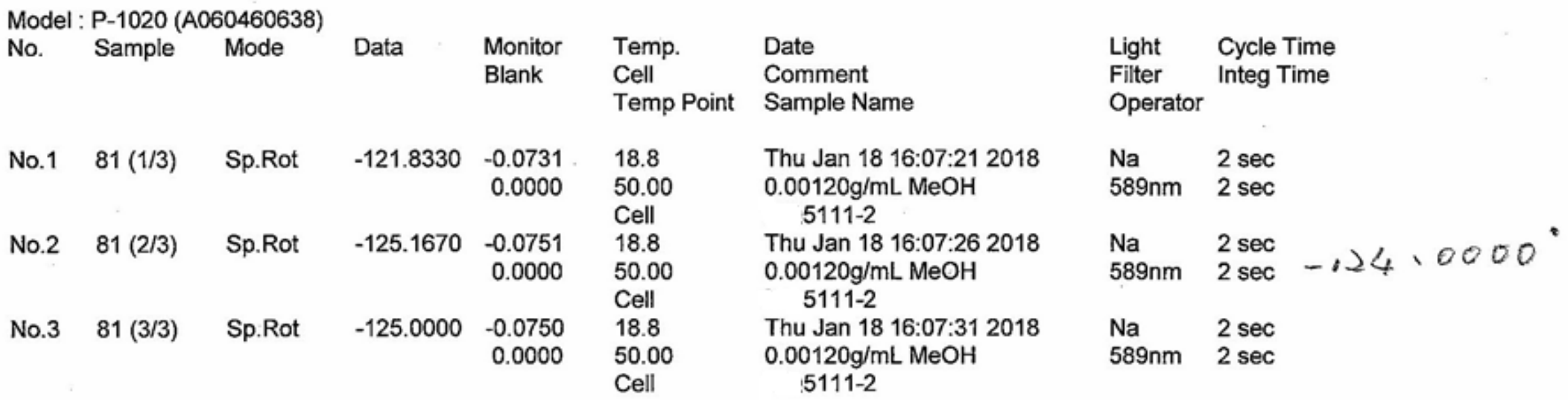

Figure S59. ORD of compound (-)-2 

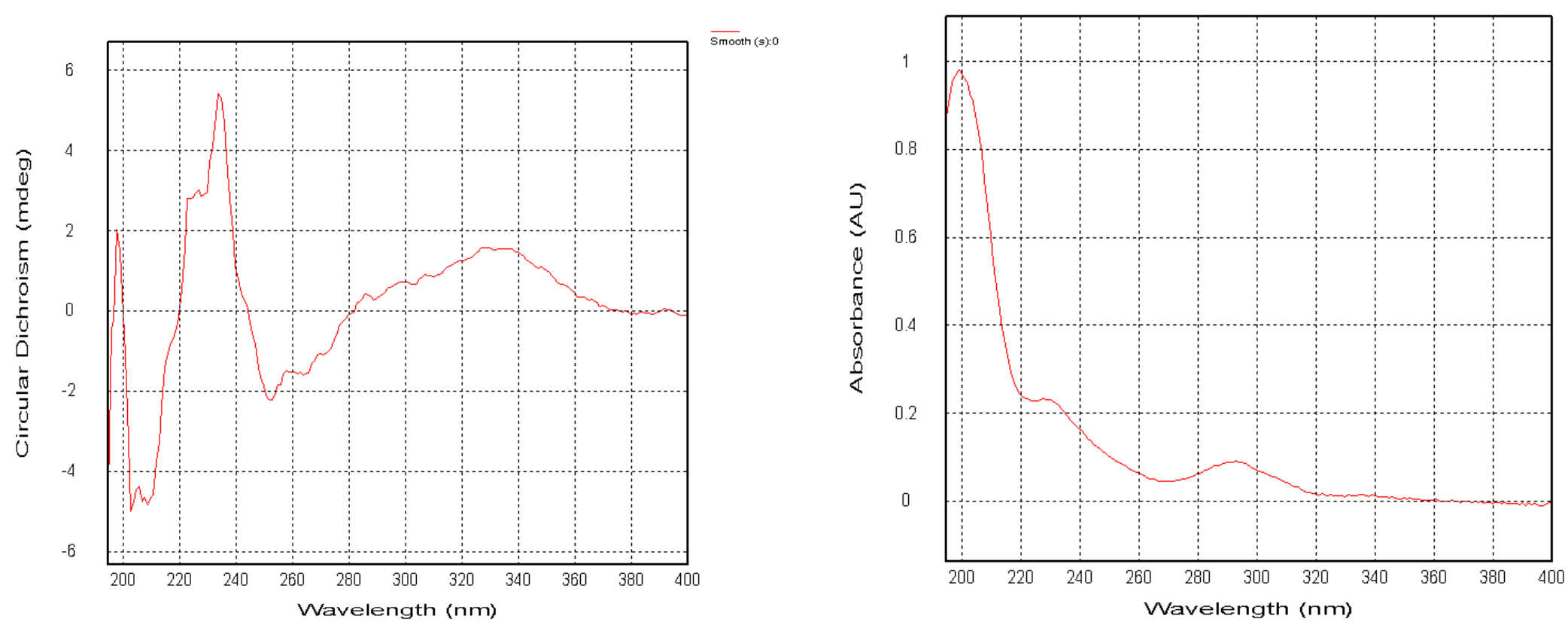

Figure S60. CD spectrum of compound (+)-2 
Supporting Information
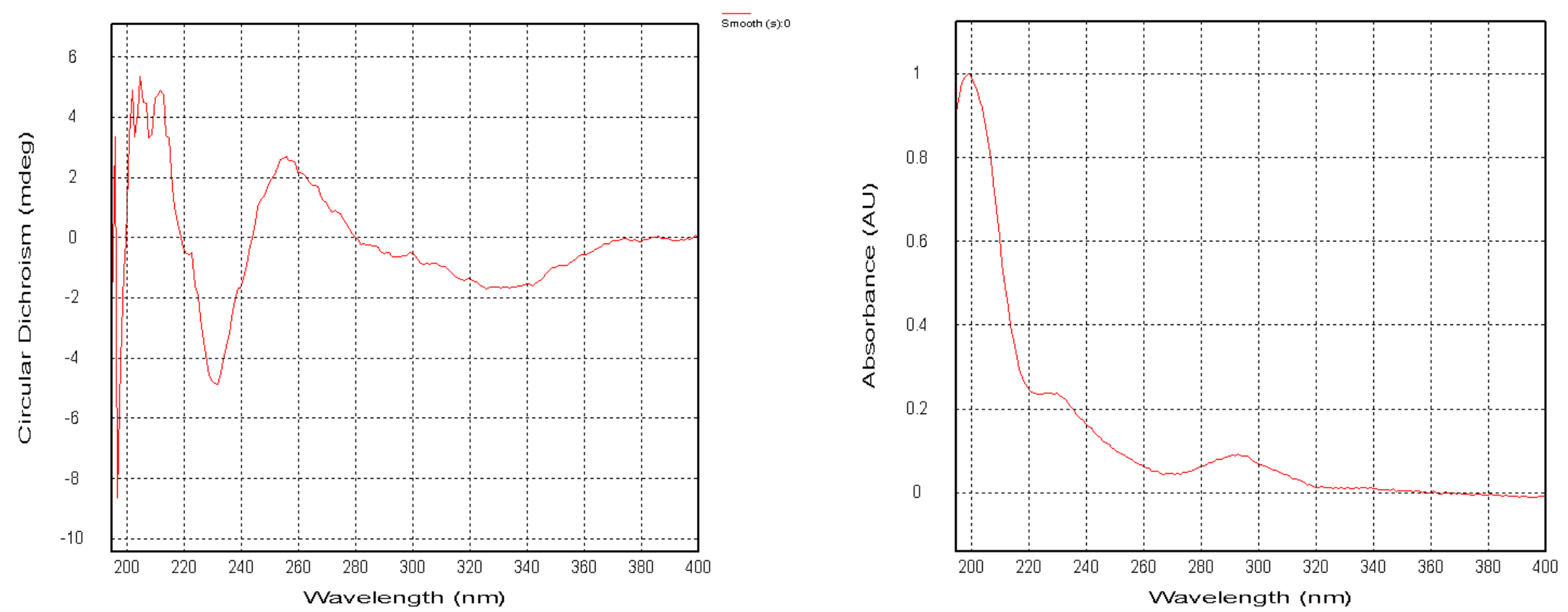

Sutracted:0

Figure S61. CD spectrum of compound (-)-2 


\section{Reference}

1. Morris, G. M.; Huey, R.; Lindstrom, W.; Sanner, M. F.; Belew, R. K.; Goodsell, D. S.; Olson, A. J., AutoDock4 and AutoDockTools4: Automated docking with selective receptor flexibility. Journal of Computational Chemistry 2009, 30 (16), 2785-2791.

2. (a) Giardina, G.; Montioli, R.; Gianni, S.; Cellini, B.; Paiardini, A.; Voltattorni, C. B.; Cutruzzolà, F., Open conformation of human DOPA decarboxylase reveals the mechanism of PLP addition to Group II decarboxylases. Proceedings of the National Academy of Sciences 2011, 108 (51), 20514-20519; (b) Ren, J.; Zhang, Y.; Jin, H.; Yu, J.; Zhou, Y.; Wu, F.; Zhang, W., Novel Inhibitors of Human DOPA Decarboxylase Extracted from Euonymus glabra Roxb. ACS Chemical Biology 2014, 9 (4), 897-903.

3. Zhou, Y.; Yu, J.; Lei, X.; Wu, J.; Niu, Q.; Zhang, Y.; Liu, H.; Christen, P.; Gehring, H.; Wu, F., High-throughput tandem-microwell assay identifies inhibitors of the hydrogen sulfide signaling pathway. Chemical Communications 2013, 49 (100), 11782-11784. 